LUCAS DE ANGELIS CÔRTES

\title{
AVALIAÇÃO DO PERFIL ANALGÉSICO DO TRAMADOL ATRAVÉS DA VERIFICAÇÃO TEMPORAL DE SUA CONCENTRAÇÃO PLASMÁTICA EM CADELAS SUBMETIDAS A OVÁRIO-SALPINGO-HISTERECTOMIA
}




\section{Lucas de Angelis Côrtes}

\section{Avaliação do perfil analgésico do tramadol através da verifica- ção temporal de sua concentração plasmática em cadelas submetidas a ovário-salpingo-histerectomia}

Dissertação Apresentada ao Programa de PósGraduação em Patologia Experimental e Comparada da Faculdade de Medicina Veterinária e Zootecnia da Universidade de São Paulo para obtenção de Título de Mestrado em Ciências

Departamento:

Patologia

Área de Concentração:

Patologia Experimental e Comparada

Orientadora:

Profa. Dra. Helenice de Souza Spinosa

São Paulo 2006 
Autorizo a reprodução parcial ou total desta obra, para fins acadêmicos, desde que citada a fonte.

\section{DADOS INTERNACIONAIS DE CATALOGAÇÃO-NA-PUBLICAÇÃO}

(Biblioteca Virginie Buff D’Ápice da Faculdade de Medicina Veterinária e Zootecnia da Universidade de São Paulo)

\begin{tabular}{|c|c|}
\hline $\begin{array}{l}\text { T.1730 } \\
\text { FMVZ }\end{array}$ & $\begin{array}{l}\text { Côrtes, Lucas de Angelis } \\
\text { Avaliação do perfil analgésico do tramadol através da verificação } \\
\text { temporal de sua concentração plasmática em cadelas submetidas a } \\
\text { ovário-salpingo-histerectomia / Lucas de Angelis Côrtes. - São Paulo: L. A. } \\
\text { Côrtes, 2006. } \\
88 \text { f. : il. } \\
\text { Dissertação (mestrado) - Universidade de São Paulo. Faculdade de } \\
\text { Medicina Veterinária e Zootecnia. Departamento de Patologia, } 2006 \text {. } \\
\text { Programa de Pós-graduação: Patologia Experimental e Comparada. } \\
\text { Área de concentração: Patologia Experimental e Comparada. } \\
\text { Orientador: Profa. Dra. Helenice de Souza Spinosa. } \\
\text { 1. Tramadol. 2. Concentração plasmática. 3. Cadelas. 4. Escala de dor. } \\
\text { I. Título. }\end{array}$ \\
\hline
\end{tabular}




\section{$P A R E C E R$}

Interessado: Lucas de Angelis Côrtes

Assunto: Protocolo de experimentação adotado em experimento animal.

A Comissão de Bioética da Faculdade de Medicina Veterinária e Zootecnia da Universidade de São Paulo, após analisar o projeto sob o número 601/2005, intitulado: "Avaliar o perfil plasmático do tramadol e seu efeito analgésico em cães submetidos à cirurgia ortopédica", utilizando de 10 cães, sob responsabilidade da $\operatorname{Prof}^{\mathrm{a}} \operatorname{Dr}^{\mathrm{a}}$ Helenice de Souza Spinosa, constatou que o mesmo foi realizado de acordo com os princípios de bioética, adotados por esta Comissão.

-. São Paulo, 15 de fevereiro de 2005

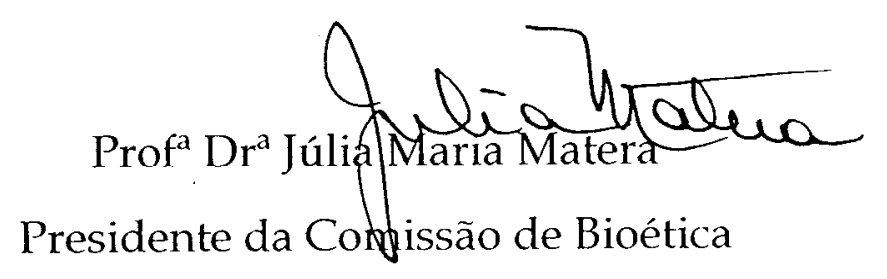

FMVZ/USP 


\section{FOLHA DE AVALIAÇÃO}

NOME: CÔRTES, Lucas de Angelis.

Título: Avaliação do perfil analgésico do tramadol através da verificação temporal de sua concentração plasmática em cadelas submetidas a ovário-salpingo-histerectomia

Data:

Dissertação Apresentada ao Programa de Pós-Graduação em Patologia Experimental e Comparada da Faculdade de Medicina Veterinária e Zootecnia da Universidade de São Paulo para obtenção de Título de Mestrado em Ciências

\section{BANCA EXAMINADORA}

Prof. Dr. Instituição

Assinatura: Julgamento

Prof. Dr. Instituição

Assinatura: Julgamento

Prof. Dr. Instituição

Assinatura: Julgamento 


\section{DEDICATÓRIAS}

Aos meus pais José e Marina pelos exemplos de vida, dignidade e bondade, ensinamentos que formaram meu ser, além da amizade e carinho incondicional ofertados da forma mais pura e transparente, o que nos tornou uma família unida e feliz. 
Ao meu irmão Leandro pela amizade, companheirismo e pelo orgulho do grande ser humano que se tornou. 
À professora Helenice de Souza Spinosa, orientadora deste estudo, pela compreensão, atenção, orientação e apoio que sempre me ofereceu. 
Às professoras Denise Tabacchi Fantoni e Silvia Renata Gaido Cortopassi, a quem devo minha iniciação na área de anestesiologia e que atuaram de forma decisiva na minha profissão e me ajudaram a trilhar novos caminhos. 
À Viviane Azevedo Ferreira, pessoa imprescindível para a concretização desta dissertação, e, sobretudo no apoio, compreensão, amizade e carinho nos momentos mais importantes. 


\section{AGRADECIMENTOS}

Ao Jorge C. Flório, pela paciência e maneira solícita com que se disponibilizou para o sucesso deste estudo.

Ao amigo Rafael Costa Jorge pela sua participação efetiva em minha iniciação na área de anestesiologia, e a quem sou muito grato pelos ensinamentos ofertados.

À amiga Karina Yazbek, pelo apoio, incentivo e orientações que foram de suma importância para a realização deste trabalho.

Ao amigo Reynaldo Teruel que desde o início da graduação permanece ao meu lado, participando de maneira decisiva e leal, colaborando grandiosamente para todas as conquistas.

Aos amigos Guto e Alex, que sempre estiveram presentes nos momentos de dúvidas e incertezas, prestando seus serviços quando mais precisei.

Nosso profundo agradecimento à equipe da Biblioteca Virginie Buff D’Ápice pelo empenho e solicitude a nós dispensado em todas oportunidades em que necessitamos deste apoio essencial.

Aos funcionários Otávio, Jesus, Lélis e Miron pela ajuda prestimosa e principalmente pelo convívio que muito contribuiu para meu aprendizado.

Ao Hospital Veterinário Santa Inês, que possibilitou a realização deste sonho.

Aos amigos Pacheco, Renato e João, pessoas que apoiaram e compreenderam as dificuldades deste longo percurso.

A meu inestimável amigo Miguel, que demonstrou lealdade e confiança em todos os momentos em que fraquejei.

À Giovana que muito contribuiu na obtenção dos resultados exames laboratoriais desta dissertação.

Aos amigos Fabio, Ricardo, Henrique, Marcelo, Marcelo Silva, Pedro, Gil, Robério, Chico e Adenildo pelo apoio e torcida pelo meu sucesso.

Às funcionárias da recepção do Hospital Veterinário Santa Inês meu muito obrigado.

Aos meus inseparáveis amigos, Digo, Xandão e Keiko, pela grande história de vida que compartilhamos, e pelo imenso carinho que sobrevive apesar do tempo e da distância.

A CAPES pelo apoio financeiro. 


\section{EPÍGRAFE}

"Nosso respeito e gratidão aos animais de experiência e estudo, vítimas da ciência em benefício da humanidade". 


\section{SUMÁRIO}

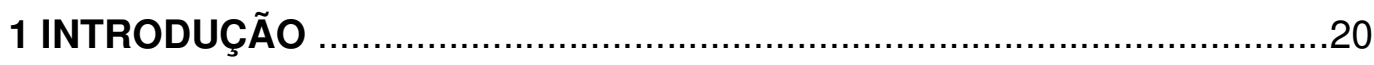

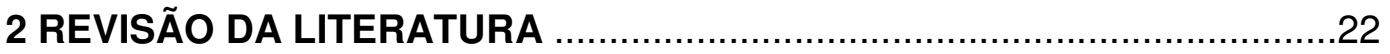

2.1 A importância da dor na Saúde Animal.................................................22

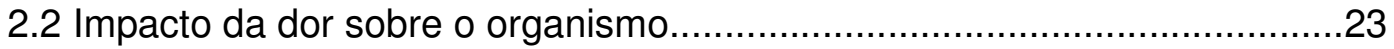

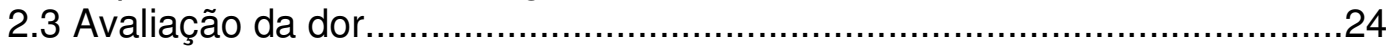

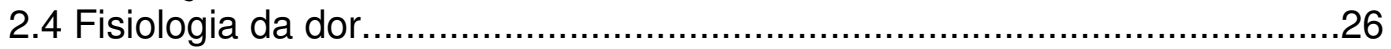

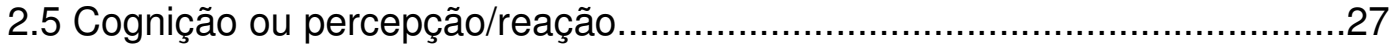

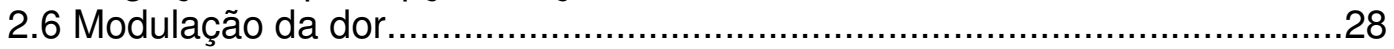

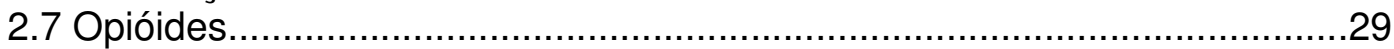

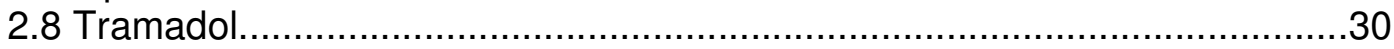

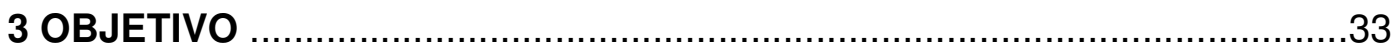

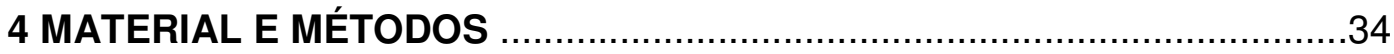

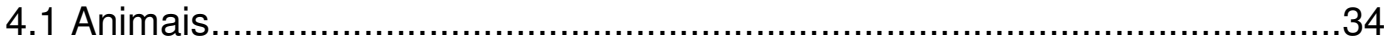

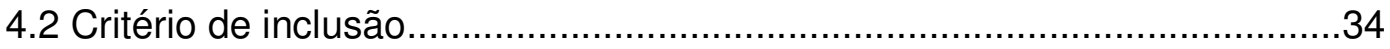

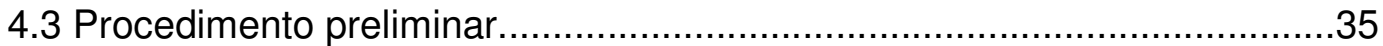

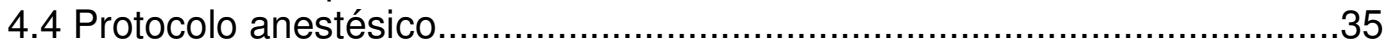

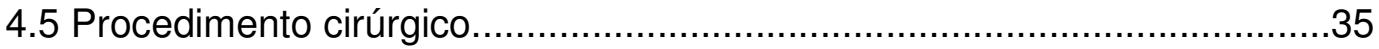

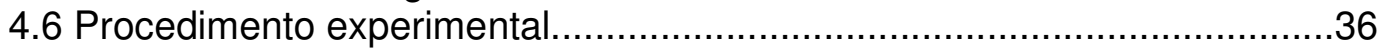

4.6.1 Administração dos fármacos analgésicos.................................36

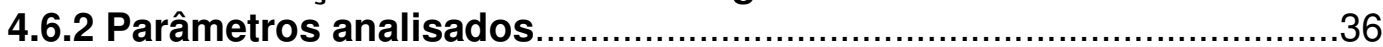

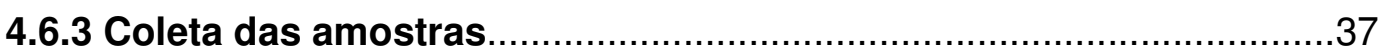

4.6.4 Mensuração dos parâmetros cardiovasculares e respiratórios........37

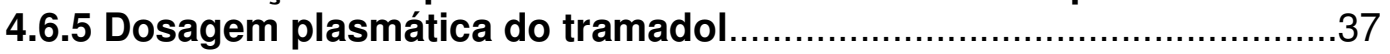

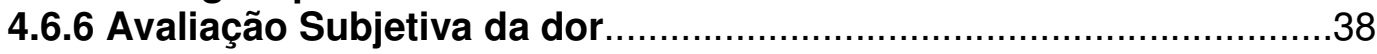

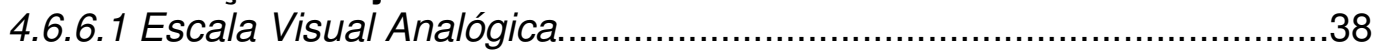

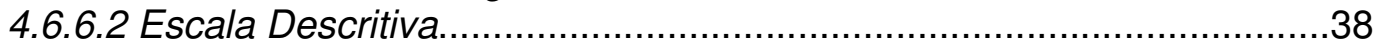

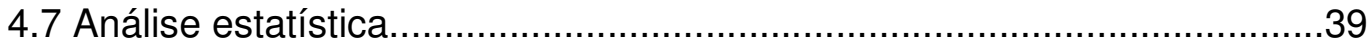

5 RESULTADOS

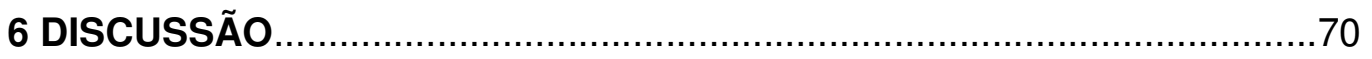

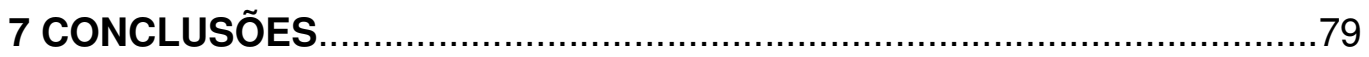

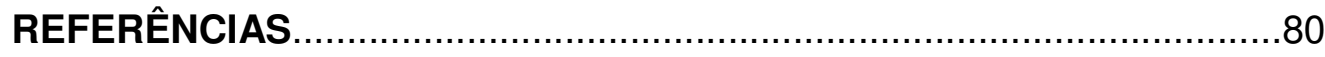




\section{LISTA DE FIGURAS}

Figura 1 - Valores médios relativos à freqüência respiratória, (expressa em movimentos respiratórios por minuto) de cadelas (sem raça definida) tratadas, com 1 ou $4 \mathrm{mg} / \mathrm{kg}$ de tramadol (grupo I e II respectivamente) pela via intravenosa, imediatamente após o término da ovário-salpingo-histerectomia

Figura 2 - Valores médios relativos à freqüência cardíaca, expressa em batimentos por minuto, de cadelas (sem raça definida) tratadas, com 1 ou $4 \mathrm{mg} / \mathrm{kg}$ de tramadol (grupo I e II respectivamente) pela via intravenosa, imediatamente após o término da ováriosalpingo-histerectomia 46

Figura 3 - Valores médios relativos à pressão arterial sistólica (PAS - em mm de Hg), de cadelas (sem raça definida) tratadas, com 1 ou $4 \mathrm{mg} / \mathrm{kg}$ de tramadol (grupo I e II respectivamente) pela via intravenosa, imediatamente após o término da ovário-salpingohisterectomia 48

Figura 4 - Valores médios relativos à pressão arterial diastólica (PAD - em mm de Hg), de cadelas (sem raça definida) tratadas, com 1 ou $4 \mathrm{mg} / \mathrm{kg}$ de tramadol (grupo I e II respectivamente) pela via intravenosa, imediatamente após o término da ovário-salpingohisterectomia .50

Figura 5 - Valores médios relativos à pressão arterial média (PAM- em mm $\mathrm{Hg}$ ), de cadelas (sem raça definida) tratadas, com 1 ou $4 \mathrm{mg} / \mathrm{kg}$ de tramadol (grupo I e II respectivamente) pela via intravenosa, imediatamente após o término da ovário-salpingohisterectomia .52

Figura 6 - Valores médios relativos à concentração plasmática (expressa em $\mathrm{mcg} / \mathrm{ml}$ ) e desvios padrões (DP), de cadelas (sem raça definida) tratadas, com 1 ou $4 \mathrm{mg} / \mathrm{kg}$ de tramadol (grupo I e II respectivamente) pela via intravenosa, imediatamente após o término da ovário-salpingo-histerectomia .54

Figura 7 - Níveis plasmáticos de tramadol $(\mathrm{mcg} / \mathrm{ml})$ e analgesia avaliados por duas diferentes escalas (escala descritiva - ED e escala visual analógica - EVA), na cadela $n^{\circ} 3$ que recebeu $1 \mathrm{mg} / \mathrm{kg}$ de tramadol pela via intravenosa imediatamente após o término da ovário-salpingo-histerectomia. .58

Figura 8 - Níveis plasmáticos de tramadol (mcg/ml) e analgesia avaliados por duas diferentes escalas (escala descritiva - ED e escala visual analógica - EVA), na cadela n 5 que recebeu $1 \mathrm{mg} / \mathrm{kg}$ de tramadol pela via intravenosa imediatamente após o término da ovário-salpingo-histerectomia. 59

Figura 9 - Níveis plasmáticos de tramadol $(\mathrm{mcg} / \mathrm{ml})$ e analgesia avaliados por duas diferentes escalas (escala descritiva - ED e escala visual analógica - EVA), na cadela no 7 que recebeu $1 \mathrm{mg} / \mathrm{kg}$ de tramadol pela via intravenosa imediatamente após o término da ovário-salpingo-histerectomia. 60

Figura 10 - Níveis plasmáticos de tramadol (mcg ml) e analgesia avaliados por duas diferentes escalas (escala descritiva - ED e escala visual analógica - EVA), na cadela $n$ 으 8 que recebeu $1 \mathrm{mg} / \mathrm{kg}$ de tramadol pela via intravenosa imediatamente após o término da ovário-salpingo-histerectomia.... 61

Figura 11 - Níveis plasmáticos de tramadol $(\mathrm{mcg} / \mathrm{ml})$ e analgesia avaliados por duas diferentes escalas (escala descritiva - ED e escala visual analógica - EVA), na cadela no 10 que recebeu $1 \mathrm{mg} / \mathrm{kg}$ de tramadol pela via intravenosa imediatamente após o término da ovário-salpingo-histerectomia. 62

Figura 12 - Níveis plasmáticos de tramadol $(\mathrm{mcg} / \mathrm{ml})$ e analgesia avaliados por duas diferentes escalas (escala descritiva - ED e escala visual analógica - EVA), na cadela no 12 que recebeu $1 \mathrm{mg} / \mathrm{kg}$ de tramadol pela via intravenosa imediatamente após o término da ovário-salpingo-histerectomia. 63

Figura 13 - Níveis plasmáticos de tramadol $(\mathrm{mcg} / \mathrm{ml})$ e analgesia avaliados por duas diferentes escalas (escala descritiva - ED e escala visual analógica - EVA), na cadela no 1 que recebeu $4 \mathrm{mg} / \mathrm{kg}$ de tramadol pela via intravenosa imediatamente após o término da ovário-salpingo-histerectomia 
Figura 14 - Níveis plasmáticos de tramadol $(\mathrm{mcg} / \mathrm{ml})$ e analgesia avaliados por duas diferentes escalas (escala descritiva - ED e escala visual analógica - EVA), na cadela no 2 que recebeu $4 \mathrm{mg} / \mathrm{kg}$ de tramadol pela via intravenosa imediatamente após o término da ovário-salpingo-histerectomia...... 65

Figura 15 - Níveis plasmáticos de tramadol $(\mathrm{mcg} / \mathrm{ml})$ e analgesia avaliados por duas diferentes escalas (escala descritiva - ED e escala visual analógica - EVA), na cadela no 4 que recebeu $4 \mathrm{mg} / \mathrm{kg}$ de tramadol pela via intravenosa imediatamente após o término da ovário-salpingo-histerectomia. 66

Figura 16 - Níveis plasmáticos de tramadol $(\mathrm{mcg} / \mathrm{ml})$ e analgesia avaliados por duas diferentes escalas (escala descritiva - ED e escala visual analógica - EVA), na cadela no 6 que recebeu $4 \mathrm{mg} / \mathrm{kg}$ de tramadol pela via intravenosa imediatamente após o término da ovário-salpingo-histerectomia....

Figura 17 - Níveis plasmáticos de tramadol $(\mathrm{mcg} / \mathrm{ml})$ e analgesia avaliados por duas diferentes escalas (escala descritiva - ED e escala visual analógica - EVA), na cadela no 9 que recebeu $4 \mathrm{mg} / \mathrm{kg}$ de tramadol pela via intravenosa imediatamente após o término da ovário-salpingo-histerectomia.. 68

Figura 18 - Níveis plasmáticos de tramadol $(\mathrm{mcg} / \mathrm{ml})$ e analgesia avaliados por duas diferentes escalas (escala descritiva - ED e escala visual analógica - EVA), na cadela $\mathrm{n}^{\circ} \mathbf{1 1}$ que recebeu $4 \mathrm{mg} / \mathrm{kg}$ de tramadol pela via intravenosa imediatamente após o término da ovário-salpingo-histerectomia. 


\section{LISTA DE TABELAS}

Tabela 1 - Valores individuais relativos à idade (expressa em meses), médias e desvios padrões (DP), bem como o peso das cadelas (sem raça definida) tratadas com 1 ou 4 $\mathrm{mg} / \mathrm{kg}$ de tramadol pela via intravenosa.

Tabela 2 - Valores relativos ao tempo de extubação (expressa em minutos) após o termino da anestesia volátil, médias e desvios padrões de cadelas (sem raça definida) tratadas, com 1 ou $4 \mathrm{mg} / \mathrm{kg}$ de tramadol (grupo I e II respectivamente) pela via intravenosa.

Tabela 3 - Valores individuais relativos à freqüência respiratória, expressa em movimentos respiratórios por minuto, médias e respectivos desvios padrão (DP), de cadelas (sem raça definida) tratadas, com 1 ou $4 \mathrm{mg} / \mathrm{kg}$ de tramadol (grupo I e II respectivamente) pela via intravenosa, imediatamente após o término da ovário-salpingohisterectomia. 43

Tabela 4 - Valores individuais relativos à freqüência cardíaca (expressa em batimentos por minuto), médias e respectivos desvios padrão (DP), de cadelas (sem raça definida) tratadas, com 1 ou $4 \mathrm{mg} / \mathrm{kg}$ de tramadol (grupo I e II respectivamente) pela via intravenosa, imediatamente após o término da ovário-salpingo-

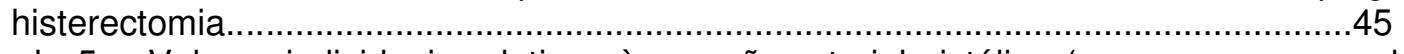

Tabela 5 - Valores individuais relativos à pressão arterial sistólica (expressa em $\mathrm{mm}$ de $\mathrm{Hg}$ ), médias e respectivos desvios padrão (DP), de cadelas (sem raça definida) tratadas, com 1 ou $4 \mathrm{mg} / \mathrm{kg}$ de tramadol (grupo I e II respectivamente) pela via intravenosa, imediatamente após o término da ovário-salpingo-histerectomia. 47

Tabela 6 - Valores individuais relativos à pressão arterial diastólica (expressa em $\mathrm{mm}$ de $\mathrm{Hg}$ ), médias e respectivos desvios padrão (DP), de cadelas (sem raça definida) tratadas, com 1 ou $4 \mathrm{mg} / \mathrm{kg}$ de tramadol (grupo I e II respectivamente) pela via intravenosa, imediatamente após o término da ovário-salpingo-histerectomia. 49

Tabela 7 - Valores individuais relativos à pressão arterial média (expressa em $\mathrm{mm} \mathrm{de} \mathrm{Hg}$ ), suas médias e respectivamente desvios padrão (DP), de cadelas (sem raça definida) tratadas, com 1 ou $4 \mathrm{mg} / \mathrm{kg}$ de tramadol (grupo I e II respectivamente) pela via intravenosa, imediatamente após o término da ovário-salpingohisterectomia..... .51

Tabela 8 - Valores individuais relativos à concentração plasmática (expressa em $\mathrm{mcg} / \mathrm{ml}$ ), médias e respectivos desvios padrões (DP) e coeficiente de variação (CV- em \%), de cadelas (sem raça definida) tratadas, com 1 ou $4 \mathrm{mg} / \mathrm{kg}$ de tramadol (grupo I e II respectivamente) pela via intravenosa, imediatamente após o término da ovário-salpingohisterectomia.

Tabela 9 - Valores individuais e medianas relativos aos escores de algesia obtida através da escala descritiva, de cadelas (sem raça definida) tratadas, com 1 ou $4 \mathrm{mg} / \mathrm{kg}$ de tramadol pela via intravenosa, imediatamente após o término da ovário-salpingohisterectomia. .56

Tabela 10 - Valores individuais e medianas relativos ao escore de algesia obtida através da escala visual analógica de cadelas (sem raça definida) tratadas, com 1 ou $4 \mathrm{mg} / \mathrm{kg}$ de tramadol pela via intravenosa, imediatamente após o término da ovário-salpingohisterectomia. 


\section{RESUMO}

CÔRTES, L. A. Avaliação do perfil analgésico do tramadol através da verificação temporal de sua concentração plasmática em cadelas submetidas a ovário-salpingo-histerectomia. [Evaluation of analgesic profile of tramadol by the temporal verification of its plasmatic concentration in bitches submitted to ovariohisterectomy]. 2006. 87 f. Dissertação (Mestrado em Ciências) - Faculdade de Medicina Veterinária e Zootecnia, Universidade de São Paulo, São Paulo, 2006.

Nos últimos anos tem sido verificado um aumento crescente do uso do tramadol no controle da dor em Medicina Veterinária, ainda quando seja evidente a escassa base literária acerca de seu uso em pequenos animais. O presente estudo avaliou o perfil analgésico deste opióide através da verificação temporal de sua concentração plasmática em cadelas submetidas à ovário-salpingo-histerectomia. Dois grupos de 6 cadelas cada, com idade entre 2 e 5 anos e peso superior a $15 \mathrm{~kg}$ foram inoculadas pela via intravenosa com $1 \mathrm{mg} / \mathrm{kg}$ ou $4 \mathrm{mg} / \mathrm{kg}$ (grupos I e II), respectivamente, imediatamente após a sutura da pele. Os animais foram monitorados por um período de 480 minutos, quando foram aferidos os períodos de extubação; as freqüências cardíaca freqüência respiratória; a pressão arterial (sistólica, diastólica e média); procedidas as coletas de amostras para dosagem plasmática de tramadol, mensuradas através de HPLC; bem como a avaliação da sensibilidade dolorosa. Até decorridas 8 horas de monitoramento não foram registradas alterações importantes na freqüência cardíaca, freqüência respiratória e pressão arterial (sistólica, diastólica e média) atribuíveis ao tramadol em qualquer um dos grupos, nem diferenças estatisticamente significantes entre eles, mas detectou-se um aumento da pressão sistólica e, consequentemente, da média do grupo que recebeu $4 \mathrm{mg} / \mathrm{kg}$ de tramadol, apenas aos 30 minutos. Os valores de concentração plasmática do tramadol puseram em evidência diferenças significantes estatisticamente $(p<0,05)$ em sete momentos de aferição $(10,20,30,45,90,240$ e 480 minutos) assinalando que nos animais tratados com 4 $\mathrm{mg} / \mathrm{kg}$ (grupo II) as concentrações plasmáticas médias foram mais elevadas ( $\mathrm{p}<$ $0,05)$ do que aquelas do grupo I $(1 \mathrm{mg} / \mathrm{kg}$ ). Os escores de dor, obtidos pela avaliação de um mesmo observador e utilizando as duas escalas escolhidas, revelaram que os dados obtidos pela escala descritiva (cujos escores variam de 0 -3) não assinalaram diferenças estatísticas significantes entre os dois grupos, porém a escala analógica (cujos escores variam de 0 - 10) mostrou, em um único momento (120 minutos), diferença significante estatisticamente $(p<0,05)$, revelando um maior es- 
core de dor no grupo tratado com $1 \mathrm{mg} / \mathrm{kg}$ de tramadol. Quando cotejados os dados obtidos pelas duas escalas verifica-se, exceção feita ao animal de número 3 (grupo I), a existência de uma correspondência entre os escores indicativos de resgate, comprovando serem equivalentes, as escalas visual analógica e descritiva, permitindo a opção por qualquer uma na avaliação álgica dos animais. O tramadol, administrado pela via intravenosa nas doses de $1 \mathrm{mg} / \mathrm{kg}$ ou $4 \mathrm{mg} / \mathrm{kg}$, produziu analgesia em $83 \%$ das cadelas por até 150 ou 240 minutos, respectivamente. Administrado pela mesma via na dose de $1 \mathrm{mg} / \mathrm{kg}$ produziu analgesia adequada, por um período de 8 horas, em 17\% (1/6) das cadelas e, na dose de $4 \mathrm{mg} / \mathrm{kg}$, em 50\% (3/6) desses animais. O período médio de resgate foi de 247,5 minutos e nenhum dos 8 animais resgatados manifestou escore de dor, indicativo deste procedimento, em período inferior a 120 minutos, nem foi encontrado correlação entre os níveis plasmáticos do tramadol e os escores de dor nos limites das observações do presente estudo.

Palavras-chave: Tramadol. Concentração plasmática. Cadelas. Escala de dor. 


\section{ABSTRACT}

CÔRTES, L. A. Evaluation of analgesic profile of tramadol by the temporal verification of its plasmatic concentration in bitches submitted to ovariohisterectomy. [Avaliação do perfil analgésico do tramadol através da verificação temporal de sua concentração plasmática em cadelas submetidas a ováriosalpingo-histerectomia]. 2006. 87 f. Dissertação (Mestrado em Ciências) - Faculdade de Medicina Veterinária e Zootecnia, Universidade de São Paulo, São Paulo, 2006.

In the last few years have been verified an increase of tramadol use in pain control in Veterinary Medicine, even when the literary basis were very poor (rare). The present study evaluates the analgesic profile of this opioid by the temporal verification of its plasmatic concentration in bitches submitted to ovariohysterectomy. Two groups of 6 bitches each, with age between 2 to 5 years and weight over $15 \mathrm{~kg}$ were treated with tramadol $1 \mathrm{mg} / \mathrm{kg}$ or $4 \mathrm{mg} / \mathrm{kg}$ (groups I and II respectively) immediately after skin suture. The animals were monitored by a period of 480 minutes, evaluating extubation time, cardiac frequency, respiratory frequency and arterial pressure (systolic, diastolic and median); and collecting blood samples for plasmatic dosage of tramadol, analyzed by HPLC, and evaluation of pain sensibility. Until 8 hours of monitoring there was neither important variation on the cardiac frequency, respiratory frequency and arterial pressure (systolic, diastolic and median) in any group, attributed to tramadol, nor statistic differences between them, but was detected an increasing in systolic and median pressure of group that received $4 \mathrm{mg} / \mathrm{kg}$ de tramadol, only at 30 minutes observation. The values of plasmatic concentration of tramadol have showed statistic differences $(p<0,05)$ in seven verified moments $(10,20,30,45,90,240,480$ minutes) pointing out that in the animals treated with $4 \mathrm{mg} / \mathrm{kg}$ (group II) mean plasmatic concentration were higher $(p<0,05)$ than the group I $(1 \mathrm{mg} / \mathrm{kg})$. The pain score, evaluated by the same observer using both pain scales chosen, revealed that obtained data by the descriptive scale (whose scores ranges $0-3$ ) did not show significant statistical differences between the two groups, however the analogical scale (whose scores ranges $0-10$ ) showed, in only one moment (120 minutes) statistic difference $(p<0,05)$, configuring a higher pain score in the group I, treated with 1 $\mathrm{mg} / \mathrm{kg}$ of tramadol. The compared data obtained by the two scales shows, with exception of the animal 3 (group I), the existence of a correspondence between rescue scores, proving that both scales (visual analogical and descriptive) are equivalents, which allowed choose anyone of them for purpose of pain sensitivity evaluation. The 
intravenous administration of tramadol, in dosage of $1 \mathrm{mg} / \mathrm{kg}$ or $4 \mathrm{mg} / \mathrm{kg}$, produced analgesia in $83 \%$ of the bitches until 150 or 240 minutes, respectively. When administrated by the same route in the dosage of $1 \mathrm{mg} / \mathrm{kg}$ produced analgesia, for an 8 hour period, in $17 \%(1 / 6)$ of the females and, on dosage of $4 \mathrm{mg} / \mathrm{kg}$, in $50 \%(3 / 6)$ of these animals. The mean period of rescue was 247,5 minutes and none of the 8 animals, which received additional treatment, revealed rescue pain score in an inferior period of 120 minutes, nor was correlation found between the plasmaticcon centration of tramadol and pain scores beyond the limits of observation in the present study.

Key words: Tramadol. Plasmatic concentration. Bitches. Pain scale. 


\section{INTRODUÇÃO}

A analgesia pós-operatória tem sido, de longa data, uma preocupação para medicina humana e, também para a medicina veterinária que, nos últimos anos, não tem poupado esforços para solucionar a questão da sensibilidade dolorosa e promover uma melhor qualidade de vida para os animais submetidos a procedimentos cirúrgicos anestésicos.

Sabe-se que o estresse decorrente de uma condição potencialmente dolorosa tem sido considerado como causa de imunossupressão, atraso na cicatrização de feridas e até aumento nas taxas de morbidade e mortalidade (ROLLIN, 1997; THURMON et al., 1996).

A escolha de um analgésico apropriado que acarrete efeitos adversos mínimos é tarefa de extrema importância em ambas as áreas médicas. Dentre os fármacos utilizados em medicina veterinária, com finalidade analgésica, os opióides têm sido uma alternativa bastante promissora devido à sua eficiência no que diz respeito ao controle da dor e à reduzida presença de efeitos adversos (PAPICH, 1997).

O tramadol, um opióide que vem sendo utilizado em seres humanos, desde a década de 1970 (LEHMANN, 1994), é um análogo sintético da codeína, e possui ação analgésica central com baixa afinidade pelos receptores opióides e efeitos diversos daqueles observados nos opióides agonista puros, disponíveis na prática clínica. Apesar de ter sido inicialmente considerado opióide agonista puro, na atualidade é reconhecida sua baixa afinidade pelo receptor $\mu$, em contraposição a seu metabólito, o desmetiltramadol, que revela uma afinidade muito mais pronunciada por este receptor (DUTHIE, 1998). O tramadol ainda apresenta a capacidade de inibir a recaptação de norepinefrina e de serotonina, levando a uma ação analgésica via bloqueio de impulso na medula espinhal (BUDD; LANGFORD, 1999; DAYER et al., 1997; DRIESSEN; REIMANN, 1992; FRANCESCHINI et al., 1999; HALPENNY et al., 1999; LEE et al., 1993).

O efeito mais temido quando da utilização de opióides pela via parenteral é a depressão respiratória. Neste sentido, Bosenberg e Ratcliffe (1998) es- 
tudando a ação do tramadol no sistema respiratório de pacientes pediátricos anestesiados com halotano, compararam a utilização desse fármaco, com a meperidina, ambos na dose de $1 \mathrm{mg} / \mathrm{kg}$, e verificaram que o tramadol é mais seguro no que diz respeito à depressão respiratória, uma vez que não causou apnéia em nenhum dos pacientes observados. A meperidina, em contrapartida, ocasionou apnéia em algumas crianças, necessitando reversão com naloxona, além de ter revelado, nestes pacientes, maior teor de dióxido de carbono, no ar expirado $\left(\mathrm{ETCO}_{2}\right)$, que o tramadol. Comparando a utilização de meperidina e tramadol, no ser humano, para o controle da dor pós-operatória de cirurgias ortopédicas, Tarradel et al. (1996), concluíram que a administração de $100 \mathrm{mg}$ de meperidina ou $100 \mathrm{mg}$ de tramadol produz grau de analgesia semelhante; porém a meperidina induz à sedação, depressão respiratória e hipercapnia, fato não observado quando se utilizou o tramadol.

O tramadol além de promover mínimas alterações cardiovasculares, respiratórias, baixos efeitos na motilidade gastrintestinal, tem sido efetivo na analgesia pós-operatória em cirurgias ortopédicas, cirurgias ginecológicas e em situações não cirúrgicas (GROND et al., 1995; LEHMANN et al., 1990).

Por mais que existam estudos buscando elucidar a ação e os efeitos do tramadol, são ainda limitadas respostas relativas ao seu uso na medicina veterinária, de sorte que novas pesquisas sobre este fármaco, em pequenos animais, são bem-vindas, posto que possam trazer um valioso aliado para o controle da dor nestes pacientes. 


\section{REVISÃO BIBLIOGRÁFICA}

\subsection{A Importância da dor na Saúde Animal}

Até o século passado, a dor era um componente implícito ao ato cirúrgico, no entanto, com o advento da anestesia geral e os progressos da anestesia regional, recursos essenciais aos procedimentos cirúrgicos têm buscado propiciar ao paciente um transcurso operatório indolor. Contudo, por motivos variados, a dor pós-operatória, nas duas últimas décadas e, em alguns lugares, até nos dias atuais, continua sendo encarada como uma fatalidade, uma aceitação tácita, tanto por parte do doente quanto da equipe cirúrgica (DRUMMOND, 2000).

Embora a espécie humana ainda admita que os animais estejam sujeitos a experiências dolorosas, em tempos remotos, as violentas reações de luta e vocalização verificadas durante ou após as intervenções cirúrgicas eram inter-

pretadas como respostas do sistema nervoso autônomo ou reflexos musculares não controlados (HELLEBREKERS, 2002).

Neste sentido Drummond (2000) pondera que, com o avanço dos conhecimentos, as drogas e os métodos ora disponíveis, a dor pós-operatória, na quase totalidade dos casos, deve ser considerada como uma complicação, resultante de desinformação, omissão ou negligência da equipe cirúrgica.

Do mesmo modo, a posição do Colégio Americano dos Anestesiologistas Veterinários - ACVA (1998) em relação ao tratamento da dor em animais, estabelece que a dor é uma condição clínica importante e prejudicial a qualidade de vida, devendo ser obrigatoriamente prevenida e tratada para que o animal possa não apenas manter as suas atividades diárias normais, como: sono, lazer, alimentação e higiene adequadas, mas também estabelecer a correspondente relação interativa com o seu proprietário.

Nesta mesma publicação, o ACVA, estipulou que um estímulo considerado doloroso no ser humano também deve ser considerado em animais e que a inabilidade de comunicação verbal em nenhum momento impossibilita a expressão da sensação álgica.

Ademais dos aspectos éticos envolvidos, o alívio da dor é fundamental 
do ponto de vista fisiológico, sendo um dever incondicional do médico veterinário em aliviar o sofrimento do animal acometido por este agravo (GAYNOR, 2001; ROBERTSON, 2002), particularmente porque a dor indevidamente tratada acarreta estresse, sofrimento, ansiedade e diminuição da qualidade de vida de qualquer indivíduo (MCMILLAN, 2003a).

Após décadas sendo sub-tratada, subestimada e muitas vezes ignorada, a dor, atualmente, é considerada um fator de grande importância em relação à qualidade de vida tanto no homem quanto nos animais (MCMILLAN, 2003a).

Embora o conceito de qualidade de vida venha sendo considerado pela literatura médico veterinária, a sua caracterização para os animais tem sido objeto de controvérsias e os critérios e questionários de avaliação permanecem ainda muito limitados (MCMILLAN, 2003b; MELLANBY et al., 2003). Tal conceito é complexo e subjetivo, sendo que os vocábulos encontrados na literatura médica e médica veterinária para caracterizá-los são contraditórios. Mas, na visão da maioria dos autores, a escolha dos fatores que compõem a condição de qualidade de vida tem como base a noção de saúde; este se configura como sendo o complexo bem-estar físico, mental e social e não meramente a ausência da enfermidade. McMillan (2000) tenta estabelecer a idéia de qualidade de vida para animais como a ausência ou presença mínima de desconfortos físicos (por exemplo: náusea, retenção urinária, prurido, dor, tosse, dispnéia) e emocionais (por exemplo: medo, ansiedade, solidão e frustração).

\subsection{Impacto da dor sobre o organismo}

Sempre que a dor assume uma condição patológica, alterações de caráter variado podem ocorrer entre as quais, a elevação da taxa de hormônios e de outras substâncias de efeito catabólico, como catecolaminas, cortisol, hormônio adrenocorticotrópico (ACTH), hormônio antidiurético (ADH), reninaangiotensina, glucagon, aldosterona e interleucina-1; e, ainda, a redução de hormônios que agem anabolicamente, tais como a insulina e a testosterona (DRUMMOND, 2000; GAYNOR, 2001; TRANQUILLI et al., 2005). Além disso, pode-se observar a retenção de sódio e água e o aumento na excreção de potássio devido à ativação do sistema renina-angiotensina-aldosterona, resultando em retenção hídrica com conseqüente aumento da pressão arterial e dimi- 
nuição da perfusão renal. O consumo de oxigênio pelo miocárdio pode aumentar e, isto, associado à liberação de catecolaminas culmina em hipóxia no músculo cardíaco ou isquemia e arritmias atriais e ventriculares importantes. Por outro lado, o aumento do cortisol secundário à dor, pode reduzir a eficácia do sistema imunológico e a estimulação simpática excessiva pode desviar sangue do sistema gastrintestinal, prejudicando a motilidade e reduzindo a integridade da mucosa, ocasionando absorção inadequada dos alimentos, translocação bacteriana e sepse (FANTONI; MASTROCINQUE, 2002; LESTER; GAYNOR, 2000).

Adicionalmente verificam-se também respostas corticais a dor que podem provocar aumento da viscosidade sangüínea e do tempo de coagulação, fibrinólise e agregação plaquetária (DRUMMOND, 2000).

As reações à dor variam entre as espécies, mas determinados comportamentos e sinais configuram-se como indícios compatíveis com condições dolorosas em andamento. Alterações, por exemplo, nos padrões de vocalização normal, são comuns, principalmente quando manipulada a região dolorida; e no comportamento, traduzidas por agressividade, agitação ou timidez, dependendo do relacionamento interativo com seus proprietários. As expressões faciais e a postura corporal podem ser bastante reveladoras, incluindo: olhar fixo, postura arqueada, diminuição de atividade e limitação da mobilidade. A aparência pode também ser muito indicativa, quando deixa antever os pêlos eriçados $\mathrm{e}$ sem brilho; e presença de descarga nasal e ocular, não sendo incomum nos estados dolorosos a anorexia, denunciada pelo baixo consumo alimentar e hídrico, bem como, alterações nos comportamentos de evacuação e micção, induzindo a uma perda de peso e até desidratação (LESTER; GAYNOR, 2000; MORTON; GRIFFITHS, 1985; TRANQUILLI et al., 2005).

\subsection{Avaliação da Dor}

O reconhecimento e a avaliação da dor são tarefas bastante difíceis, principalmente na Clínica Veterinária, uma vez que os animais não têm a habilidade de expressar, nem quantificar verbalmente a sensibilidade dolorosa, o que caracteriza a subjetividade da avaliação (GAYNOR, 2001; HARDIE; KILES, 1995). Neste caso o veterinário conta com um grande aliado, o proprietário, na 
avaliação das alterações comportamentais do animal (WISEMAN et al., 2001). Essa mesma dificuldade é encontrada pelos pediatras, posto que a avaliação comportamental feita por familiares e enfermeiros é ainda a forma mais eficaz de avaliação de dor (VLAINICH, 2004).

Uma avaliação completa da dor deve abranger: uma observação, não interativa, empreendida à distância; e uma apreciação interativa envolvendo um estímulo que provoque uma resposta no paciente. Para que a avaliação da dor seja mais fidedigna possível, ela deve ser seriada e realizada, de preferência, por um mesmo observador (TRANQUILLI et al., 2005).

Diversas escalas têm sido utilizadas como ferramentas de avaliação de dor. Entre elas, figuram: Escala Visual Analógica (EVA- escala visual analógica); Escala de Graduação Numérica (NRS - numerical rating scale), Escala Numérica Verbal, Escala Categórico Verbal e Escala Descritiva (DRUMMOND, 2000; LASCELLES et al., 1994; TRANQUILLI, 2005).

A Escala Visual Analógica consiste em uma linha de comprimento padrão $(10 \mathrm{~cm})$, contemplando uma extremidade que representa o conceito "ausência de dor" (zero) e a outra, valor dez, significando a "pior dor imaginável". O paciente ou o observador, com uma caneta, deve fazer uma marca simbolizando a "quantidade" de dor sofrida (AMARAL et al., 1996; DRUMMOND, 2000; FIRTH; HALDANE, 1999; GAYNOR, 2001; LESTER; GAYNOR, 2000; TRANQUILLI, 2005).

A Escala de Graduação Numérica é semelhante à EVA, no que se refere à sua representação por uma linha de comprimento padrão; no entanto, ela é dividida em intervalos regulares por números que vão de 0 a 10, cujo zero representa "ausência de dor" e o dez, a "pior dor imaginável". (DRUMMOND, 2000; TRANQUILLI et al., 2005).

$\mathrm{Na}$ Escala Numérica Verbal o paciente estabelece uma nota que vai de zero a dez, enquanto na Escala Categórico-Verbal a dor é classificada pelo paciente, consoante os seguintes critérios: ausência; dor fraca; dor moderada; dor intensa e dor insuportável (DRUMMOND, 2000; AMARAL et al., 1996).

Finalmente, no método de Escalas Descritivas o grau de desconforto é obtido por meio de sinais de vocalização, inquietação e pela resposta do animal diante de uma pressão exercida no local do agravo (LASCELLES et al., 1994), tomando-se como critérios: $\mathbf{0}$ - analgesia completa, sem sinais de desconforto 
ou sem resposta à pressão na ferida cirúrgica; 1 - boa analgesia, sem sinais de desconforto com reação à pressão exercida na ferida cirúrgica; 2 - moderada analgesia com alguns sinais de desconforto os quais se tornam mais evidentes com a pressão exercida na ferida cirúrgica; 3 - com sinais óbvios de desconforto piorando com pressão exercida na ferida cirúrgica.

\subsection{Fisiologia da dor}

A dor, não acompanhada de eventos capazes de justificá-la, era considerada, desde a antiguidade, como decorrente de causas sobrenaturais. A influência do sistema nervoso central no mecanismo das sensações e da nocicepção passou a ser admitido a partir da era Renascentista (CORTOPASSI; FANTONI, 2003), tendo, em 1986, a Associação Internacional para o Estudo da dor, caracterizado como sendo "uma experiência sensorial e emocional desagradável que está associada a lesões reais ou potenciais" (CORTOPASSI; FANTONI, 2003).

A eficácia do adequado tratamento estabelecido para o combate à condição dolorosa está intimamente associada ao entendimento dos mecanismos envolvidos em seu desencadeamento. Para Texeira (1994) e Sakata e Issy (2004) o evento doloroso é concebido por uma seqüência de fatores, sendo seu início caracterizado pela transformação de estímulos lesivos em potenciais de ação (transdução), que serão transmitidos ao sistema nervoso central através de fibras nervosas periféricas.

Terminações nervosas especializadas chamadas de nociceptores são responsáveis pela codificação da energia mecânica, química ou térmica em impulso elétrico. São estruturas livres de neurônios aferentes primários e funcionam por meio de sinalização de lesões teciduais reais ou potenciais (BONICA, 1990; CARROL, 1999; TEIXEIRA, 1994), transmitida por axônios A-delta mielinizados e de pequeno diâmetro, que conduzindo impulsos de maneira muito rápida, produzem o que é chamado, usualmente, de "primeira dor". Já a condição denominada de "dor secundária" decorre da transmissão dos referidos sinais através de fibras $\mathrm{C}$ não mielinizadas menores, que processa-se de forma muito mais lenta, e reforça a resposta imediata produzida pelas fibras A-delta. Tanto as fibras A-delta como as $\mathrm{C}$ estão dispersas em toda a pele, peritônio, pleura, 
periósteo, tecido ósseo subcondral, cápsulas articulares, vasos sanguíneos, músculos, tendões, fáscias e vísceras. Os corpos celulares de ambos os tipos de fibras aferentes situam-se nos gânglios de raízes dorsais e estendem axônios para formar sinapses com neurônios do corno dorsal dentro da substância cinzenta da medula espinhal. Os axônios das células de projeção (neurônios de segunda ordem), cujos corpos celulares se encontram no corno posterior, vão ascender na medula, sob a forma de feixes ou tratos, até alcançarem centros nervosos superiores. Denomina-se sistema ascendente nociceptivo o conjunto desses tratos medulares, que são em número de seis: o espinotalâmico (TST); o espinorreticular (TSR); o espinomesencefálico (TSM); o sistema pós-sináptico da coluna dorsal (SPCD), também conhecida como trato de segunda ordem da coluna dorsal; o trato espinocervical (TSC); e o sistema ascendente multissináptico próprio espinhal (SAMP). Os dois primeiros estão localizados no quadrante anterolateral, o terceiro no mesmo quadrante e no funículo dorsolateral, o quarto e o quinto na coluna dorsal e o sexto é composto por neurônios de cadeia curta, situados em diversas partes do eixo nervoso. As informações nociceptivas, após percurso medular, alcançam estruturas nervosas superiores, nos níveis bulbares, mesencefálico e diencefálico, onde terminam ou constituem sinapses (neurônios de terceira ordem). Entre estas estruturas incluem-se a formação reticular, o tálamo, o hipotálamo, o sistema límbico e o córtex.

\subsection{Cognição ou percepção/reação}

A percepção, conquanto não seja considerada uma parte do processo nociceptivo, resulta de transdução, transmissão e modulação bem sucedidas e da integração das funções talamocortical, reticular e límbica para produzir a experiência subjetiva e emocional consciente final da dor. A entrada de dados nociceptivos é modulada em cada nível do trajeto sensorial, desde a periferia até o córtex cerebral, onde ocorre a percepção, sendo que esta representação cerebral da dor leva em consideração suas múltiplas dimensões - a sensorialdiscriminativa; a afetivo-motivacional e a cognitivo-avaliativa - mostrando que a dor não consiste na simples ativação de um sistema sinalizador em si, isolado e específico, mas que o estimulo nociceptivo está sujeito a uma série de con- 
troles, que agem no contexto de um sistema nervoso totalmente integrado (TRANQUILLI et al., 2005).

Para estes autores é evidente que todo este envolvimento neuroquímico reflita na complexidade do mecanismo decodificador, que traduz o estímulo da lesão tecidual em termos sensório-afetivo-comportamentais, no processo álgico. Além disso, a dualidade do fenômeno percepção/reação, exige que do ponto de vista terapêutico, não se detenha apenas na localização e na eliminação ou atenuação da nocicepção, mas que considere também a atitude de cada paciente diante da própria dor.

A percepção da dor não envolve apenas uma análise momentânea dos estímulos nociceptivos, mas também implica um processo dinâmico, o qual é influenciado pelos efeitos de experiências passadas. Os estímulos sensoriais atuam sobre estruturas nervosas, que têm sido modificadas por estímulos anteriores, e a reação comportamental é, significativamente, influenciada pela "memória" daqueles eventos vivenciados (DRUMMOND, 2000).

\subsection{Modulação da Dor}

A percepção da dor é peculiar a cada individuo. Assim, ainda quando sejam semelhantes os estímulos indutores da dor esta é sentida de maneira distinta em cada pessoa. A modulação do estímulo doloroso ocorre em diversos níveis no Sistema Nervoso Central por meio de sistemas anatômica e neurofisiologicamente diferentes, podendo, a mensagem original, ser modificada (aumentada ou diminuída) a cada sinapse. Assim, em sentido lato, a modulação é o processo pelo qual a transmissão é facilitada ou inibida, onde, cada neurônio age como um integrador do conjunto de informações captadas e, conforme a resultante dos impulsos elétricos registrados, pode ocorrer uma ativação ou despolarização, ou inibição ou hiperpolarização (DRUMMOND, 2000).

A modulação se faz tanto em sua transmissão ascendente como descendente. A inibição da dor no nível espinal é mediada principalmente pela: serotonina, noradrenalina, encefalina, GABA, glicina e acetilcolina; já no encéfalo as regiões envolvidas na inibição descendente incluem: hipotálamo anterior, área septal inferior, núcleo centro-mediano do tálamo, cápsula interna, substância cinzenta periaqueductal e núcleo da rafe. O mecanismo de ativação de neurô- 
nios do corno dorsal pelas fibras finas (A-delta e C) e inibição por fibras grossas (A beta) foi descrita inicialmente como mecanismo de "portão" ou comporta, que atualmente tem sido melhor descrito após a descoberta de receptores para as diferentes substâncias de neurotransmissores inibitórios e excitatórios, bem como de diversas vias (SAKATA; ISSY, 2004).

\subsection{Opióides}

São substâncias endógenas ou exógenas, cuja atividade analgésica decorre de sua ligação a receptores opióides específicos envolvidos na transmissão, modulação e sensação da dor (SAKATA et al., 2004). A analgesia decorre da ativação de grupos de tais receptores, entre os quais: mü $(\mu)$, kappa $(\kappa)$, delta $(\delta)$ e sigma $(\sigma)$ (CARVALHO et al., 2004). Os efeitos variam com a ligação que estabelecem com cada um dos receptores apontados. Assim para Sakata et al. (2004) e Papich (1997) a ligação com receptores mü $(\mu)$ está associada a analgesia, depressão respiratória, euforia, sedação; a ligação com receptores kappa (к) produz analgesia espinal, sedação, miose e diminuição de hormônio antidiurético (ADH). A ligação de opióides com receptores delta $(\delta)$ produz analgesia e euforia; e com receptores sigma $(\sigma)$, disforia, alucinação, estimulação psicomotora e excitação, com pouco efeito analgésico.

Dependendo da posição que ocupam e intensidade de sua atividade os opióides podem ser: agonistas (ocupam o sítio de ligação com atividade fisiológica máxima); agonistas parciais (ocupam o sítio de ligação com atividade fisiológica submáxima); agonistas-antagonistas (agem como agonistas ou agonistas parciais em uns receptores e antagonistas em outros); e, antagonistas (ocupam o sítio de ligação, sem ação fisiológica) (CARVALHO et al., 2004; FANTONI, MASTROCINQUE, 2002; SAKATA et al., 2004).

No nível medular, os opióides provocam redução da liberação de substância $\mathrm{P}$ (um neurotransmissor excitatório da sinapse entre a fibra aferente primária e o segundo neurônio da dor), acarretando efeito analgésico desejado (SAKATAet al., 2004; TEIXEIRA, 2003). Além disso, alteram a permeabilidade das membranas neuronais a íons potássio $\left(\mathrm{K}^{+}\right)$, cálcio $\left(\mathrm{Ca}^{++}\right)$e sódio $\left(\mathrm{Na}^{+}\right)$, ini- 
bindo a liberação de neurotransmissores das terminações nervosas (SAKATA et al., 2004; TEIXEIRA; VALLE, 2001).

Os opióides, de modo geral, podem ser administrados por diversas vias, como: oral, sublingual, retal, subcutânea, intramuscular, intravenosa, epidural, transdérmica, intra-articular e intratecal (TEIXEIRA; VALLE, 2001).

Os efeitos colaterais dos opióides manifestam-se diferentemente consoante o sistema orgânico do indivíduo. Assim, no sistema nervoso central observou-se sedação, confusão, euforia, medo, agitação, disforia, miose e desorientação; no trato gastrintestinal observou-se náusea, vômitos, diminuição do peristaltismo, constipação, cólica biliar; no sistema respiratório observou-se depressão respiratória, supressão do reflexo da tosse; no sistema cardiovascular observou-se hipotensão conseqüente a bradicardia; no sistema urinário observou-se retenção (CARVALHO et al., 2004; DRUMMOND, 2000; SAKATA et al., 2004; TRANQUILLI et al., 2005). Todavia tais inconvenientes deixam de ser causa de preocupações quando consegue-se ajustar a dose individual de sorte a obter-se o máximo efeito analgésico com mínimas conseqüências colaterais indesejáveis (PORTENOY; LESAGE, 1999).

\subsection{Tramadol}

É um opióide sintético análogo da codeína com ação agonista (CARVALHO et al., 2004; SAKATA et al., 2004), com fraca afinidade para os receptores $\mu$ e $\delta$, e menor afinidade ainda para o receptor $\kappa$. Sua interferência na liberação e recaptação da serotonina ( $5 \mathrm{HT})$ e da noradrenalina (NA) reflete uma tendência inibitória decrescente (RAFFA et al., 1992; SAKATA et al., 2004).

O tramadol é uma mistura racêmica constituída por dois enantiômeros farmacologicamente ativos. A demetilação hepática do tramadol produz o metabólito ativo, O-desmethyltramadol (M1), que também existe como uma mistura racêmica. $O$ enantiômero (+)-tramadol interage com receptores opiáceos $(\mu$, $\kappa$ e $\delta$ ), adrenérgicos ( -2$)$ e de serotonina, enquanto que enantiômero (-)tramadol interage com receptores adrenérgicos ( -2). O (+)-M1 interage com receptores $\mu$-opiáceos, enquanto o (-)-M1 interage com receptores adrenérgicos ( -2) (DRIESSEN et al., 1993; HALFPENNY et al., 1999; RAFFA et al., 
1993; SEVCIK et al., 1993). A afinidade do metabólico ativo ao receptor $\mu$ opióide é de 2 a 200 vezes maior que a do tramadol (LEE et al., 1993; POULSEN et al., 1996).

Estudos farmacocinéticos e farmacodinâmicos consideram a isoenzima citocromo P450 2D6 (CYP2D6) como a responsável pelo processo de demetilação e produção do $\mathrm{M} 1$, além de demonstrar que a maior porcentagem da analgesia decorrente da administração do tramadol é devida a seu metabólito ativo (M1) (GARRIDO et al., 2000; GARRIDO et al., 2003; POULSEN et al., 1996; RAFFA et al., 1993;).

Em seres humanos, após administração oral de $100 \mathrm{mg}$ de tramadol, observa-se uma biodisponibilidade de $68 \%$ do medicamento, com uma meiavida de eliminação de 5,5 horas (SCOTT; PERRY, 2000). Em cães resultados similares foram observados, com uma biodisponibilidade de $65 \pm 35 \%$, e uma meia vida de eliminação de $1,71 \pm 0,12$ horas.

Relativamente ao metabólito M1, em seres humanos, Kukanich e Papich (2004) verificaram ser a meia-vida de 6,7 horas, após a administração oral de $100 \mathrm{mg}$ de tramadol, contrastando com o valor correspondente obtido na espécie canina submetida ao mesmo tratamento, da ordem de 2,18 $\pm 0,55$ horas.

O tempo de eliminação total do tramadol da circulação sanguínea, em cães, foi 5 vezes menor que em seres humanos; e o número de metabólitos do tramadol identificados em cães após administração oral de tramadol foi de pelo menos 32 (WU et al., 2001), enquanto em seres humanos, pelo menos 11 metabólitos foram identificados, dos quais apenas o O-demethyltramadol (M1) tem revelado atividade farmacológica.

Em comparação aos opióides convencionais o tramadol produz baixa depressão respiratória, além disso, não apresenta sedação significativa e não altera o tempo de extubação (BAMIGBADE et al., 1998; HOUMES et al., 1992; VICKERS et al., 1992). Ocasionalmente, a hipotensão pode ocorrer secundariamente como decorrência da vasodilatação periférica e pode ser minimizada pela aplicação lenta do medicamento ou pela limitação da dose (BAMIGBADE et al., 1998).

Estudo realizado na Universidade de Hong Kong demonstrou, em seres humanos, uma similar qualidade de analgesia e grau de satisfação de pacientes usando tramadol para pós-operatório PCA (Patient-controlled analgesia), 
quando comparado à morfina num grupo de pacientes após cirurgia abdominal baixa (NG et al., 1998). Num abrangente estudo em seres humanos comparando tramadol com morfina, por via intravenosa, para analgesia pós-operatória, tanto Vickers et al. (1995) como Stamer et al. (1997) obtiveram resultados similares em relação à eficácia nas duas drogas.

Engelhardt et al. (2003) demonstraram, em seres humanos, que tramadol intravenoso ( $1 \mathrm{mg} / \mathrm{kg}$ e $2 \mathrm{mg} / \mathrm{kg}$ ) é uma alternativa para morfina intravenosa $(0,1 \mathrm{mg} / \mathrm{kg})$ em pós-operatório de pacientes submetidos à tonsilectomia. Não houveram diferenças entre os dois grupos quando comparados relativamente à analgesia, à sedação e ao escore de dor.

Em estudos em seres humanos, sobre o tramadol no tratamento dos tremores pós-anestésicos, De Witte et al. (1997) verificaram que quando administrado, na dose de $3 \mathrm{mg} / \mathrm{kg}$, no momento da sutura, os tremores foram completamente abolidos (DE WITTE et al., 1998). Nesse sentido, Mathews et al. (2002) concluíram que a administração de tramadol na dose de $2 \mathrm{mg} / \mathrm{kg}$ ou 1 $\mathrm{mg} / \mathrm{kg}$ no momento da sutura previne efetivamente os tremores pósanestésicos, e Bhatnagar et al. (2001) trataram tremores pós-operatórios com tramadol ou petidina, num estudo comparativo, e concluíram que o tramadol revelou-se superior a petidina inclusive não acarretando depressão respiratória.

E um dos trabalhos de investigação farmacocinética do tramadol foi determinado que, em coelhos, a concentração plasmática declinou rapidamente após o final da primeira hora da infusão do tramadol e sua concentração começou a desaparecer do plasma após 8 horas passadas (KÜÇÜK et al., 2005). Em outro estudo comparativo entre a bupivacaina e o tramadol, em seres humanos submetidos a cirurgia de laparoscopia, foi definido que o tramadol promoveu uma analgesia aceitável por aproximadamente 3 horas pós-operatória (DARWISH; HASSAN, 1999).

Os dados acima expostos mostram que os efeitos do tramadol foram melhor avaliados na espécie humana quando comparados com aqueles obtidos nas demais espécies de mamíferos. 


\section{OBJETIVO}

Estudar o perfil analgésico do tramadol administrado, por via intravenosa, em cadelas imediatamente após o término da ovário-salpingohisterectomia, avaliando-se a sensibilidade dolorosa e os níveis plasmáticos deste fármaco. 


\section{MATERIAL E MÉTODOS}

\subsection{Animais}

Foram utilizados 12 (doze) fêmeas da espécie canina, sem raça definida, com idade situada entre 2 (dois) e 5 (cinco) anos e peso superior a 15 (quinze) kg; domiciliados, cujos proprietários solicitaram o procedimento cirúrgico e autorizaram a realização dos procedimentos estabelecidos no presente estudo, posto que sem qualquer ônus adicional o monitoramento realizado somente se traduziria em beneficio ao bem estar dos animais.

\subsection{Critério de inclusão}

Todos os animais foram avaliados fisicamente e submetidos a uma tomada de amostras de sangue para efeito de exames complementares que incluíram: hematócrito (HTO), proteína total (PT), perfil hepático (alanina amino transferase - ALT, fosfatase alcalina - FA) e perfil renal (uréia - U e creatinina $\mathrm{C})$, os valores obtidos encontraram-se dentro daqueles considerados normais para a espécie (JAIN, 1993; KANECO et al, 1997).

\begin{tabular}{c|c|c|c|c|c|c}
\hline ANIMAL & HTO & PT & ALT & FA & U & C \\
\hline 1 & 37 & 5,5 & 30 & 58 & 50 & 1,2 \\
2 & 40 & 5,7 & 26 & 74 & 20 & 1,2 \\
3 & 38 & 7,2 & 19 & 74 & 19 & 0,9 \\
4 & 40 & 5,2 & 31 & 75 & 35 & 0,9 \\
5 & 39 & 7,0 & 20 & 75 & 34 & 1,6 \\
6 & 37 & 6,9 & 15 & 33 & 25 & 1,6 \\
7 & 38 & 6,2 & 19 & 30 & 25 & 1,5 \\
8 & 37 & 5,8 & 20 & 70 & 30 & 1,2 \\
9 & 40 & 5,6 & 26 & 41 & 34 & 1,5 \\
10 & 37 & 6,2 & 31 & 41 & 20 & 1,3 \\
11 & 37 & 6,2 & 19 & 41 & 20 & 1,2 \\
12 & 39 & 6,8 & 17 & 50 & 22 & 1,5 \\
\hline
\end{tabular}

Quadro 1 - Valores individuais relativos aos exames complementares que incluíram: hematócrito (HTO: 37-55 \%), proteína total (PT: 5,4-7,5 $\mathrm{g} / \mathrm{dl}$ ), perfil hepático (alanina amino transferase - ALT: 7-92 U.I/L, fosfatase alcalina - FA: 15-80 U.I/L) e perfil renal (uréia- U: 10-56 $\mathrm{mg} / \mathrm{dl}$ e creatinina- C: 0,5-1,6 U.I/L) 


\subsection{Procedimento preliminar}

Para assegurar-se uma adequada avaliação, os animais foram internados no dia anterior e submetidos a um jejum prévio de sólidos de 8 (oito) horas e de líquidos de 4 (quatro) horas.

\subsection{Protocolo anestésico}

A técnica anestésica empregada em todos os animais deste experimento foi constituída da administração de acepromazina (Acepran ${ }^{\circledR}$ - Univet S.A) na dose de 0,1 mg/kg, pela via intramuscular, como medicação pré-anestésica. Passados 10 (dez) minutos, a veia cefálica foi apropriadamente cateterizada consoante o tamanho do animal, e concluído o acesso venoso, deu-se início à indução anestésica com propofol (Provine $1 \%{ }^{\circledR}$ - Claris Lifesciences Limited) na dose de $5 \mathrm{mg} / \mathrm{kg}$ administrado em um período de 2 minutos, e procedeu-se a intubação orotraqueal com sonda traqueal de calibre apropriado.

A manutenção da anestesia realizou-se em circuito circular semifechado, em aparelho de anestesia (HB Hospitalar - Conquest $2003^{\circledR}$ - Indústria e Comércio Ltda.) com isoflurano (Isoforine ${ }^{\circledR}$ - Cristália - Produtos Químicos Farmacêuticos Ltda.) em 100\% de oxigênio. Os animais foram mantidos em nível anestésico de $3^{\circ}$ plano através da monitoração dos reflexos protetores, assim como variações dos parâmetros cardio-respiratórios.

Durante todo o procedimento cirúrgico, os animais receberam fluidoterapia com Solução de Ringer com Lactato de Sódio (Ringer Lactato ${ }^{\circledR}$ - Áster Produtos Médicos Ltda.) na taxa de $10 \mathrm{ml} / \mathrm{kg} / \mathrm{hora}$.

\subsection{Procedimento cirúrgico}

O procedimento realizado constituiu-se da ovário-salpingo-histerectomia, realizado através da técnica padrão. 


\subsection{Procedimento experimental}

\subsubsection{Administração dos fármacos analgésicos}

Os animais foram distribuídos aleatoriamente em dois grupos numericamente iguais resgardando-se a homogeneidade relativamente às demais características bioestruturais, e cada um dos 6 animais de um grupo recebeu 1 $\mathrm{mg} / \mathrm{kg}$ de tramadol (Dorless ${ }^{\circledR}$ - União Química Farmacêutica Nacional S/A) pela via intravenosa, imediatamente após à sutura da pele, enquanto o outro grupo recebeu $4 \mathrm{mg} / \mathrm{kg}$ de tramadol também intravenoso, no momento correspondente. A partir de 30 minutos após a administração do tramadol, caso os parâmetros para avaliação de analgesia indicassem a necessidade de medicação analgésica resgate, o cetoprofeno (Ketofen ${ }^{\circledR}$ - Merial Saúde Animal Ltda.) na dose de $2 \mathrm{mg} / \mathrm{kg}$ foi administrado pela via intravenosa, e quando necessário utilizou-se adicionalmente dipirona (D $500^{\circledR}$ - Fort Dodge) pela mesma via, na dose de $25 \mathrm{mg} / \mathrm{kg}$ e em alguns casos morfina Dimorf ${ }^{\circledR}$ - Cristália - Produtos Químicos Farmacêuticos Ltda.) na dose de $0,1 \mathrm{mg} / \mathrm{kg}$, pela mesma via.

Os animais foram identificados de A1 a A12 e distribuídos aleatoriamente nos grupos experimentais de sorte que durante os procedimentos operacionais o médico veterinário desconhecia o tratamento realizado no animal.

\subsubsection{Parâmetros analisados}

Avaliou-se o tempo de extubação, isto é, o período compreendido entre o término do fornecimento do anestésico volátil e a retirada da sonda endotraqueal. A freqüência cardíaca $(F C)$, freqüência respiratória $(F R)$, pressão arterial sistólica (PAS), média (PAM) e diastólica (PAD), escore de dor (Escala visual analógica, e Método de escalas descritivas) e a temperatura $\left({ }^{\circ} \mathrm{C}\right)$ foram avaliados em oportunidades de intervalos regulares de 30 minutos após administração do tramadol pela via intravenosa. 


\subsubsection{Coleta das amostras}

A cateterização da veia jugular com a adaptação da torneira de 3 vias foi elaborada para maior facilidade da coleta sanguínea, a qual foi feita utilizandose seringa heparinizada com capacidade para $10 \mathrm{ml}$.

A primeira coleta de sangue ocorreu imediatamente antes da adoção do tratamento com tramadol. Subseqüentes coletas foram tomadas nos seguintes momentos: 10, 20, 30, 45, 60, 90, 120, 180, 240, 360, 420 e 480 minutos após a administração do tramadol.

Cada amostra foi submetida, de imediato, à centrifugação (Modelo Baby 18 tubos, Fanem São Paulo, Brasil) (2500 rotações por minuto) durante $10 \mathrm{mi}$ nutos para obtenção das amostras de plasma, que foram congeladas a $-20^{\circ} \mathrm{C}$ para posterior processamento.

\subsubsection{Mensuração dos parâmetros cardiovasculares e respiratórios}

Para mensuração das freqüências cardíaca $(F C)$ e respiratória (FR) foi utilizado o estetoscópio, tanto no exame físico, antes da realização do protocolo anestésico, como em seu período de observação pós-operatório que perdurou 8 horas. Durante o procedimento cirúrgico a freqüência cardíaca, bem como o traçado eletrocardiográfico foram monitorizados através do monitor cardíaco (Dixtal Biomédica - DX $2010^{\circledR}$ - Indústria e Comércio.).

A mensuração da pressão arterial (sistólica, média e diastólica) foi feita através do método não invasivo neste mesmo período pós-operatório (Dixtal Biomédica - DX $2010^{\circledR}$ - Indústria e Comércio.).

\subsubsection{Dosagem plasmática do tramadol}

Os níveis plasmáticos de tramadol foram analisados por meio de cromatografia líquida de alta performance (HPLC) com detector UV e o método foi baseado nos princípios descritos por Gan e Ismail (2001) e Nobilis et al. (2002), adaptado para as condições do laboratório de Farmacologia Aplicada e Toxicologia do Departamento de Patologia da Faculdade de Medicina Veterinária e Zootecnia da Universidade de São Paulo. 


\subsubsection{Avaliação Subjetiva da Dor}

Foram utilizadas 2 escalas distintas para avaliar o grau de analgesia proporcionado pelo tramadol:

\subsubsection{Escala Visual Analógica}

A avaliação do grau de analgesia, sempre feita pelo mesmo pesquisador, colocando-se o resultado em uma escala de 0 a $10 \mathrm{~cm}$, onde 0 corresponde a "nenhuma" demonstração de dor e 10 corresponde a mais elevada demonstração de dor, "pior dor possível" (HANSEN, 1997; HOPKINS et al., 1998; LASCELLES et al., 1994; LLOYD-THOMAS, 1990).

\subsubsection{Escala Descritiva}

Nesta escala o grau de desconforto é obtido observando-se sinais de vocalização, inquietação e pela resposta do animal diante de uma pressão exercida sobre a ferida cirúrgica (LASCELLES et al., 1994), consoante os seguintes critérios:

0: analgesia completa, sem sinais de desconforto ou sem resposta à pressão na ferida cirúrgica;

1: boa analgesia, sem sinais de desconforto com reação à pressão exercida na ferida cirúrgica;

2: moderada analgesia com alguns sinais de desconforto os quais se tornam mais evidentes com a pressão exercida na ferida cirúrgica;

3: com sinais óbvios de desconforto piorando com pressão exercida na ferida cirúrgica.

Caso a sensibilidade dolorosa fosse detectada pela escala visual analógica com o escore maior ou igual a 5 e/ou superior ou igual 2 na escala descritiva , a medicação resgate era administrada pela via intravenosa. 


\subsection{Análise estatística}

Para a análise estatística dos resultados foi utilizado o programa computacional GraphPad Instat Software (versão 3,01; 1998), empregando o test t na comparação, entre as médias de dois grupos, para os parâmetros fisiológicos, tempo de extubação, peso, idade e concentração plasmática, o test U na comparação entre as medianas dos escores de dor entre os dois grupos; e o teste de correlação (Spearman) na comparação entre os valores das médias da concentração plasmática e os valores das medianas dos escores de dor. Adotou-se o nível de significância de $5 \%$ para todos os testes realizados. 


\section{RESULTADOS}

Foram utilizadas no presente estudo 12 fêmeas, da espécie canina, sem raça definida, com idade situada entre 2 e 5 anos, divididas, em igualdade numérica, em 2 grupos tratados, no pós-operatório imediato com tramadol, pela via intravenosa, na dose de $1 \mathrm{mg} / \mathrm{kg}$ (grupo I) ou $4 \mathrm{mg} / \mathrm{kg}$ (grupo II), cujos valores individuais e respectivas médias e desvios padrões são apresentados na tabela 1. Assim, não foram observadas diferenças significativas no peso e idades dos animais quando se comparou as médias obtidas entre os dois grupos ( $p>0,05$, teste $t)$.

Tabela 1 - Valores individuais relativos à idade (expressa em meses), médias e desvios padrões (DP), bem como o peso das cadelas (sem raça definida) tratadas com 1 ou $4 \mathrm{mg} / \mathrm{kg}$ de tramadol pela via intravenosa

\begin{tabular}{l|c|c|c}
\hline $\begin{array}{l}\text { TRAMADOL } \\
\mathrm{mg} / \mathrm{kg}\end{array}$ & $\begin{array}{c}\text { ANIMAL } \\
\text { № }\end{array}$ & $\begin{array}{c}\text { PESO } \\
(\mathrm{kg})\end{array}$ & IDADE (Meses) \\
\hline \multirow{4}{*}{1} & 3 & 20,0 & 30,0 \\
& 5 & 26,4 & 30,0 \\
& 7 & 18,1 & 24,0 \\
& 8 & 22,0 & 60,0 \\
& 10 & 23,0 & 24,0 \\
& 12 & 25,0 & 24,0 \\
\cline { 2 - 4 } & Média & 22,4 & 32,0 \\
\cline { 2 - 4 } & DP & 2,8 & 12,8 \\
\hline \multirow{4}{*}{4} & 1 & 13,6 & 36,0 \\
& 2 & 16,2 & 48,0 \\
& 4 & 40,0 & 30,0 \\
& 6 & 14,7 & 36,0 \\
& 9 & 36,5 & 60,0 \\
& 11 & 17,0 & 24,0 \\
\cline { 2 - 4 } & Média & 23,0 & 39,0 \\
\cline { 2 - 4 } & DP & 10,9 & 12 \\
\hline
\end{tabular}

$p>0,05$, teste $t$ (comparação entre as médias dos grupos $\mathrm{I}-1 \mathrm{mg} / \mathrm{kg}$ e $\|-4 \mathrm{mg} / \mathrm{kg}$ ).

O tempo de extubação, período compreendido entre o término do fornecimento de anestésico volátil e a retirada da sonda endotraqueal, foi outra variável avaliada cujos valores relativos aos grupos I (1 mg/kg) e II (4 mg/kg) estão descritos na tabela 2. Assim, nota-se aumento do tempo de extubação nos a- 
nimais do grupo tratado com $4 \mathrm{mg} / \mathrm{kg}$ de tramadol (grupo I), quando comparado com aqueles que receberam $1 \mathrm{mg} / \mathrm{kg}$ deste mesmo fármaco $(p<0,05$, teste $t)$.

Tabela 2 - Valores relativos ao tempo de extubação (expressa em minutos) após o termino da anestesia volátil, médias e desvios padrões de cadelas (sem raça definida) tratadas, com 1 ou $4 \mathrm{mg} / \mathrm{kg}$ de tramadol (grupo I e II respectivamente) pela via intravenosa

\begin{tabular}{c|c|c}
\hline $\begin{array}{c}\text { TRAMADOL } \\
\text { mg/kg }\end{array}$ & ANIMAL №. & Tempo (minutos) \\
\hline \multirow{5}{*}{1} & 3 & 8 \\
& 5 & 10 \\
& 8 & 10 \\
& 10 & 4 \\
& 12 & 10 \\
& & 10 \\
\cline { 2 - 3 } & Média & 8,7 \\
\cline { 2 - 3 } & DP & 2,2 \\
\hline \multirow{5}{*}{4} & 1 & 10 \\
& 2 & 15 \\
& 6 & 20 \\
& 9 & 20 \\
& 11 & 20 \\
& & 13 \\
\cline { 2 - 3 } & Média & $16,3^{*}$ \\
\cline { 2 - 3 } & DP & 3,9 \\
\hline
\end{tabular}

${ }^{*} p<0,05$, teste t.

As tabelas 3 à 7 e as figuras 1 à 5 mostram os valores individuais, médios e respectivos desvios padrões das freqüências cardíaca e respiratória, as pressões arteriais sistólica, diastólica e média de cadelas tratadas com $1 \mathrm{mg} / \mathrm{kg}$ ou $4 \mathrm{mg} / \mathrm{kg}$ de tramadol (grupo I e II respectivamente). As análises estatísticas realizadas mostraram diferenças entre os grupos apenas nas pressões arteriais 
sistólica e média, aos 30 minutos, onde notou-se aumento destes parâmetro no grupo $4 \mathrm{mg} / \mathrm{kg}$ (grupo II) quando comparado com o grupo $1 \mathrm{mg} / \mathrm{kg}$ (grupo I), $p<0,05$, teste $t-$ Tabela 5 e 7 , Figura 3 e 5 ). 


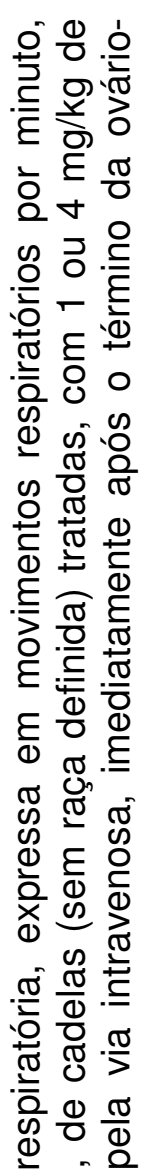

숭

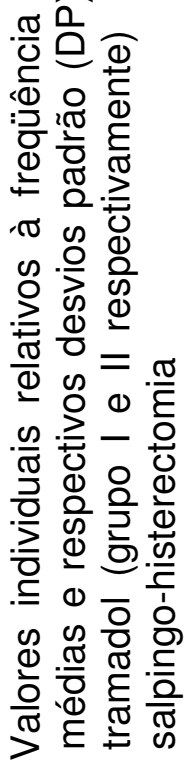

I

$m$

$\frac{\pi}{\frac{\pi}{0}}$

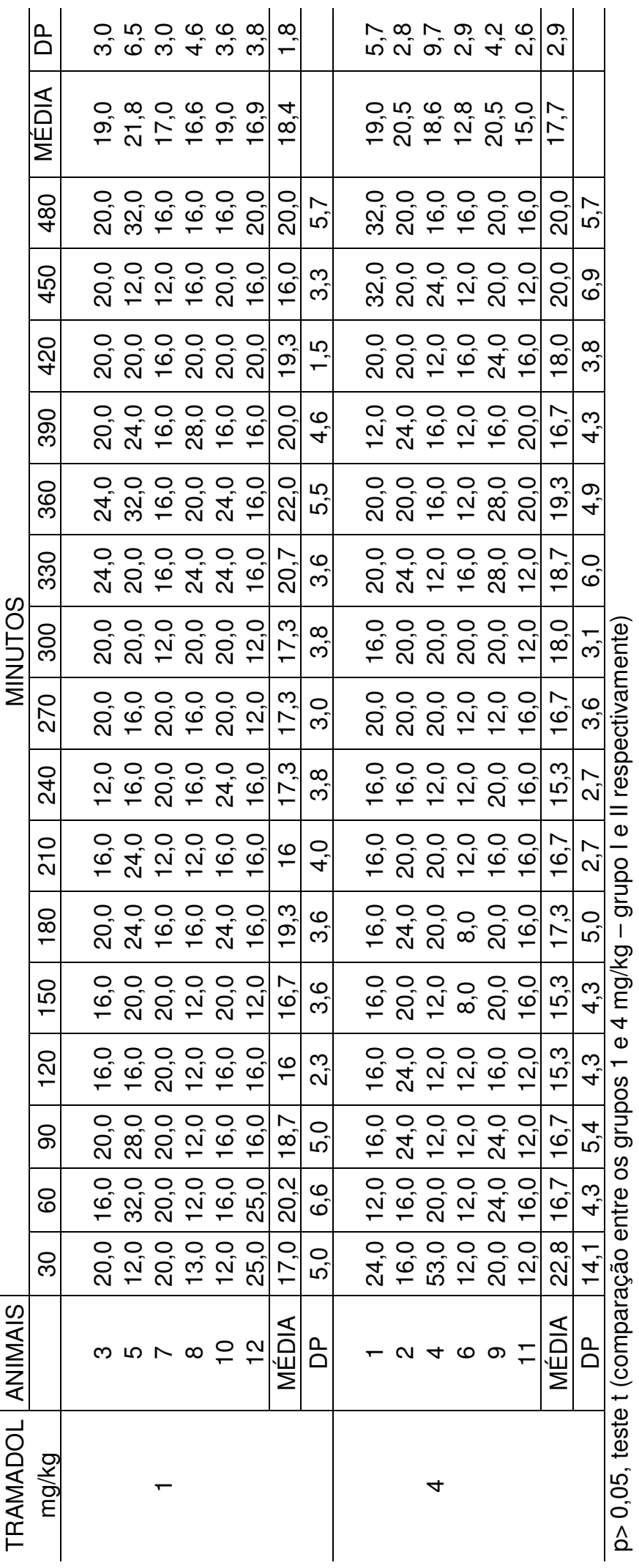




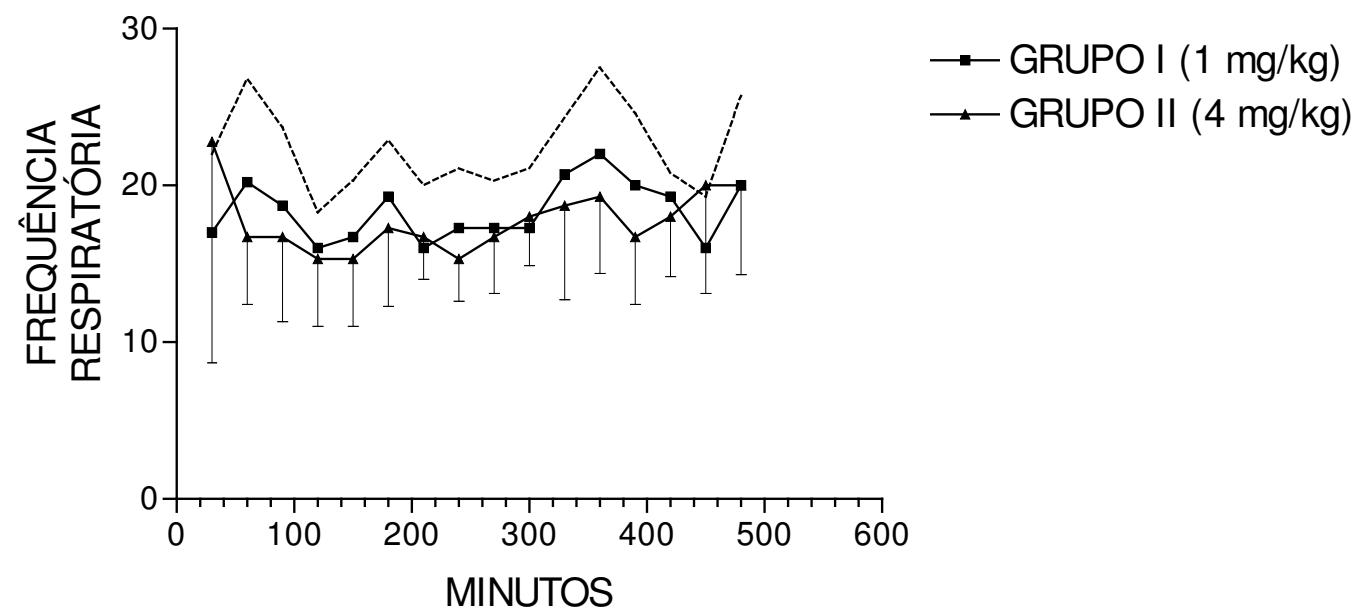

Figura 1 - Valores médios relativos à freqüência respiratória, (expressa em movimentos respiratórios por minuto) de cadelas (sem raça definida) tratadas, com 1 ou $4 \mathrm{mg} / \mathrm{kg}$ de tramadol (grupo I e II respectivamente) pela via intravenosa, imediatamente após o término da ovário-salpingo-histerectomia; $p>0,05$, teste $t$ 


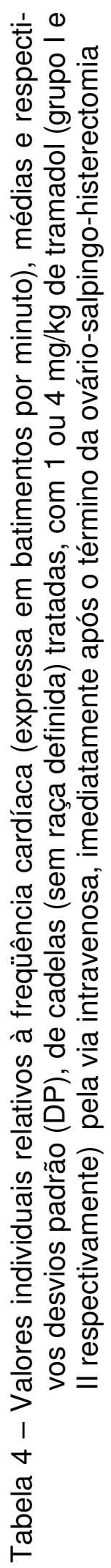

\begin{tabular}{|c|c|c|c|c|c|c|}
\hline 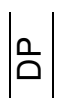 & 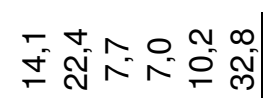 & & & 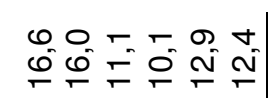 & & \\
\hline $\mid \begin{array}{c}\Delta \\
\text { 岗 } \\
\Sigma\end{array}$ & 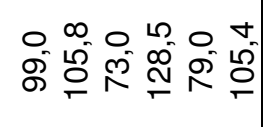 & & & 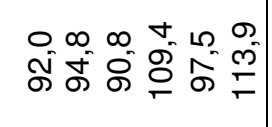 & & \\
\hline $\begin{array}{l}\stackrel{\infty}{+} \\
\end{array}$ & 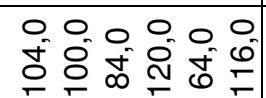 & $\begin{array}{l}0 \\
\infty \\
\infty\end{array}$ & $\sigma^{\circ}$ & 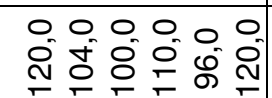 & \begin{tabular}{l|l|} 
\\
0 \\
0 \\
0 \\
\end{tabular} & $\begin{array}{l}m \\
\sigma\end{array}$ \\
\hline 号 & 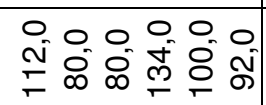 & $\hat{8}$ & $\stackrel{\circ}{-}$ & 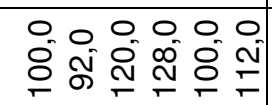 & \begin{tabular}{|l|l|}
0 \\
oे \\
ㅇ.
\end{tabular} & 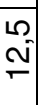 \\
\hline 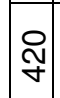 & 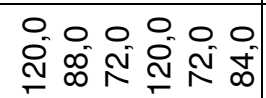 & مิ & 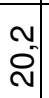 & 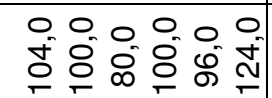 & $\begin{array}{l}0 \\
0 \\
0 \\
\end{array}$ & $\begin{array}{l}\text { a } \\
\stackrel{N}{-}\end{array}$ \\
\hline ஓ్ల & 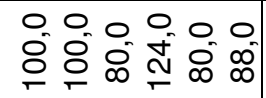 & $\mid \begin{array}{l}m \\
\qquad \\
\mathscr{\sigma}\end{array}$ & $\begin{array}{c}\stackrel{v}{\omega} \\
\stackrel{5}{\sigma}\end{array}$ & 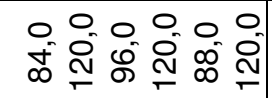 & \begin{tabular}{|c|c|}
0 \\
0 \\
0 \\
0
\end{tabular} & 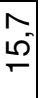 \\
\hline $\begin{array}{l}\text { ठ্ল } \\
\end{array}$ & 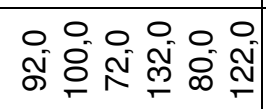 & s. & $\stackrel{+}{\sim}$ & 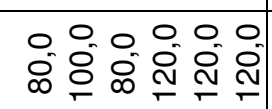 & 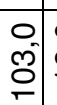 & $\begin{array}{l}0 \\
\infty \\
\infty \\
-\end{array}$ \\
\hline ్্লి & 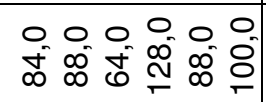 & م્ & $\begin{array}{l}m \\
\sigma^{\circ}\end{array}$ & 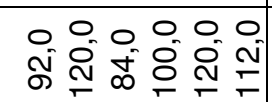 & \begin{tabular}{l|l}
0 \\
0 \\
0 \\
0
\end{tabular} & $\hat{s}$ \\
\hline ৪্ & 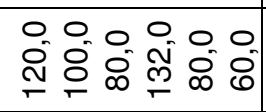 & \begin{tabular}{|c|}
$m$ \\
2 \\
$\sigma$
\end{tabular} & $\begin{array}{l}\infty \\
\stackrel{N}{+}\end{array}$ & 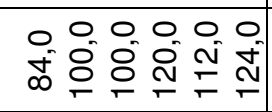 & 엄 & 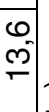 \\
\hline 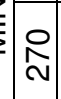 & 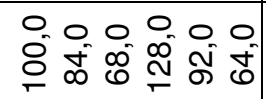 & $\mid \begin{array}{l}\infty \\
\infty \\
\infty\end{array}$ & $\frac{\dot{\sigma}}{\mathrm{N}}$ & 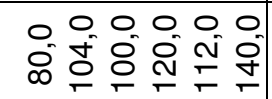 & 영 & $\begin{array}{l}\overbrace{0} \\
\infty \\
\infty^{\prime}\end{array}$ \\
\hline 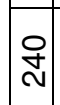 & 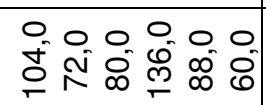 & : & $\begin{array}{c}0 \\
\stackrel{\sim}{N}\end{array}$ & 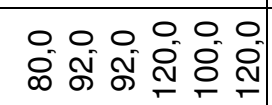 & $\begin{array}{l}0 \\
\\
0 \\
0\end{array}$ & $\begin{array}{l}0 \\
+ \\
+\end{array}$ \\
\hline$\stackrel{0}{\frac{0}{N}}$ & 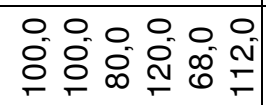 & ' & 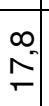 & 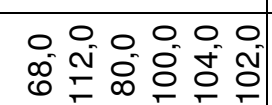 & $\begin{array}{l}m \\
\dot{m} \\
\dot{\sigma}\end{array}$ & $\begin{array}{l}\mathfrak{N} \\
10 \\
\end{array}$ \\
\hline $\begin{array}{l}\stackrel{\infty}{-} \\
-\end{array}$ & 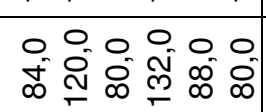 & $\mid \begin{array}{l}m \\
\text { à }\end{array}$ & $\hat{\mathrm{N}}$ & 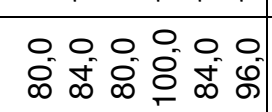 & 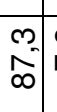 & $\infty$ \\
\hline 号 & 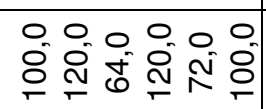 & $\mid$ & $\stackrel{n}{\mathrm{~N}}$ & 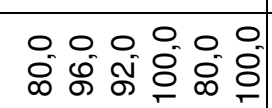 & $\begin{array}{l}m \\
\bar{\sigma}\end{array}$ & $\begin{array}{l}+ \\
\infty\end{array}$ \\
\hline 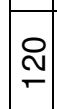 & 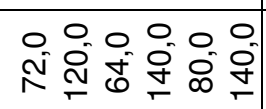 & \begin{tabular}{|c|}
0 \\
0 \\
0 \\
\end{tabular} & $\hat{\bar{m}}$ & 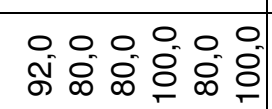 & $\begin{array}{l}\widehat{N} \\
\infty \\
\infty\end{array}$ & $\bar{\sigma}$ \\
\hline ৪ & 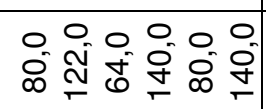 & $\begin{array}{l}0 \\
0 \\
0\end{array}$ & $\begin{array}{l}\hat{0} \\
\bar{m}\end{array}$ & 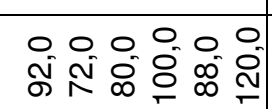 & مे & $\begin{array}{l}9 \\
\stackrel{9}{10}\end{array}$ \\
\hline 8 & 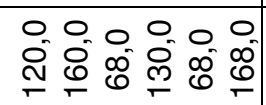 & $\begin{array}{l}0 \\
0 \\
\frac{1}{7}\end{array}$ & ô & 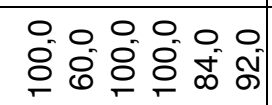 & $\begin{array}{l}m \\
\infty \\
\infty\end{array}$ & $\begin{array}{l}\nabla_{0} \\
\dot{\tau}\end{array}$ \\
\hline ৪) & 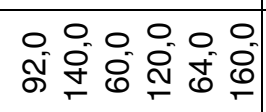 & \begin{tabular}{|l|}
0 \\
0 \\
0 \\
\end{tabular} & 心 & 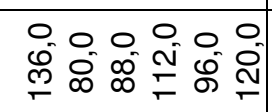 & $\begin{array}{l}0 \\
\text { 오 } \\
\text { 음 }\end{array}$ & m. \\
\hline & $m\llcorner\wedge \infty \stackrel{ }{\sim}$ & 这 & 号 & $-N+\theta \sigma=$ & $\begin{array}{l}\overleftarrow{\Delta} \\
\stackrel{\mathrm{w}}{\Sigma}\end{array}$ & 0 \\
\hline & & & & $\checkmark$ & & \\
\hline
\end{tabular}




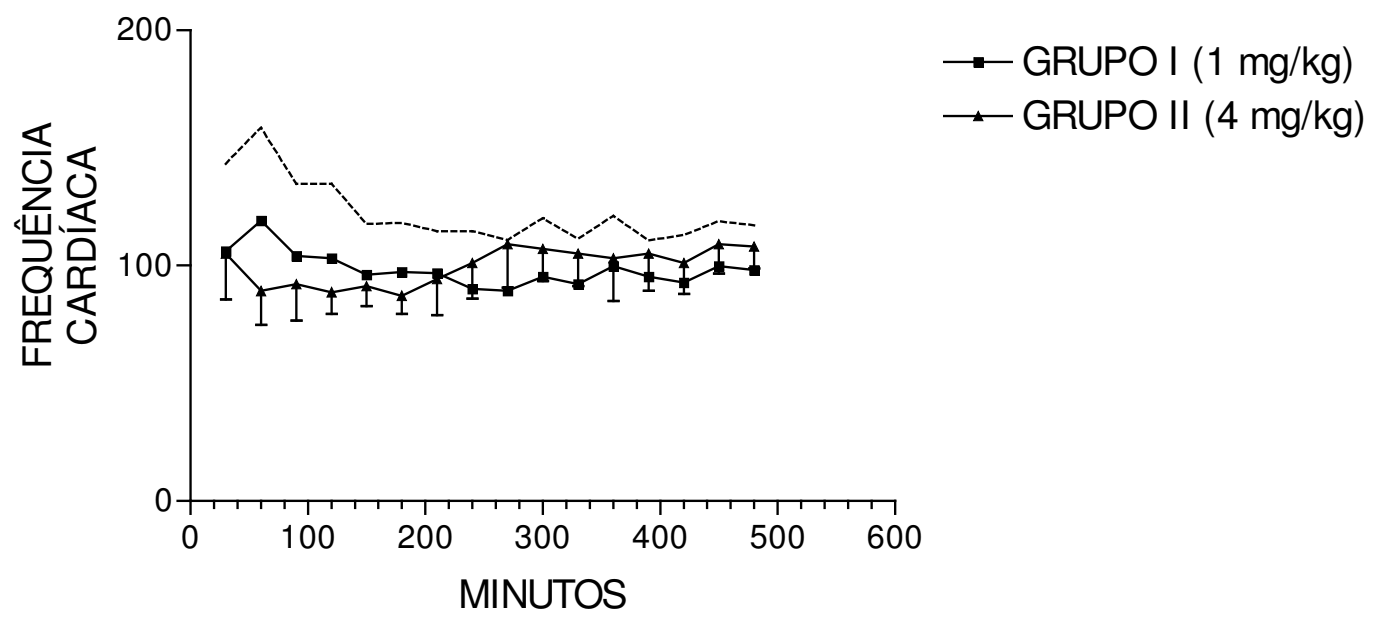

Figura 2 - Valores médios relativos à freqüência cardíaca, expressa em batimentos por minuto, de cadelas (sem raça definida) tratadas, com 1 ou $4 \mathrm{mg} / \mathrm{kg}$ de tramadol (grupo I e II respectivamente) pela via intravenosa, imediatamente após o término da ovário-salpingo-histerectomia; $p>0,05$, teste $t$ 


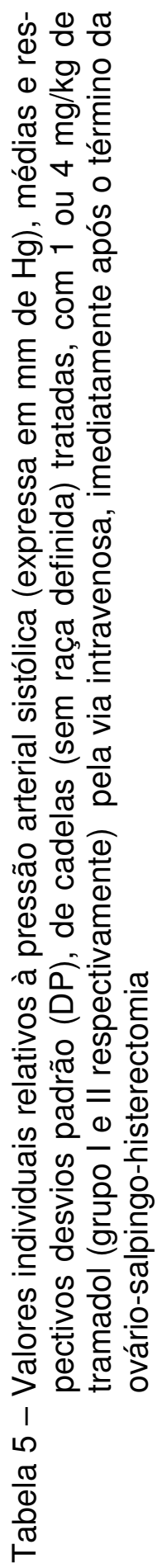

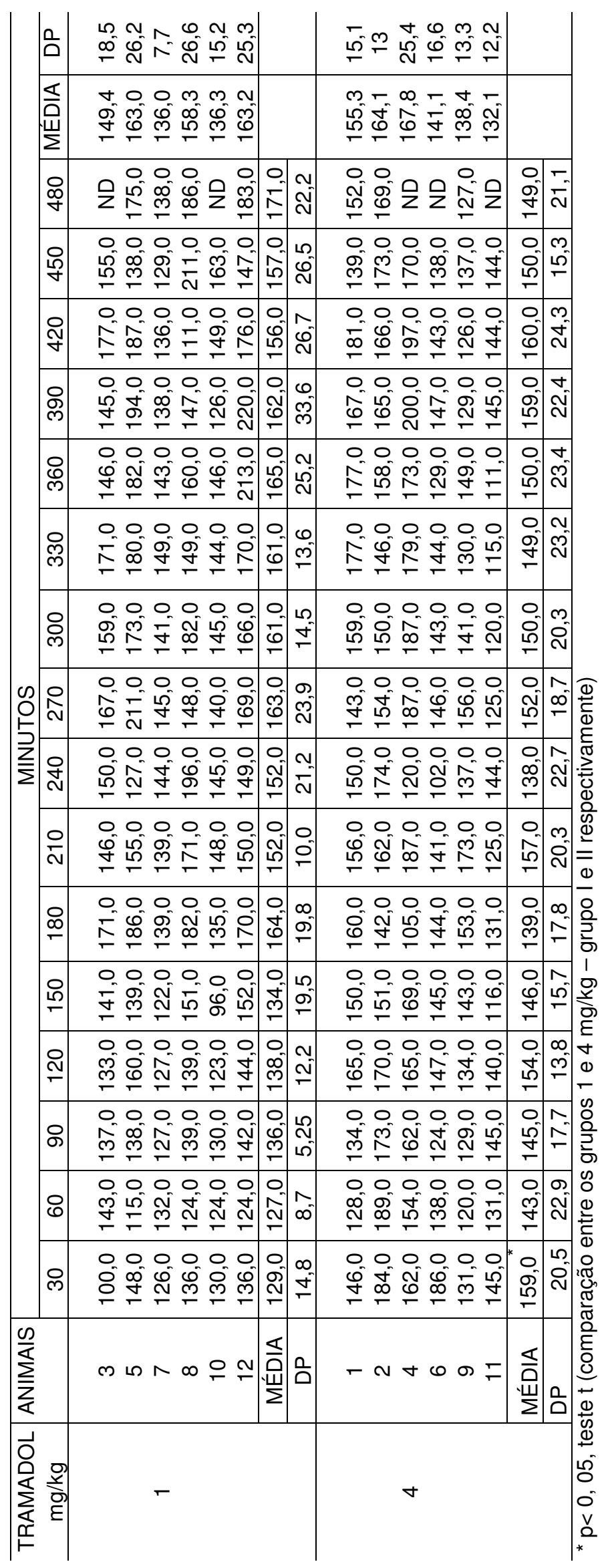




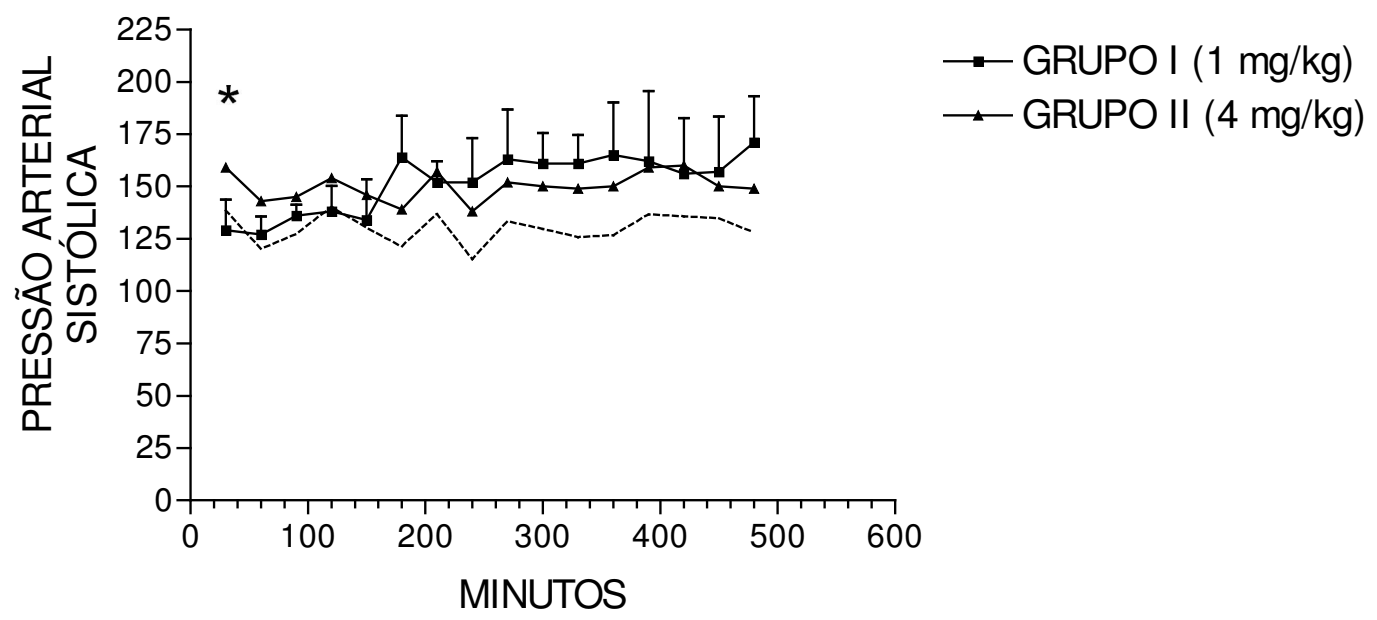

Figura 3 - Valores médios relativos à pressão arterial sistólica (PAS em $\mathrm{mm}$ de $\mathrm{Hg}$ ), de cadelas (sem raça definida) tratadas, com 1 ou $4 \mathrm{mg} / \mathrm{kg}$ de tramadol (grupo I e II respectivamente) pela via intravenosa, imediatamente após o término da ováriosalpingo-histerectomia; * $p<0,05$, teste $t$ 


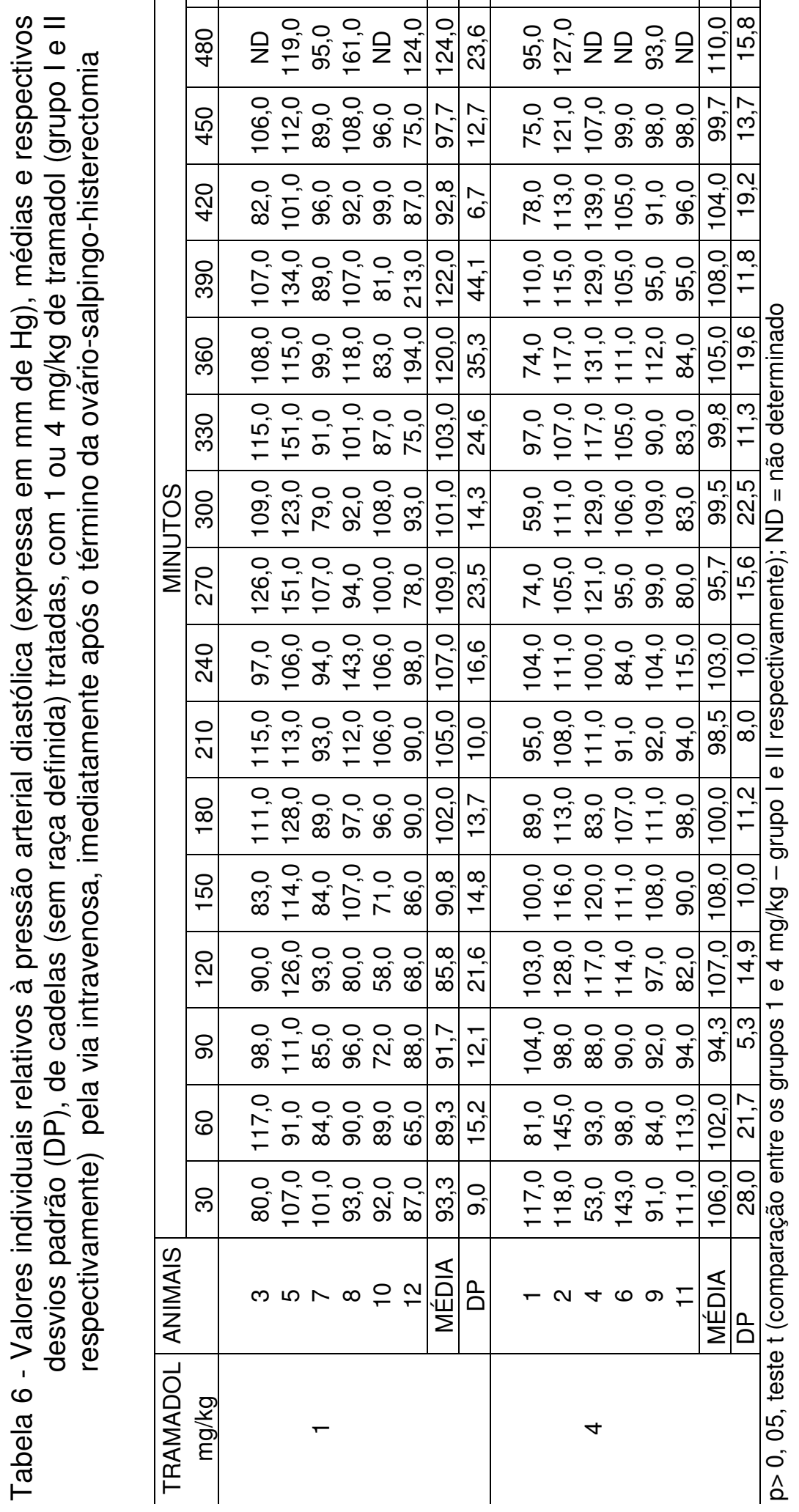




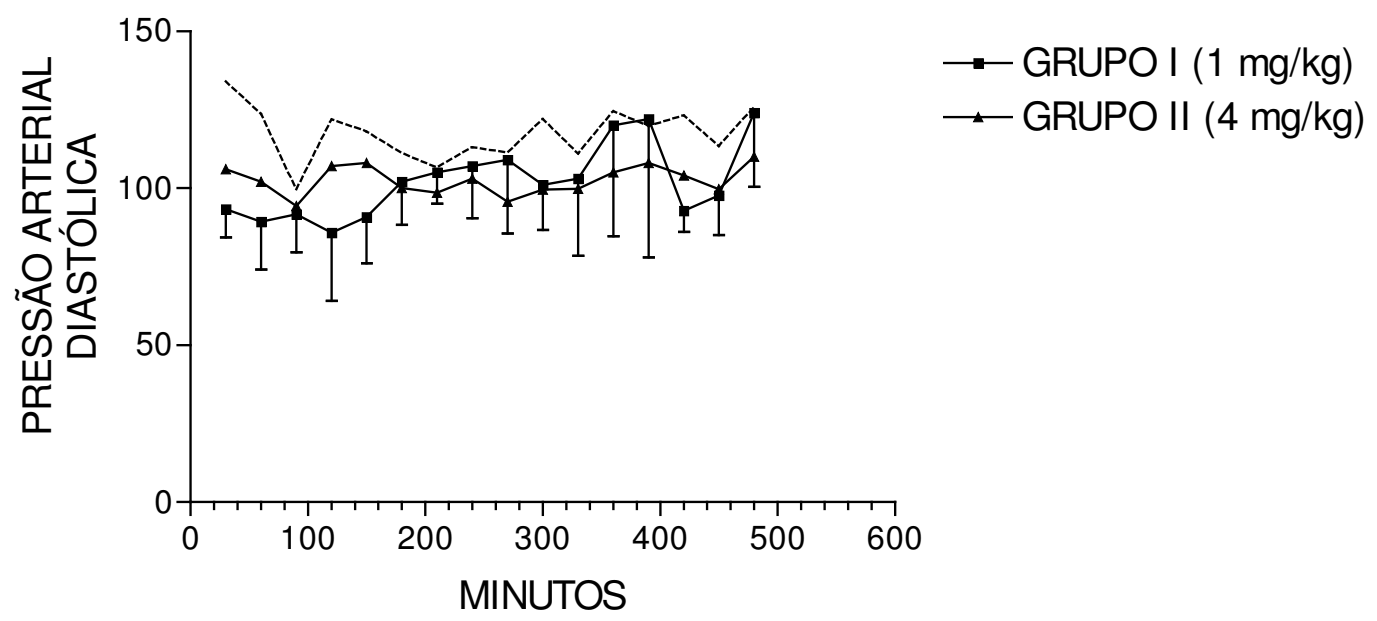

Figura 4 - Valores médios relativos à pressão arterial diastólica (PAD em $\mathrm{mm}$ de $\mathrm{Hg}$ ), de cadelas (sem raça definida) tratadas, com 1 ou $4 \mathrm{mg} / \mathrm{kg}$ de tramadol (grupo I e II respectivamente) pela via intravenosa, imediatamente após o término da ováriosalpingo-histerectomia; $p>0,05$, teste $t$ 


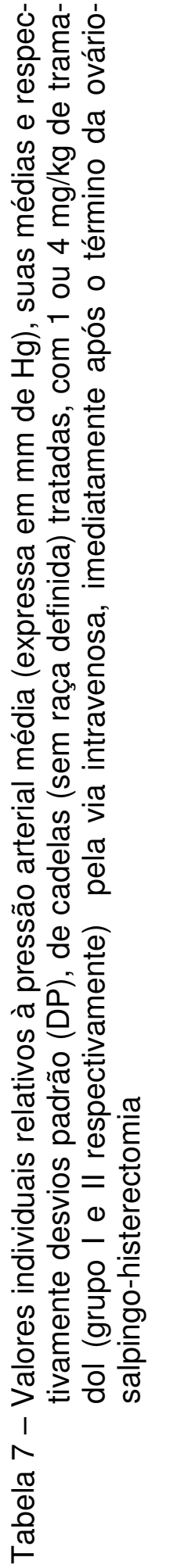

\begin{tabular}{|c|c|c|c|c|c|}
\hline 各 & 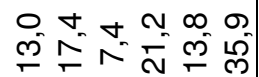 & $\left|\begin{array}{c}\infty \\
\stackrel{2}{a} \\
\sigma\end{array}\right|$ & 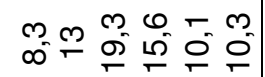 & $\stackrel{N}{\sigma}$ & \\
\hline $\mid \frac{\overleftarrow{s}}{\dot{\omega}}$ & 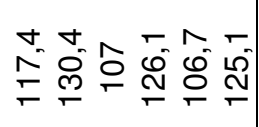 & $\mid \begin{array}{l}\infty \\
\infty \\
\mp \\
\leftarrow\end{array}$ & 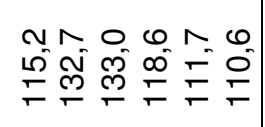 & $\begin{array}{l}m \\
\stackrel{0}{N} \\
\end{array}$ & \\
\hline 官 & 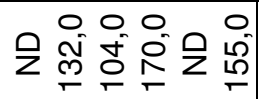 & \begin{tabular}{l|l}
0 \\
0 \\
$\dot{q}$ & 0 \\
& \multicolumn{1}{c}{}
\end{tabular} & $\begin{array}{l}0 \\
\overline{\mathrm{N}} \\
\stackrel{m}{+}\end{array}$ & ิㅗㅁ & $\frac{N}{N}$ \\
\hline ㅇำ & 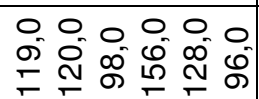 & 임 & 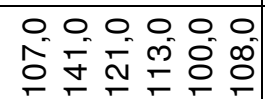 & $\begin{array}{l}0 \\
\stackrel{0}{\circ} \\
\frac{10}{\mp}\end{array}$ & $\begin{array}{l}m \\
m \\
-\infty\end{array}$ \\
\hline ঙे & 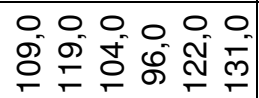 & $\begin{array}{l}0 \\
\dot{7} \\
\frac{1}{\tau}\end{array}$ & 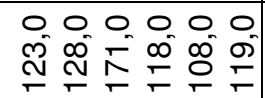 & 엄 & 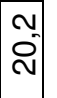 \\
\hline প্লি & 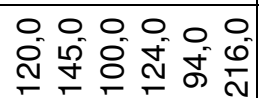 & 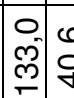 & 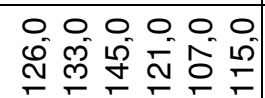 & $\begin{array}{l}0 \\
\stackrel{\circ}{\leftarrow} \\
\stackrel{\omega}{ }\end{array}$ & 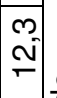 \\
\hline 过 & 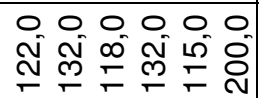 & 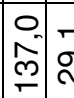 & 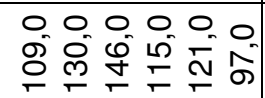 & 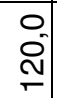 & 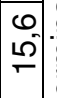 \\
\hline ల্লি & 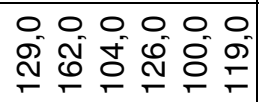 & 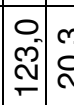 & 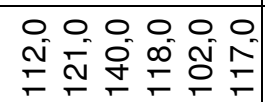 & $\begin{array}{l}0 \\
\infty \\
\infty \\
\mp\end{array}$ & $\vec{\nabla}_{-}$ \\
\hline & 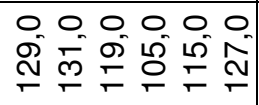 & $\stackrel{0}{\stackrel{0}{\sim}} \bar{\sigma}$ & 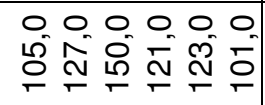 & $\begin{array}{l}\text { O্- } \\
\stackrel{-}{N}\end{array}$ & \begin{tabular}{|c|} 
\\
0 \\
0 \\
\end{tabular} \\
\hline 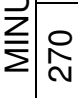 & 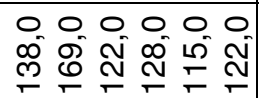 & \begin{tabular}{l|l}
0 & $\infty$ \\
$\hat{i}$ & $\infty$ \\
& 1
\end{tabular} & 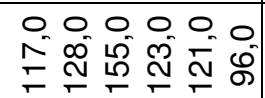 & ్ㅗ- & $\begin{array}{l}n \\
n \\
n\end{array}$ \\
\hline 宲 & 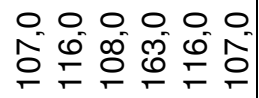 & 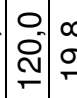 & 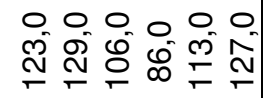 & $\begin{array}{l}0 \\
+ \\
+\end{array}$ & $\begin{array}{l}a \\
+ \\
-\end{array}$ \\
\hline$\frac{0}{N}$ & 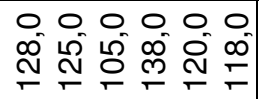 & 웜 & 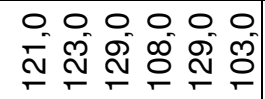 & $\begin{array}{l}0 \\
\stackrel{0}{\circ} \\
\end{array}$ & 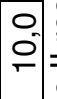 \\
\hline$\stackrel{\infty}{\infty}$ & 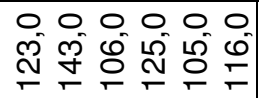 & \begin{tabular}{l|l}
0 \\
0 \\
0 & 0 \\
& 0
\end{tabular} & 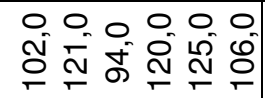 & $\begin{array}{l}0 \\
\overline{-} \\
\mp\end{array}$ & $m$ \\
\hline 遂 & 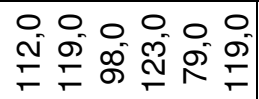 & 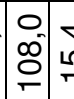 & 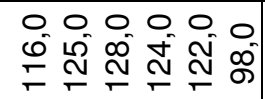 & $\begin{array}{l}0 \\
\stackrel{0}{\circ} \\
\end{array}$ & : \\
\hline$\stackrel{\text { I }}{\sim}$ & 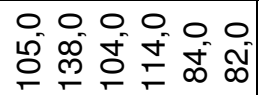 & \begin{tabular}{l|l}
0 & 0 \\
0 & 0 \\
0 & 0 \\
0 & 0
\end{tabular} & 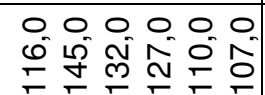 & 을 & $\begin{array}{c}m \\
m \\
m\end{array}$ \\
\hline ৪ & 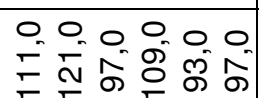 & $\begin{array}{l}0 \\
0 \\
0 \\
0\end{array}$ & 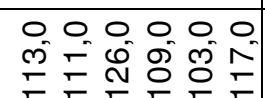 & 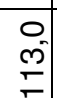 & 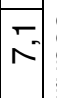 \\
\hline 8 & 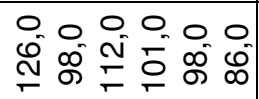 & $\begin{array}{lll}0 & 6 \\
0 & 0 & 0\end{array}$ & 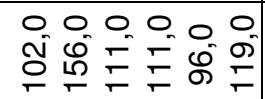 & \begin{tabular}{l}
0 \\
0 \\
\hdashline
\end{tabular} & \begin{tabular}{|l|}
$\dot{\sigma}$ \\
$\sigma$ \\
\end{tabular} \\
\hline স্ল & 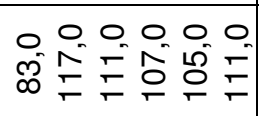 & $\begin{array}{ll}0 & a \\
0 & 0 \\
0 & 0\end{array}$ & 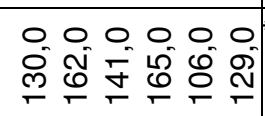 & | & $\begin{array}{l}m \\
\text { N" }\end{array}$ \\
\hline$\sum_{<}^{\frac{N}{\delta}}$ & $m \backsim \wedge \infty \cong$ & 玄 & $-N+0 \Omega F$ & . & $\stackrel{0}{0}$ \\
\hline 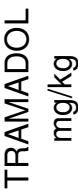 & $\tau$ & & $\forall$ & & \\
\hline
\end{tabular}




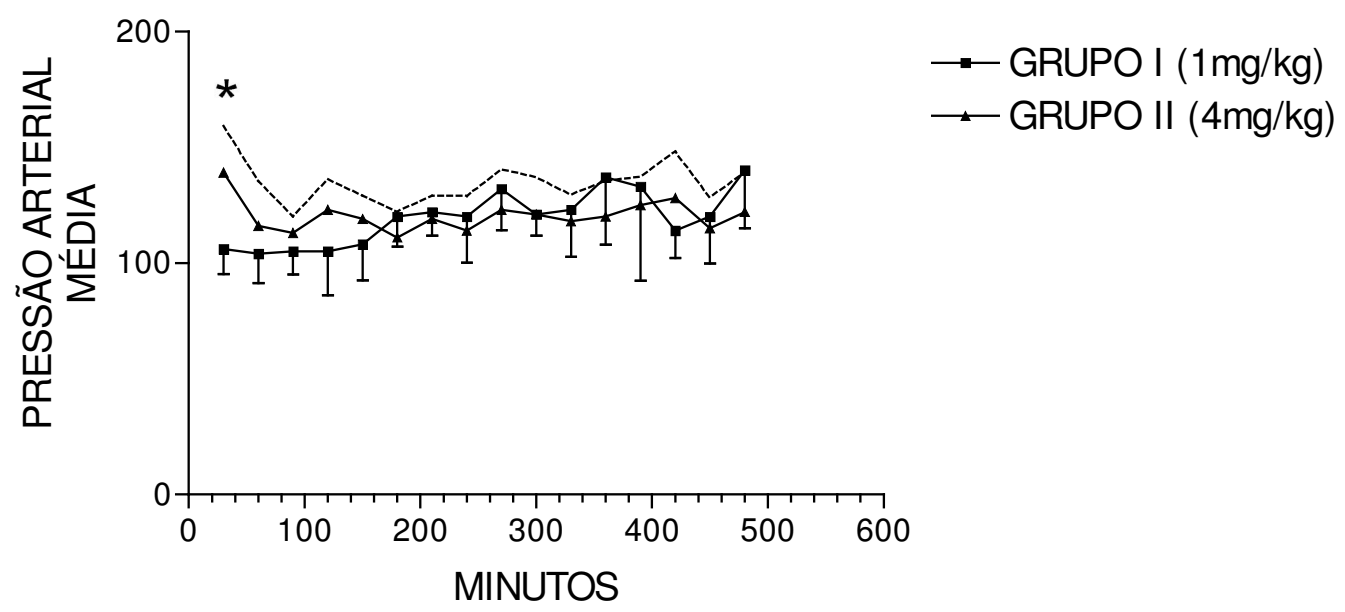

Figura 5 - Valores médios relativos à pressão arterial média (PAMem $\mathrm{mm} \mathrm{Hg}$ ), de cadelas (sem raça definida) tratadas, com 1 ou $4 \mathrm{mg} / \mathrm{kg}$ de tramadol (grupo I e II respectivamente) pela via intravenosa, imediatamente após o término da ovário-salpingo-histerectomia; * $\mathrm{p}<0,05$, teste $t$

A Tabela 8 mostra os valores, individuais, médias e respectivos desvios padrões (Figura 6), bem como os coeficientes de variação, da concentração plasmática de tramadol dos animais tratados com 1 ou $4 \mathrm{mg} / \mathrm{kg}$ de tramadol (grupo I e II respectivamente), pela via intravenosa, no período imediato ao término da ovário-salpingo-histerectomia. Assim, nota-se níveis plasmáticos de tramadol aos 10, 20, 30, 45, 90, 240 e 480 minutos, superiores em cadelas que receberam $4 \mathrm{mg} / \mathrm{kg}$ de tramadol (grupo II) , quando comparado com animais que receberam $1 \mathrm{mg} / \mathrm{kg}$ deste fármaco $(\mathrm{p}<0,05$ teste $\mathrm{t})$. 

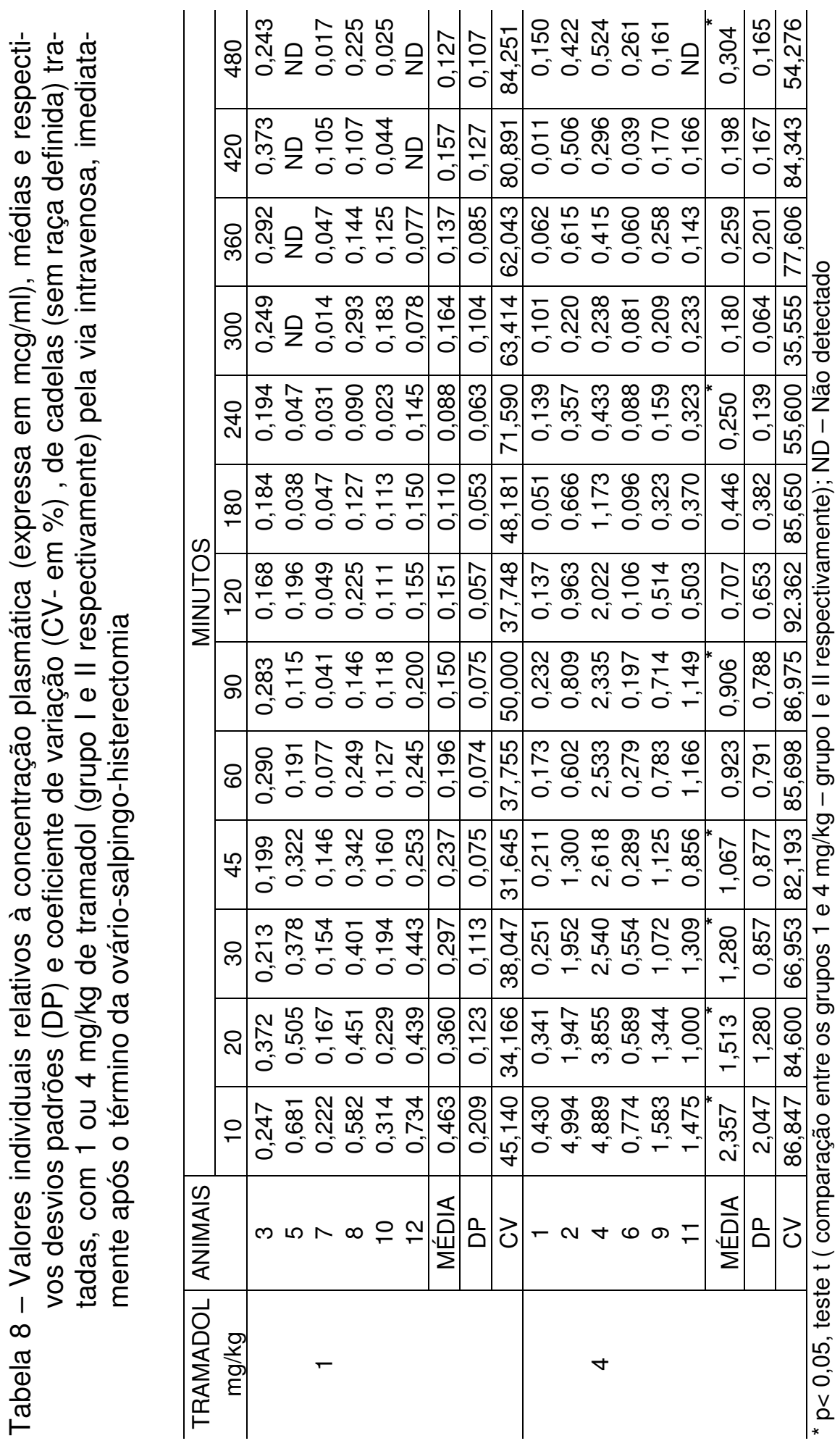


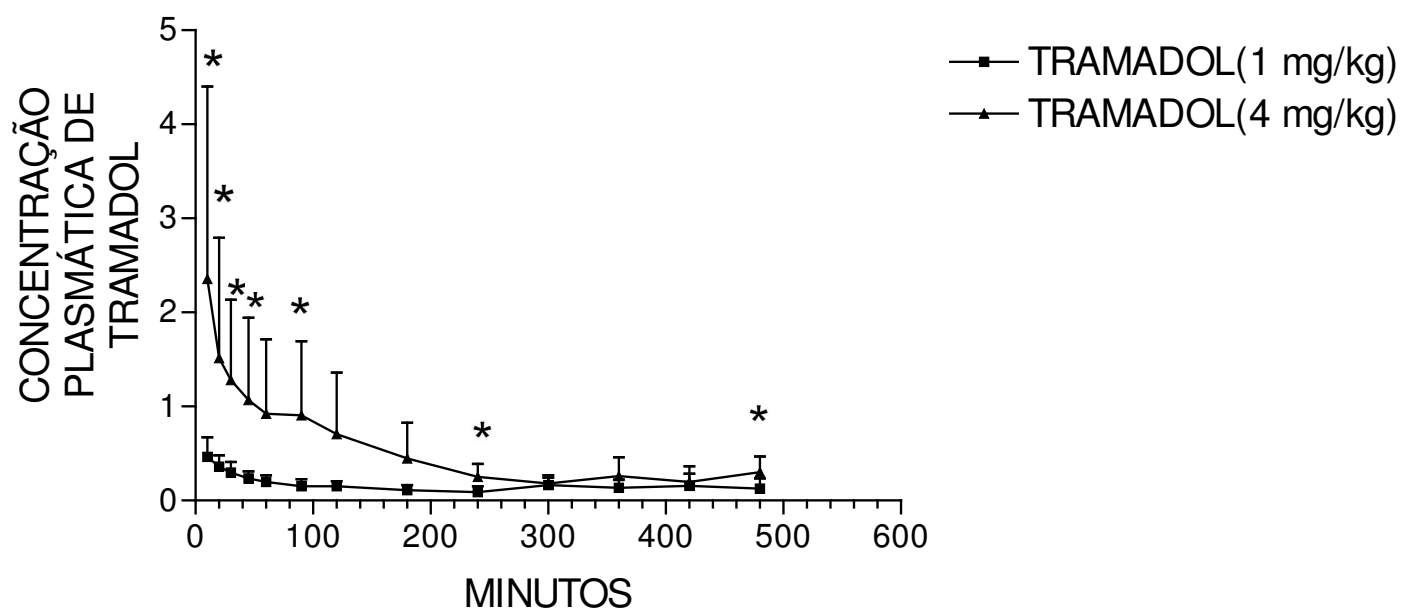

Figura 6 - Valores médios relativos à concentração plasmática (expressa em $\mathrm{mcg} / \mathrm{ml}$ ) e desvios padrões (DP), de cadelas (sem raça definida) tratadas, com 1 ou $4 \mathrm{mg} / \mathrm{kg}$ de tramadol (grupo I e II respectivamente) pela via intravenosa, imediatamente após o término da ovário-salpingo-histerectomia; ${ }^{*} p<0,05$, teste $t$ 
As tabelas 9 e 10 reúnem os escores de sensibilidade à dor obtidos respectivamente pelas escala descritiva e escalas visual analógica em cadelas tratadas com 1 ou $4 \mathrm{mg} / \mathrm{kg}$ de tramadol, pela via intravenosa, imediatamente após o término da ovário-salpingo-histerectomia. Estas tabelas também mostram os momentos dos resgates e as respectivas medicações administradas quando necessário. Dentre os animais que receberam $1 \mathrm{mg} / \mathrm{kg}$ de tramadol (grupo l) apenas uma cadela ( $\mathrm{n}^{0} 7$ - Figura 9 ) não necessitou de medicação resgate (17\% dos animais), enquanto no grupo tratado com $4 \mathrm{mg} / \mathrm{kg}$ de tramadol (grupo II), 3 cadelas ( $n^{\circ} 2$, 4 e $6-50 \%$ dos animais; figuras 14,15 e 16) não necessitaram de medicação resgate. Aos 150 minutos após a administração de $1 \mathrm{mg} / \mathrm{kg}$ de tramadol e aos 240 minutos após a administração de $4 \mathrm{mg} / \mathrm{kg}$ deste fármaco $83 \%$ dos animais não apresentaram escore indicativo de dor (Tabela 9 e 10). Apenas a cadela $\mathrm{n}^{\circ} 3$ do grupo tratado com $1 \mathrm{mg} / \mathrm{kg}$ de tramadol (grupo I) mostrou escore indicativo de dor somente em uma escala (escore 2 na escala descritiva, aos $180 \mathrm{e}$ 450 minutos - tabela 9), o que fez necessário a administração de medicação resgate, mesmo na ausência de escore indicativo de sensibilidade dolorosa pela escala visual analógica (tabela 10). O teste U mostrou maior escore de algesia do grupo que recebeu $1 \mathrm{mg} / \mathrm{kg}$ de tramadol quando comparado ao grupo $4 \mathrm{mg} / \mathrm{kg}$, apenas aos 120 minutos após a administração deste fármaco, quando empregouse a escala visual analógica (tabela 10).

As figuras 7 à 18 mostram os níveis plasmáticos de tramadol e os escores de sensibilidade dolorosa de cada animal em ambas escalas de avaliação de sensibilidade, e o momento de resgate quando necessário.

Não foi observado correlação entre as médias dos níveis plasmáticos de tramadol e as medianas dos escores de dor obtido pela escala visual analógica tanto no grupo que recebeu $1 \mathrm{mg} / \mathrm{kg}$ de tramadol $(r=-0,536)$, como no grupo 4 $\mathrm{mg} / \mathrm{kg}(\mathrm{r}=-0,592)$; o mesmo ocorreu quando empregou-se a escala descritiva (grupo $1 \mathrm{mg} / \mathrm{kg}$ - grupo I, r= - 0,6 77; grupo $4 \mathrm{mg} / \mathrm{kg}$ - grupo II, $r=-0,378$ ). 
Tabela 9 - Valores individuais e medianas relativos aos escores de algesia obtida através da escala descritiva, de cadelas (sem raça definida) tratadas, com 1 ou $4 \mathrm{mg} / \mathrm{kg}$ de tramadol pela via intravenosa, imediatamente após o término da ováriosalpingo-histerectomia

\begin{tabular}{|c|c|c|c|c|c|c|c|c|}
\hline \multirow{2}{*}{$\begin{array}{l}\text { TRAMADOL } \\
\mathrm{mg} / \mathrm{kg}\end{array}$} & \multirow{2}{*}{$\begin{array}{c}\text { TEMPO } \\
\text { MINUTOS }\end{array}$} & \multicolumn{6}{|c|}{ ANIMAIS } & \multirow[t]{2}{*}{ MEDIANA } \\
\hline & & 3 & 5 & 7 & 8 & 10 & 12 & \\
\hline \multirow{16}{*}{1} & 30 & 0 & 0 & 0 & 0 & 0 & 0 & 0 \\
\hline & 60 & 0 & 0 & 0 & 0 & 0 & 1 & 0 \\
\hline & 90 & 0 & 0 & 0 & 0 & 1 & 1 & 0 \\
\hline & 120 & 0 & 0 & 0 & 1 & 1 & $2^{\# C}$ & 1 \\
\hline & 150 & 1 & 1 & 0 & 1 & 1 & 1 & 1 \\
\hline & 180 & $2^{\# c}$ & $2^{\# c}$ & 0 & 1 & 1 & $2^{\# d}$ & 1,5 \\
\hline & 210 & 0 & $2^{\# d}$ & 0 & 1 & 1 & $2^{\# m}$ & 1 \\
\hline & 240 & 0 & 1 & 0 & 1 & 1 & 0 & 0,5 \\
\hline & 270 & 0 & 0 & 0 & 1 & 1 & 0 & 0 \\
\hline & 300 & 0 & 0 & 0 & $2^{\# c}$ & 1 & 0 & 0 \\
\hline & 330 & 0 & 0 & 0 & 1 & 1 & 0 & 0 \\
\hline & 360 & 1 & 0 & 0 & $2^{\# d}$ & 1 & 0 & 0,5 \\
\hline & 390 & 1 & 0 & 0 & 0 & 1 & 0 & 0 \\
\hline & 420 & 1 & 0 & 0 & 0 & $2^{\# c}$ & 0 & 0 \\
\hline & 450 & $2^{\# d}$ & 0 & 0 & 0 & 0 & 0 & 0 \\
\hline & 480 & 0 & 0 & 0 & 0 & 0 & 0 & 0 \\
\hline \multirow{17}{*}{4} & & 1 & 2 & 4 & 6 & 9 & 11 & \\
\hline & 30 & 0 & 0 & 0 & 0 & 0 & 0 & 0 \\
\hline & 60 & 0 & 0 & 0 & 0 & 0 & 0 & 0 \\
\hline & 90 & 0 & 0 & 0 & 0 & 0 & 0 & 0 \\
\hline & 120 & 0 & 0 & 0 & 0 & 0 & 0 & 0 \\
\hline & 150 & 0 & 0 & 0 & 0 & 0 & 1 & 0 \\
\hline & 180 & 0 & 0 & 0 & 1 & 0 & $2^{\# c}$ & 0 \\
\hline & 210 & 0 & 0 & 0 & 1 & 0 & 1 & 0 \\
\hline & 240 & 1 & 0 & 0 & 1 & 0 & 0 & 0 \\
\hline & 270 & 1 & 0 & 0 & 0 & $2^{\# c}$ & 0 & 0 \\
\hline & 300 & 1 & 0 & 0 & 0 & $3^{\# d}$ & 0 & 0,5 \\
\hline & 330 & $2^{\# c}$ & 1 & 0 & 0 & 1 & 0 & 0,5 \\
\hline & 360 & 1 & 1 & 0 & 0 & $2^{\# m}$ & 0 & 0 \\
\hline & 390 & 0 & 1 & 0 & 0 & 0 & 0 & 0 \\
\hline & 420 & 0 & 0 & 0 & 0 & 0 & 0 & 0 \\
\hline & 450 & 0 & 0 & 0 & 0 & 0 & 0 & 0 \\
\hline & 480 & 0 & 0 & 0 & 0 & 0 & 0 & 0 \\
\hline
\end{tabular}

$\mathrm{P}>0,05$, teste U;

\# = Medicação de resgate: $c$ = cetoprofeno $(2 \mathrm{mg} / \mathrm{kg}) ; \mathrm{d}=\operatorname{dipirona}(25 \mathrm{mg} / \mathrm{kg}) ; \mathrm{m}=$ morfina $(0,1 \mathrm{mg} / \mathrm{kg})$. 
Tabela 10 - Valores individuais e medianas relativos ao escore de algesia obtida através da escala visual analógica de cadelas (sem raça definida) tratadas, com 1 ou $4 \mathrm{mg} / \mathrm{kg}$ de tramadol pela via intravenosa, imediatamente após o término da ovário-salpingohisterectomia

\begin{tabular}{|c|c|c|c|c|c|c|c|c|}
\hline \multirow{2}{*}{$\begin{array}{l}\text { TRAMADOL } \\
\mathrm{mg} / \mathrm{kg}\end{array}$} & \multirow{2}{*}{$\begin{array}{c}\text { TEMPO } \\
\text { MINUTOS }\end{array}$} & \multicolumn{6}{|c|}{ ANIMAIS } & \multirow[t]{2}{*}{ MEDIANA } \\
\hline & & 3 & 5 & 7 & 8 & 10 & 12 & \\
\hline \multirow{16}{*}{ s c } & 30 & 0 & 0 & 0 & 0 & 0 & 0 & 0 \\
\hline & 60 & 0 & 0 & 0 & 0 & 0 & 3 & 0 \\
\hline & 90 & 0 & 0 & 0 & 0 & 3 & 3 & 0 \\
\hline & 120 & 3 & 2 & 0 & 3 & 3 & $5^{\# c}$ & 3 \\
\hline & 150 & 3 & 3 & 0 & 3 & 3 & 3 & 3 \\
\hline & 180 & $4^{\# c}$ & $5^{\# c}$ & 0 & 3 & 3 & $5^{\# d}$ & 3,5 \\
\hline & 210 & 0 & $5^{\# d}$ & 0 & 3 & 3 & $5^{\# m}$ & 3 \\
\hline & 240 & 0 & 3 & 0 & 3 & 3 & 0 & 1,5 \\
\hline & 270 & 0 & 0 & 0 & 3 & 3 & 0 & 0 \\
\hline & 300 & 0 & 0 & 0 & $5^{\# c}$ & 3 & 0 & 0 \\
\hline & 330 & 0 & 0 & 0 & 3 & 3 & 0 & 0 \\
\hline & 360 & 3 & 0 & 0 & $5^{\# d}$ & 3 & 0 & 1,5 \\
\hline & 390 & 3 & 0 & 0 & 0 & 3 & 0 & 0 \\
\hline & 420 & 3 & 0 & 0 & 0 & $5^{\# c}$ & 0 & 0 \\
\hline & 450 & $4^{\# d}$ & 0 & 0 & 0 & 0 & 0 & 0 \\
\hline & 480 & 0 & 0 & 0 & 0 & 0 & 0 & 0 \\
\hline \multirow{17}{*}{4} & & 1 & 2 & 4 & 6 & 9 & 11 & \\
\hline & 30 & 0 & 0 & 0 & 0 & 0 & 0 & 0 \\
\hline & 60 & 0 & 0 & 0 & 0 & 0 & 0 & 0 \\
\hline & 90 & 0 & 0 & 0 & 0 & 0 & 0 & 0 \\
\hline & 120 & 0 & 0 & 0 & 0 & 0 & 1 & 0 \\
\hline & 150 & 0 & 0 & 0 & 0 & 0 & 3 & 0 \\
\hline & 180 & 0 & 0 & 0 & 3 & 0 & $5^{\# c}$ & 0 \\
\hline & 210 & 0 & 0 & 0 & 3 & 0 & 3 & 0 \\
\hline & 240 & 2 & 0 & 0 & 4 & 0 & 0 & 0 \\
\hline & 270 & 3 & 0 & 0 & 2 & $5^{\# c}$ & 0 & 1 \\
\hline & 300 & 4 & 2 & 0 & 0 & $7^{\# d}$ & 0 & 1 \\
\hline & 330 & $5^{\# c}$ & 2 & 0 & 0 & 4 & 0 & 1 \\
\hline & 360 & 3 & 3 & 0 & 0 & $5^{\# m}$ & 0 & 1,5 \\
\hline & 390 & 0 & 3 & 0 & 0 & 0 & 0 & 0 \\
\hline & 420 & 0 & 0 & 0 & 0 & 0 & 0 & 0 \\
\hline & 450 & 0 & 0 & 0 & 0 & 0 & 0 & 0 \\
\hline & 480 & 0 & 0 & 0 & 0 & 0 & 0 & 0 \\
\hline
\end{tabular}

${ }^{*} \mathrm{p}<0,05$, teste $\mathrm{U}$

\# = Medicação de resgate: $\mathrm{c}=$ cetoprofeno $(2 \mathrm{mg} / \mathrm{kg}), \mathrm{d}=$ dipirona $(25 \mathrm{mg} / \mathrm{kg}), \mathrm{m}=$ morfina $(0,1 \mathrm{mg} / \mathrm{kg})$. 

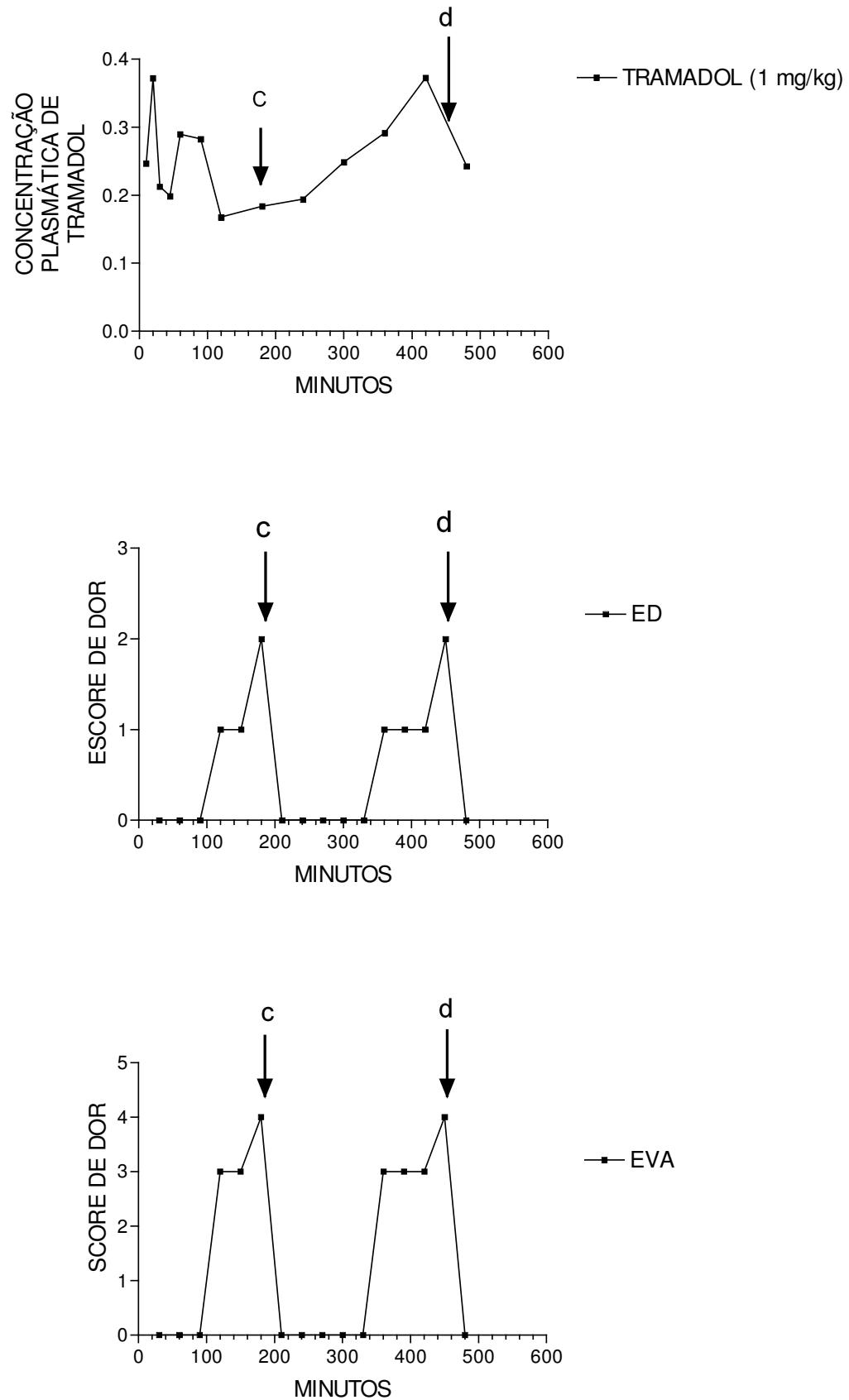

Figura 7 - Níveis plasmáticos de tramadol $(\mathrm{mcg} / \mathrm{ml})$ e analgesia avaliados por duas diferentes escalas (escala descritiva - ED e escala visual analógica - EVA), na cadela no 3 que recebeu $1 \mathrm{mg} / \mathrm{kg}$ de tramadol pela via intravenosa imediatamente após o término da ovário-salpingo-histerectomia. A seta indica o momento da administração da medicação de resgate (c = cetoprofeno $2 \mathrm{mg} / \mathrm{kg}$; $\mathrm{d}$ = dipirona 25 $\mathrm{mg} / \mathrm{kg}$ ) 

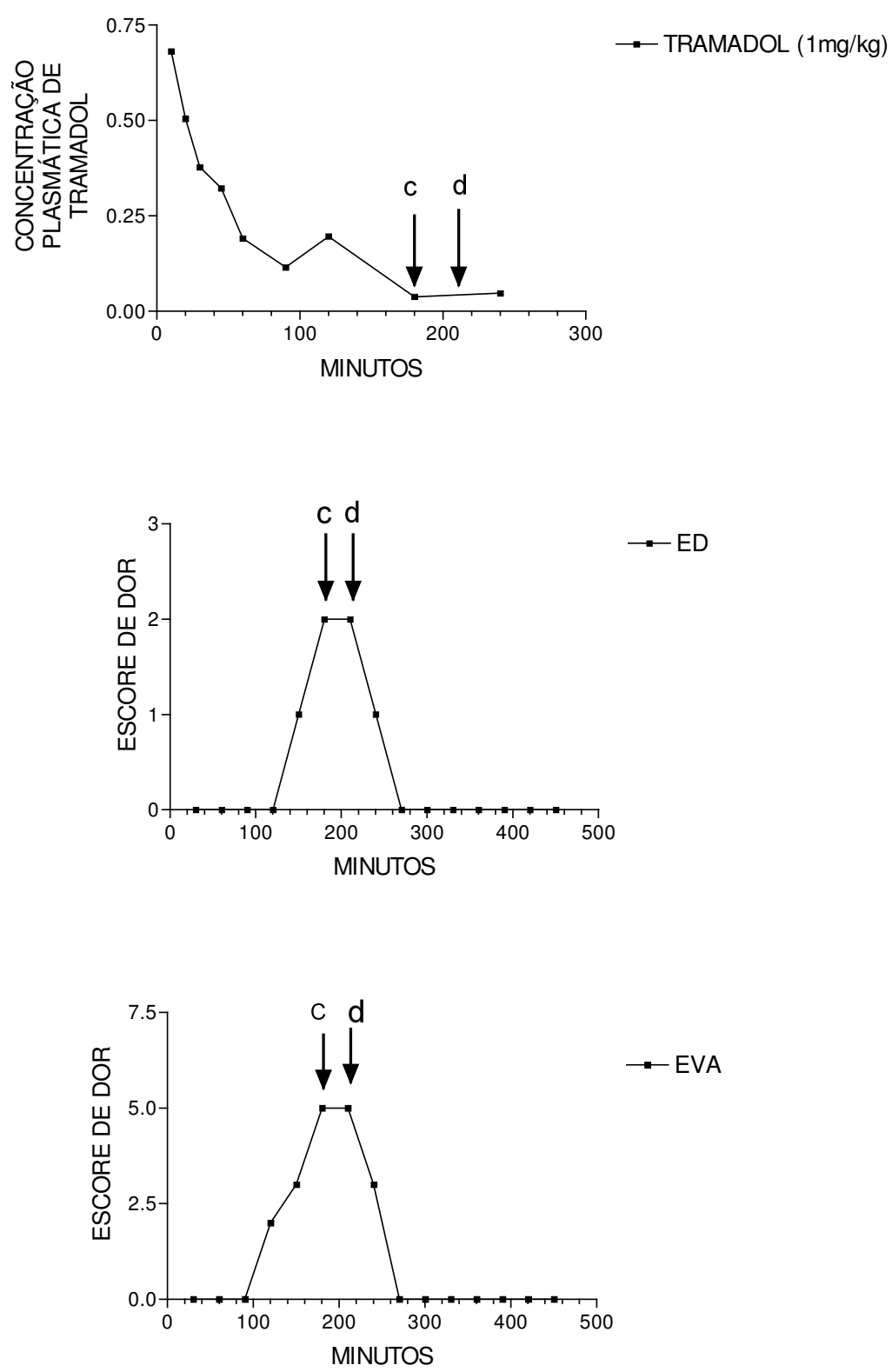

Figura 8 - Níveis plasmáticos de tramadol $(\mathrm{mcg} / \mathrm{ml})$ e analgesia avaliados por duas diferentes escalas (escala descritiva - ED e escala visual analógica - EVA), na cadela $\mathrm{n}^{\circ} 5$ que recebeu $1 \mathrm{mg} / \mathrm{kg}$ de tramadol pela via intravenosa imediatamente após o término da ovário-salpingo-histerectomia. A seta indica o momento da administração da medicação de resgate $(c=$ cetoprofeno 2 $\mathrm{mg} / \mathrm{kg} ; \mathrm{d}$ = dipirona $25 \mathrm{mg} / \mathrm{kg}$ ) 

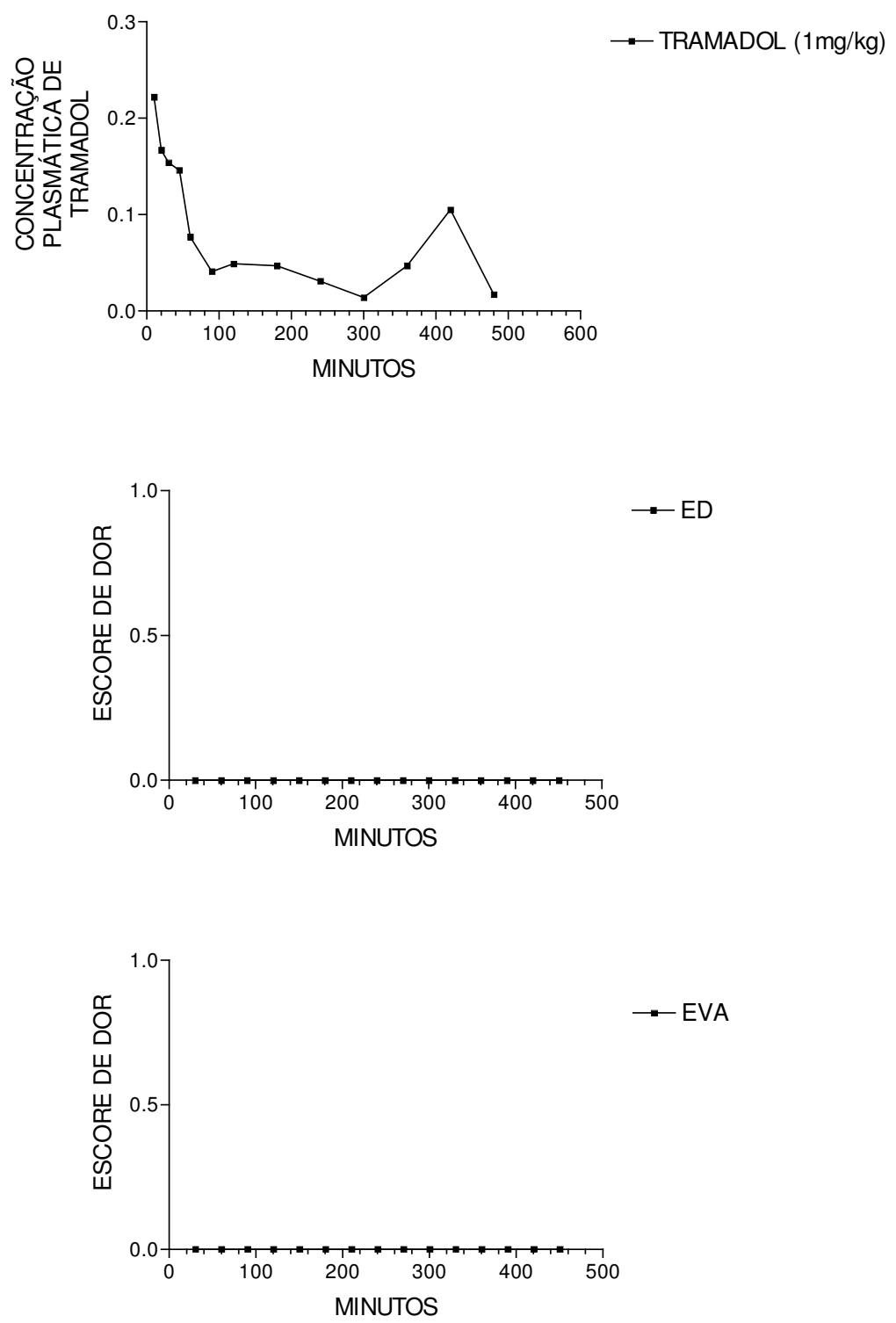

Figura 9 - Níveis plasmáticos de tramadol $(\mathrm{mcg} / \mathrm{ml})$ e analgesia avaliados por duas diferentes escalas (escala descritiva - ED e escala visual analógica - EVA), na cadela $\mathrm{n}^{\circ} 7$ que recebeu $1 \mathrm{mg} / \mathrm{kg}$ de tramadol pela via intravenosa imediatamente após o término da ovário-salpingo-histerectomia 

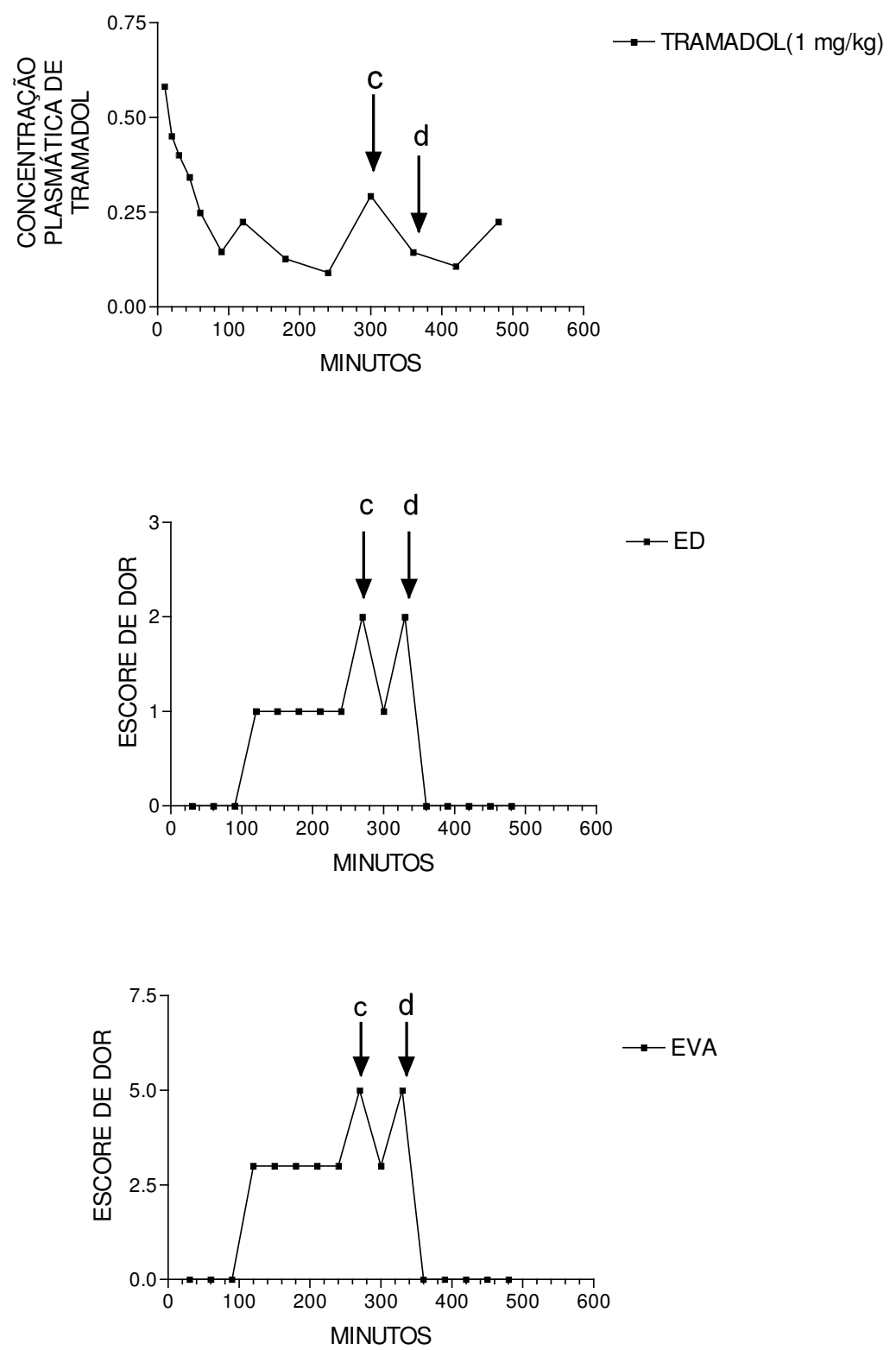

Figura 10 - Níveis plasmáticos de tramadol (mcg $\mathrm{ml}$ ) e analgesia avaliados por duas diferentes escalas (escala descritiva - ED e escala visual analógica - EVA), na cadela $\mathrm{n}^{\circ} 8$ que recebeu $1 \mathrm{mg} / \mathrm{kg}$ de tramadol pela via intravenosa imediatamente após o término da ovário-salpingo-histerectomia. A seta indica o momento da administração da medicação de resgate (c = cetoprofeno $2 \mathrm{mg} / \mathrm{kg}$; $\mathrm{d}=$ dipirona $25 \mathrm{mg} / \mathrm{kg}$ ) 

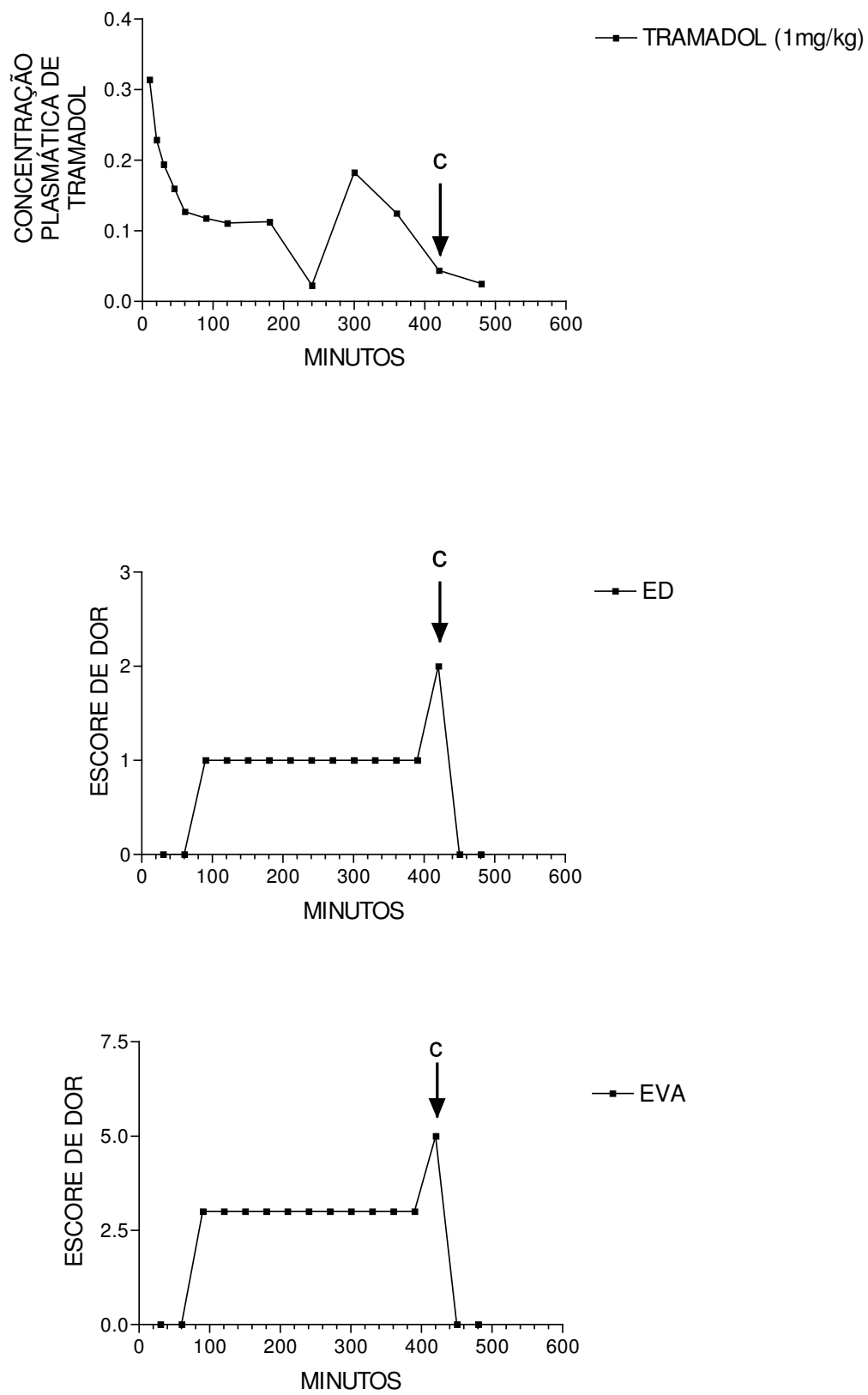

Figura 11 - Níveis plasmáticos de tramadol $(\mathrm{mcg} / \mathrm{ml})$ e analgesia avaliados por duas diferentes escalas (escala descritiva - ED e escala visual analógica - EVA), na cadela $\mathrm{n}^{\circ} 10$ que recebeu $1 \mathrm{mg} / \mathrm{kg}$ de tramadol pela via intravenosa imediatamente após o término da ovário-salpingo-histerectomia. A seta indica o momento da administração da medicação de resgate $(c=$ cetoprofeno 2 $\mathrm{mg} / \mathrm{kg}$ ) 

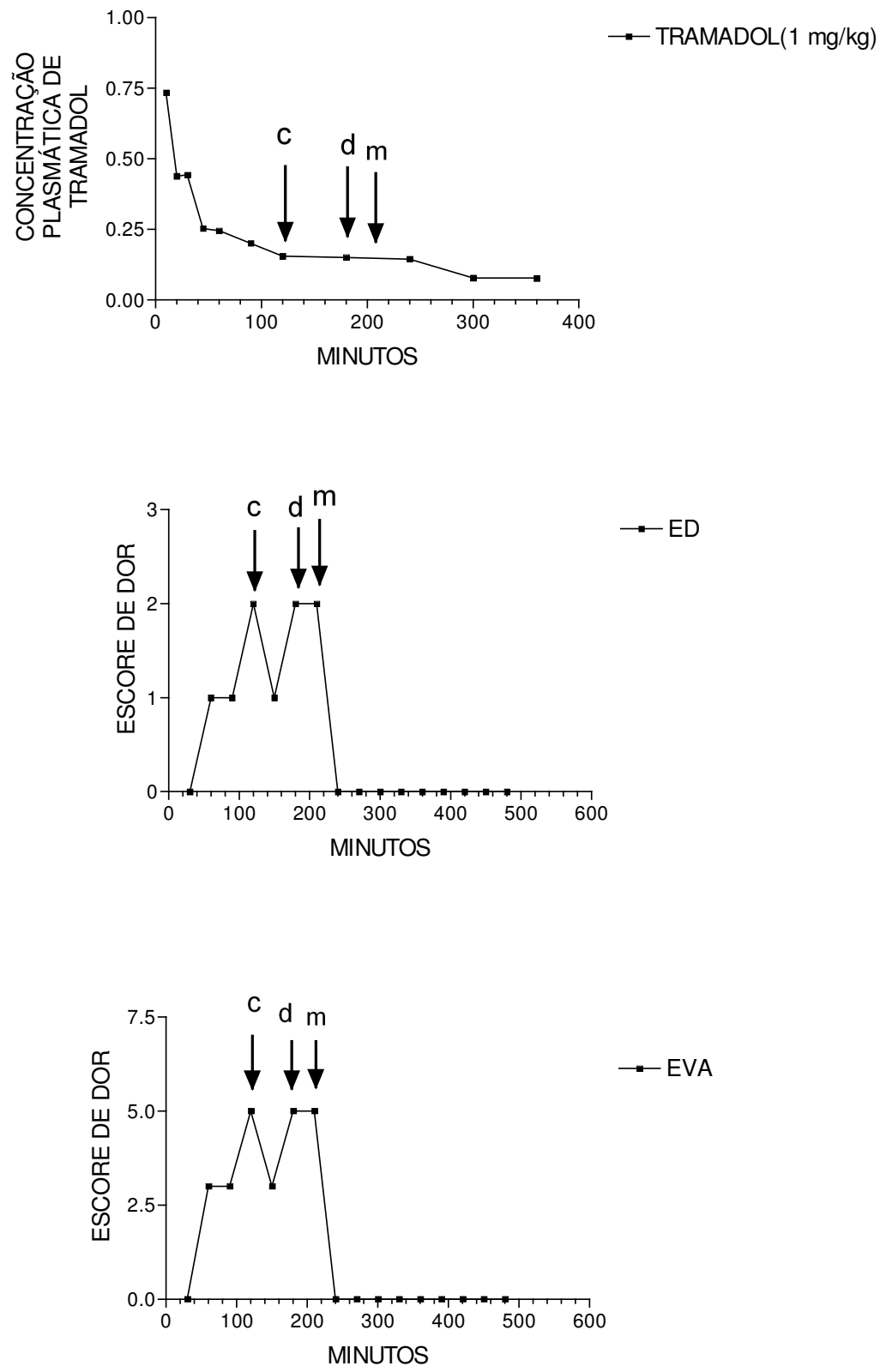

Figura 12 - Níveis plasmáticos de tramadol $(\mathrm{mcg} / \mathrm{ml})$ e analgesia avaliados por duas diferentes escalas (escala descritiva - ED e escala visual analógica - EVA), na cadela № 12 que recebeu $1 \mathrm{mg} / \mathrm{kg}$ de tramadol pela via intravenosa imediatamente após o término da ovário-salpingo-histerectomia. A seta indica 0 momento da administração da medicação de resgate $(\mathrm{c}=$ cetoprofeno 2 $\mathrm{mg} / \mathrm{kg} ; \mathrm{d}$ = dipirona $25 \mathrm{mg} / \mathrm{kg} ; \mathrm{m}$ = morfina $0,1 \mathrm{mg} / \mathrm{kg}$ ) 

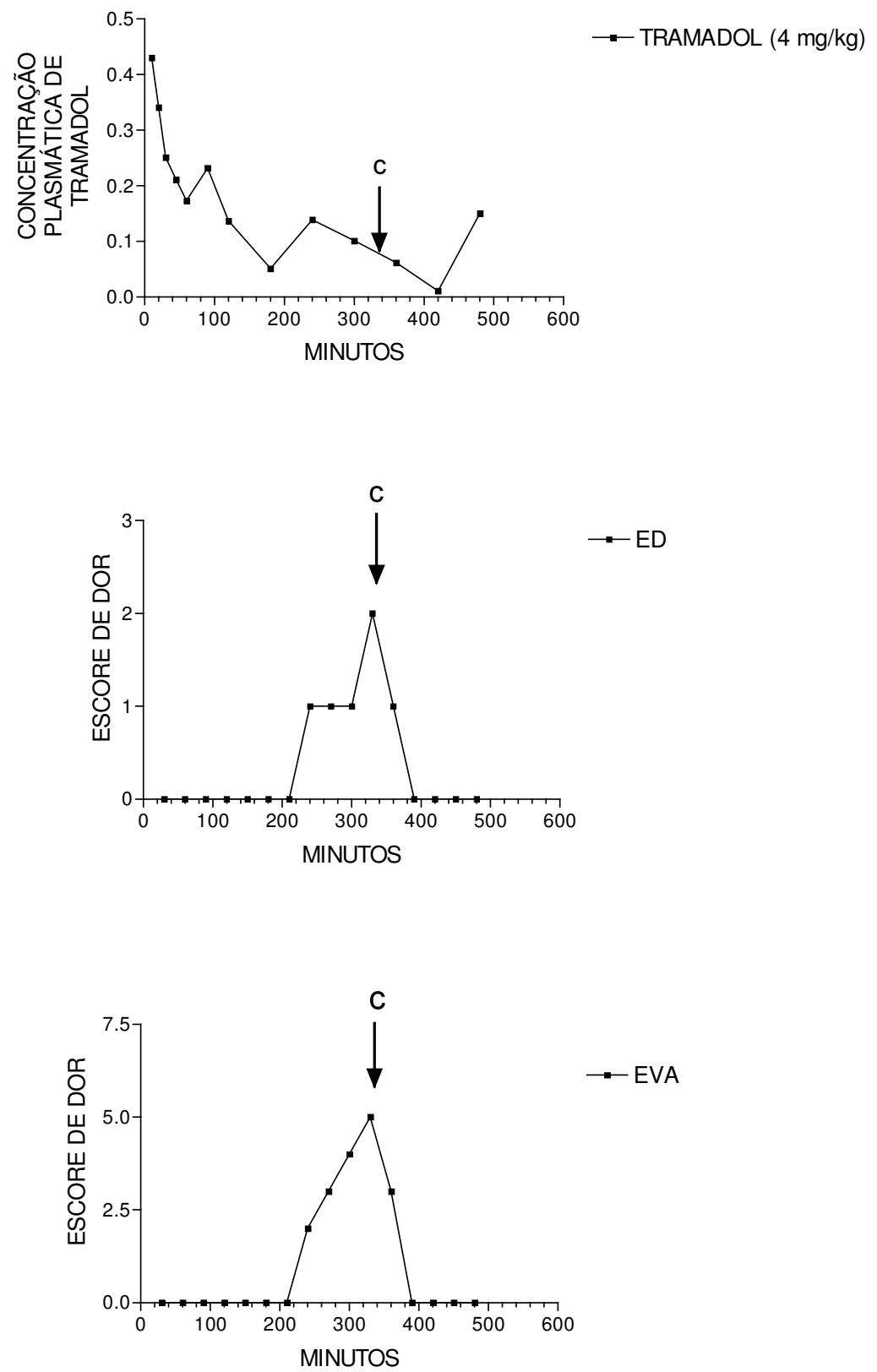

Figura 13 - Níveis plasmáticos de tramadol $(\mathrm{mcg} / \mathrm{ml})$ e analgesia avaliados por duas diferentes escalas (escala descritiva - ED e escala visual analógica - EVA), na cadela $\mathrm{n}^{\circ} 1$ que recebeu $4 \mathrm{mg} / \mathrm{kg}$ de tramadol pela via intravenosa imediatamente após o término da ovário-salpingo-histerectomia. A seta indica o momento da administração da medicação de resgate $(c=$ cetoprofeno $2 \mathrm{mg} / \mathrm{kg}$ ) 

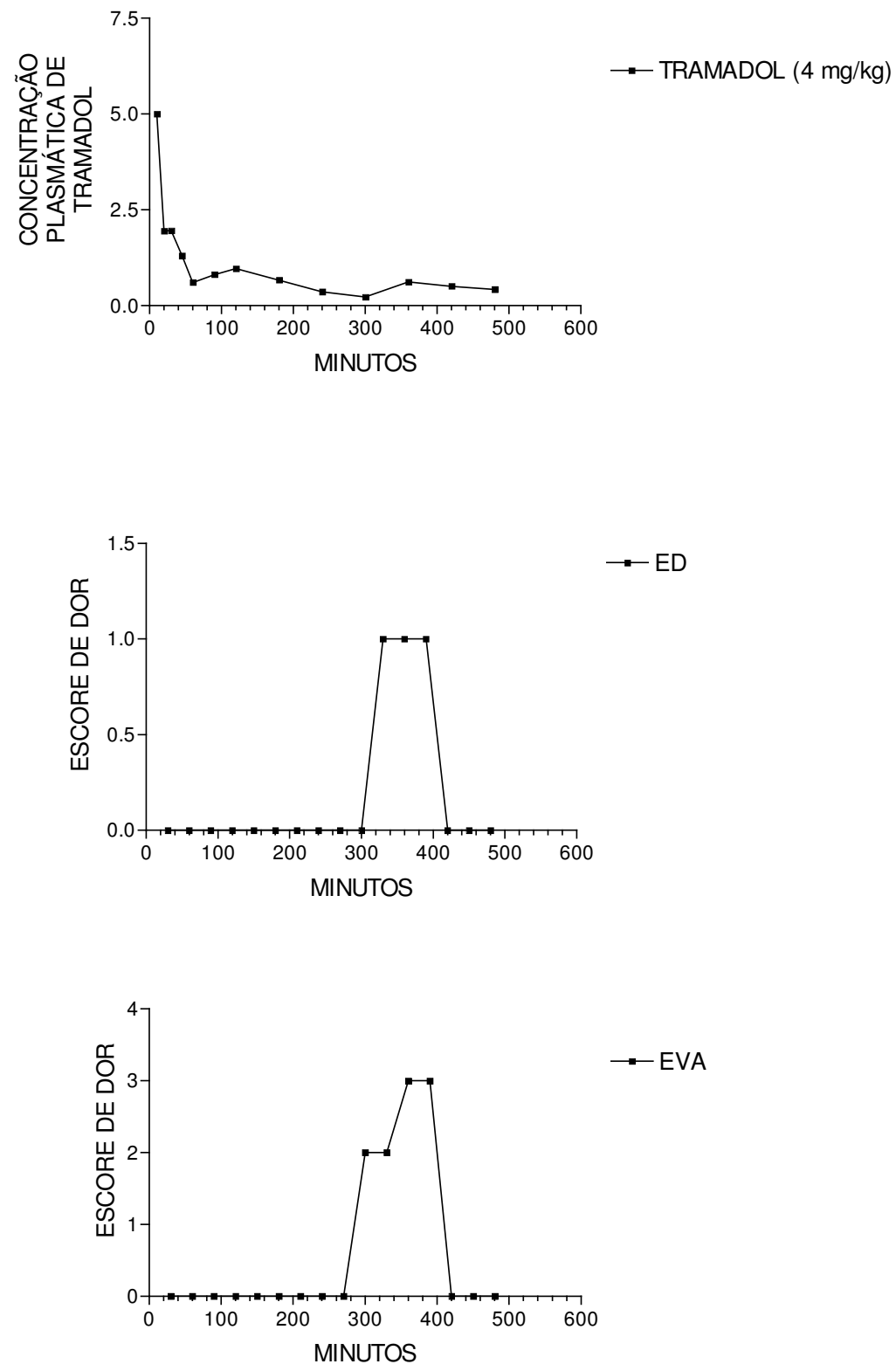

Figura 14 - Níveis plasmáticos de tramadol $(\mathrm{mcg} / \mathrm{ml})$ e analgesia avaliados por duas diferentes escalas (escala descritiva - ED e escala visual analógica - EVA), na cadela $\mathrm{n}^{\circ} 2$ que recebeu $4 \mathrm{mg} / \mathrm{kg}$ de tramadol pela via intravenosa imediatamente após o término da ovário-salpingo-histerectomia 


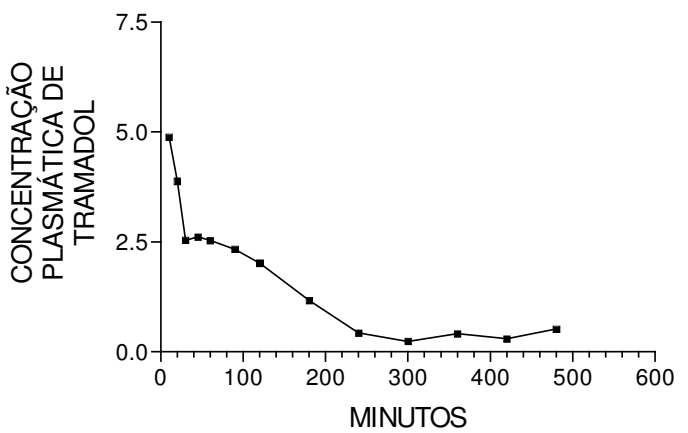

- TRAMADOl $(4 \mathrm{mg} / \mathrm{kg})$
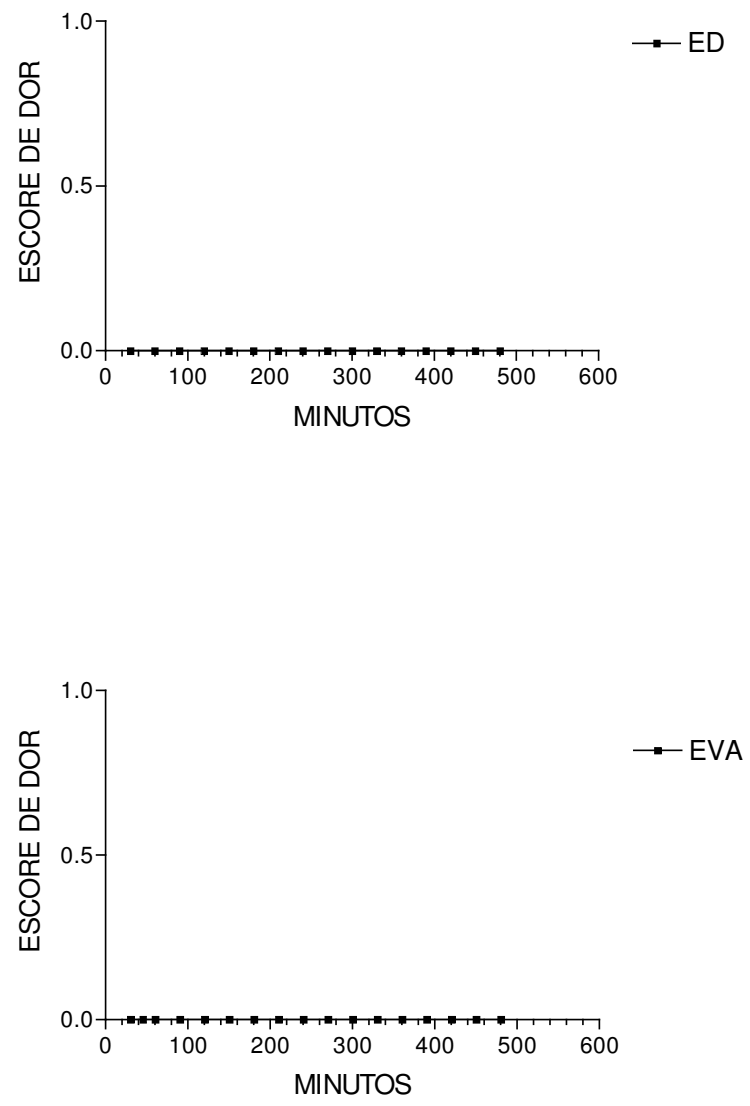

Figura 15 - Níveis plasmáticos de tramadol $(\mathrm{mcg} / \mathrm{ml})$ e analgesia avaliados por duas diferentes escalas (escala descritiva - ED e escala visual analógica - EVA), na cadela $\mathrm{n}^{\circ} 4$ que recebeu $4 \mathrm{mg} / \mathrm{kg}$ de tramadol pela via intravenosa imediatamente após o término da ovário-salpingo-histerectomia 


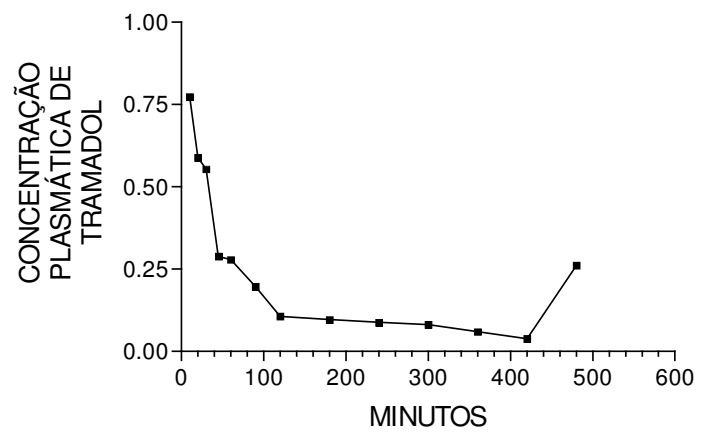

$\rightarrow$ TRAMADOl $(4 \mathrm{mg} / \mathrm{kg})$
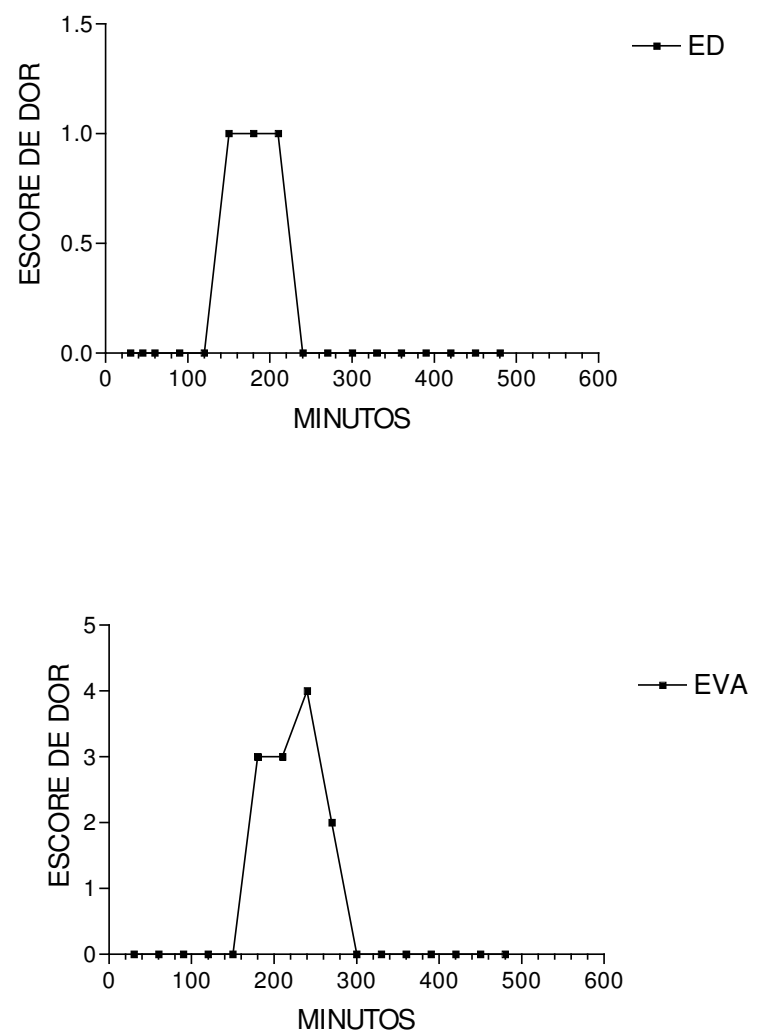

Figura 16 - Níveis plasmáticos de tramadol $(\mathrm{mcg} / \mathrm{ml})$ e analgesia avaliados por duas diferentes escalas (escala descritiva - ED e escala visual analógica - EVA), na cadela 으 6 que recebeu $4 \mathrm{mg} / \mathrm{kg}$ de tramadol pela via intravenosa imediatamente após o término da ovário-salpingo-histerectomia 

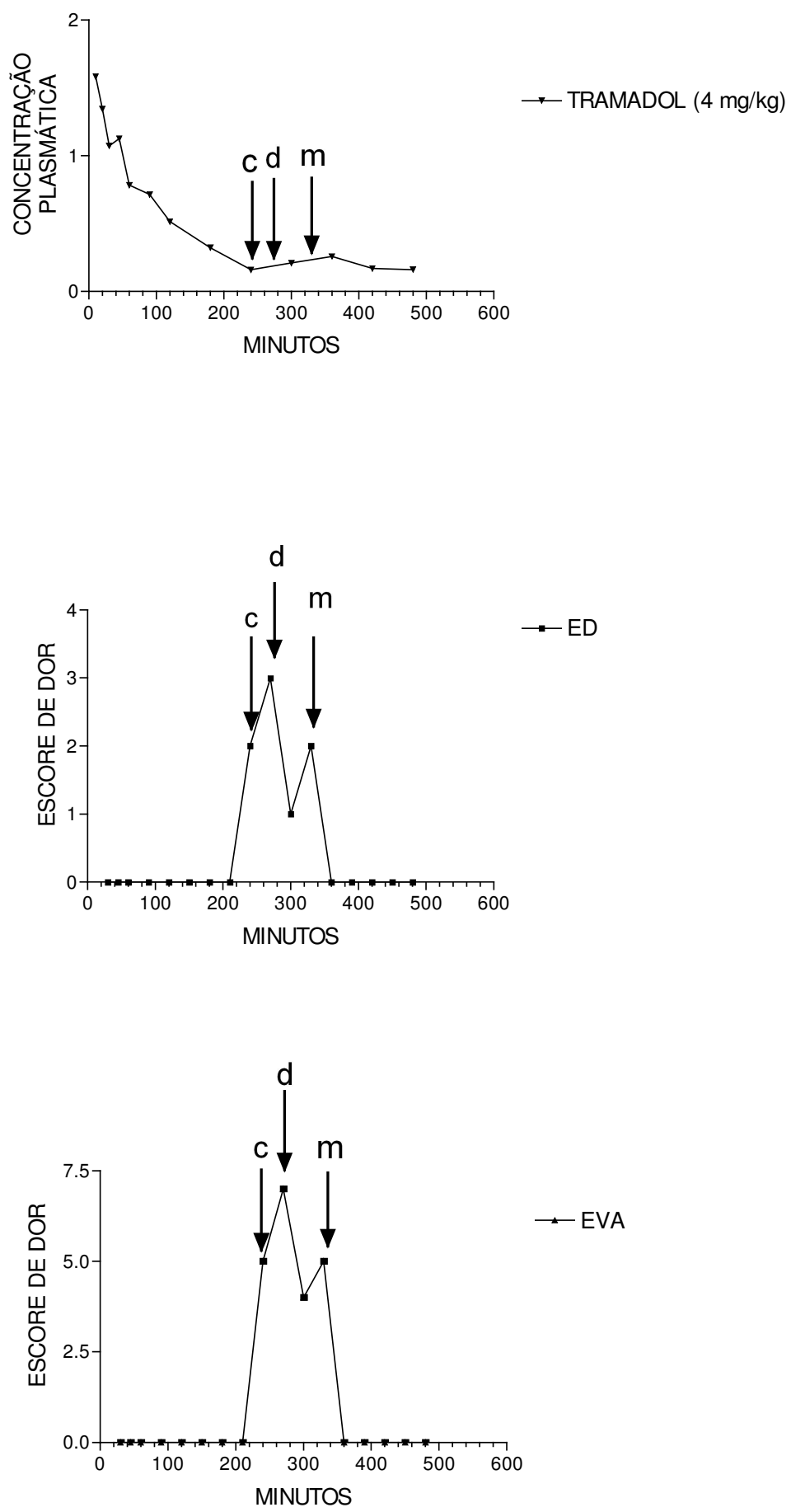

Figura 17 - Níveis plasmáticos de tramadol $(\mathrm{mcg} / \mathrm{ml})$ e analgesia avaliados por duas diferentes escalas (escala descritiva - ED e escala visual analógica - EVA), na cadela ํo 9 que recebeu $4 \mathrm{mg} / \mathrm{kg}$ de tramadol pela via intravenosa imediatamente após o término da ovário-salpingo-histerectomia. A seta indica o momento da administração da medicação de resgate $(c=$ cetoprofeno $2 \mathrm{mg} / \mathrm{kg} ; \mathrm{d}$ = dipirona $25 \mathrm{mg} / \mathrm{kg} ; \mathrm{m}=$ morfina 0,1 $\mathrm{mg} / \mathrm{kg}$ ) 

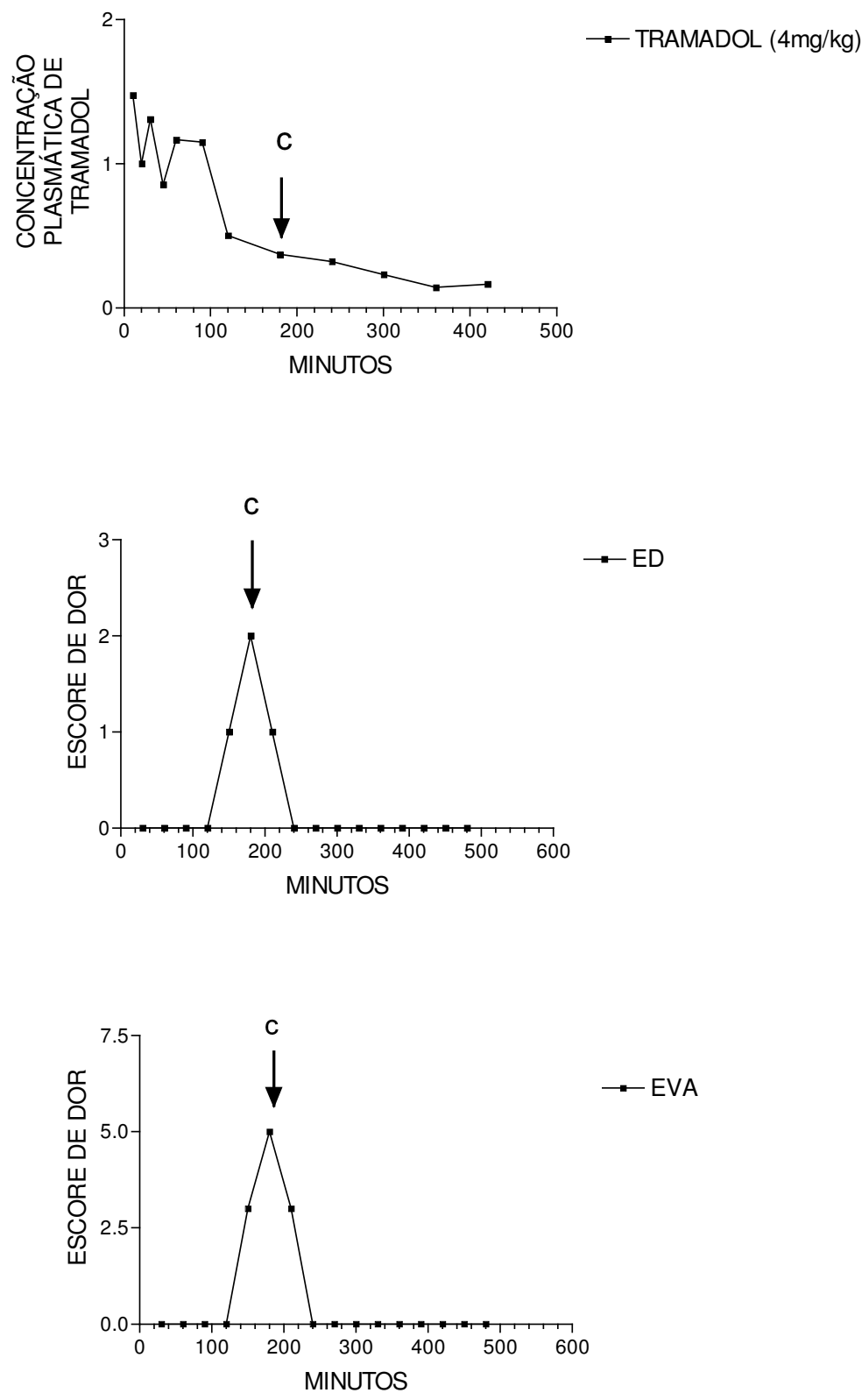

Figura 18 - Níveis plasmáticos de tramadol $(\mathrm{mcg} / \mathrm{ml})$ e analgesia avaliados por duas diferentes escalas (escala descritiva - ED e escala visual analógica - EVA), na cadela $n^{0} 11$ que recebeu $4 \mathrm{mg} / \mathrm{kg}$ de tramadol pela via intravenosa imediatamente após o término da ovário-salpingo-histerectomia. A seta indica o momento da administração da medicação de resgate $(c=$ cetoprofeno $2 \mathrm{mg} / \mathrm{kg}$ ) 


\section{DISCUSSÃO}

A escolha de um analgésico apropriado que acarrete efeitos adversos mínimos é tarefa de extrema importância em ambas as áreas médicas. Dentre os produtos utilizados em medicina veterinária, com finalidade analgésica, os opióides têm sido uma alternativa bastante promissora devido à sua eficiência no controle da dor e à reduzida presença de efeitos adversos (PAPICH, 1997). No que diz respeito ao tramadol existe ainda um grande interesse na descoberta de novas informações tanto pelo seu crescente uso no controle da dor na medicina veterinária, como pela escassa base literária acerca de seu uso em pequenos animais.

Os valores etários e ponderais foram aspectos analisados nos critérios de inclusão das cadelas submetidas a ovário-salpingo-histerectomia. A padronização destes fatores vêm minimizar a variação individual dos animais contidos nos grupos I e II (1 mg/kg e $4 \mathrm{mg} / \mathrm{kg}$, respectivamente), o que favorece a acurácia dos resultados obtidos. A análise comparativa dos valores relativos a estas características, revelou a inexistência de diferença estatística significantes $(p=0,05)$ entre os grupos I e II (1 $\mathrm{mg} / \mathrm{kg}$ e $4 \mathrm{mg} / \mathrm{kg}$, respectivamente), configurando a constituição de grupos homogêneos.

A precaução de se formar grupos homogêneos relativos a estes aspectos está relacionada à influência destes fatores na avaliação comportamental dos animais responsivos a dor.

As respostas comportamentais diante da dor e outros fatores geradores de estresse são resultados da interação entre o indivíduo e o meio, sendo afetados por muitos fatores, tais como: sexo, raça, idade, origem da dor e doença coexistente (FIRTH; HALDANE, 1999; HANSEN, 1997). No mesmo sentindo, Hellyer (1997) também relatou a influência destes fatores em seu estudo que avaliou a utilização de analgésicos em 285 animais.

Outros aspectos ainda foram motivos de preocupação para a padronização dos grupos avaliados no presente estudo. Dentre estes, destaca-se a utilização da mesma técnica cirúrgica e do mesmo cirurgião responsável pelo ato cirúrgico. Estes fatores vêm colaborar para que se tenha pouca variação no estímulo álgico, estabelecendo, assim, uma maior equivalência da intensidade da dor. 
A dor pode ser classificada em aguda ou crônica de acordo com a sua disposição temporal; em leve, moderada e intensa de acordo com sua intensidade; e, em nociceptiva, quando for resultante da ativação de nociceptores, e neuropática, quando houver alteração ou lesão do sistema nervoso (SAKATA, 2004).

Para uma análise com maior precisão da analgesia induzida pelo tramadol, foi de grande importância à existência de um estímulo álgico de intensidade moderada, uma vez que este opióide é considerado de potência fraca (SAKATA, 2004; TEIXEIRA, 2003). Por isso, optou-se pela escolha das fêmeas vinculadas ao procedimento cirúrgico denominado de ovário-salpingo-histerectomia.

Outros fatores revelaram também a importância na escolha deste procedimento cirúrgico (ovário-salpingo-histerectomia), como sua larga utilização na rotina do médico veterinário e o tratamento preventivo analgésico ineficiente.

Robertson (2002) relatou uma estimativa de 40 milhões de cães e $60 \mathrm{mi}-$ Ihões de gatos que foram submetidas a ovário-salpingo-histerectomia ou orquiectomia em um ano nos Estados Unidos.

Wright (2002) ainda caracteriza tal procedimento cirúrgico como precursor de uma sensibilidade dolorosa de moderada intensidade, devendo, portanto, merecer a devida importância em seu tratamento preemptivo ou preventivo da dor.

O tempo de extubação, (período compreendido entre o término do fornecimento do anestésico volátil e a retirada da sonda endotraqueal), avaliado no presente estudo mostrou um período significativamente maior $(p<0,05)$ nos indivíduos tratados com $4 \mathrm{mg} / \mathrm{kg}$ (grupo II) de tramadol. (BAMIGBADE et al., 1998; HOUMES et al., 1992; VICKERS et al., 1992).

O prolongamento do tempo de extubação do grupo II ( $4 \mathrm{mg} / \mathrm{kg})$ pode estar associado à intensidade da sedação promovida na utilização do tramadol nesta dose, visto também que, neste mesmo grupo ocorreu um maior grau de sonolência e uma recuperação mais demorada da atividade psicomotora no pósoperatório imediato (dado observado, porém não quantificado).

Por outro lado, alguns autores assinalaram a ausência de sedação e de alteração do tempo de extubação em seres humanos tratados com $1 \mathrm{mg} / \mathrm{kg}$ ou 2 $\mathrm{mg} / \mathrm{kg}$ de tramadol pela via intravenosa (MATHEWS et al., 2002).

A potência analgésica e os correspondentes efeitos colaterais, promovidos pelos opióides são dependentes da dose (SAKATA; ISSY, 2004), o que torna o 
grupo de animais que receberam o tratamento de $4 \mathrm{mg} / \mathrm{kg}$ (grupo II) de tramadol, o de maior tendência a apresentar efeitos indesejáveis.

Os efeitos colaterais dos opióides mais comumente citados são relacionados às funções gastrintestinal (constipação, náusea e vômito) e neurológica (sonolência e sedação), sendo importante o ajuste individual da dose para obtenção de máximo efeito analgésico, com mínimos efeitos adversos (PORTENOY; LESAGE, 1999).

Nesse mesmo sentido, Pascoe (2000) apontou como os principais efeitos colaterais dos opióides, a bradicardia, a sedação, a retenção urinária, a depressão respiratória, a estase gastrintestinal, o vômito e a náusea, e, ocasionalmente, a disforia ou a excitação.

Os efeitos farmacológicos dos opióides dependem da natureza do receptor envolvido e das suas características. Estes fármacos ligam-se a um ou mais receptores em diversas áreas do Sistema Nervoso Central que modulam a atividade sensitiva, motora e psíquica e a receptores do Sistema Nervoso Periférico (TEIXEIRA, 2003).

Os principais receptores opióides são: mi-1 e mi-2, delta, sigma, kappa-1, kappa-2, kappa-3. A ligação de opióides com receptores mi-1 está associada à analgesia supra-espinal e dependência; a ligação com receptores mi-2 está associada à analgesia espinal, miose, depressão respiratória, sedação, inibição da motilidade gastrintestinal e bradicardia; a ligação ao receptor sigma esta relacionada a disforia, alucinação, estimulação psicomotora e excitação, com pouco efeito analgésico. A ligação de opióides com receptores kappa, produz analgesia espinal, sedação, miose e inibição do hormônio antidiurético; e com receptores delta, analgesia e euforia. (NISHIMURA et al., 1984).

No presente estudo, a sedação levando ao aumento do tempo de extubação, observado em cadelas tratadas com $4 \mathrm{mg} / \mathrm{kg}$ de tramadol pode ser atribuído a atuação deste fármaco, e também do seu principal metabólito, o Odesmetiltramadol, em receptores mi opióides.

Vale ressaltar que a quantificação do grau de sedação promovido pela utilização do tramadol de ser investigada, uma vez que este foi um dado constatado durante o experimento e, por isso, não fez parte do protocolo inicialmente traçado. 
Relativamente aos parâmetros fisiológicos representados pelas freqüências cardíaca e respiratória, e pressão arterial, parece oportuno salientar a importância do papel dessas variáveis como indicadores da sensibilidade dolorosa, assim como de efeitos adversos proporcionados no tratamento preventivo da dor, principalmente quando o medicamento de escolha é um analgésico opióide.

O reconhecimento da dor em animais é muitas vezes frustrante (GAYNOR, 2001). A dor, por ser uma experiência individual, é muito difícil de ser observada e quantificada. Somente o homem tem a habilidade de expressar e quantificar verbalmente a dor, já em animais o reconhecimento é subjetivo (HARDIE; KYLES, 1995).

A avaliação da dor em animais é baseada em alterações fisiológicas e comportamentais (GAYNOR, 2001; HARDIE; KYLES, 1995; LESTER; GAYNOR, 2000).

HASKINS (1987) cita as alterações fisiológicas relacionadas aos processos dolorosos, dentre elas: midríase, sialorréia, taquipnéia, taquicardia e hiperglicemia.

Tais alterações devem ser corrigidas, ou seja, tratadas adequadamente de acordo com a intensidade dolorosa, no entanto a preocupação com os efeitos colaterais promovidos neste tratamento deve ser levada em consideração.

O efeito adverso mais importante ocasionado pelos opióides é a depressão respiratória, porem alterações do sistema cardiovascular, como bradicardia e hipotensão também são descritos. (GÓRNIAK, 2006; PAPICH, 1997; THURMON; TRANQUILLI, 1996).

No tocante à freqüência respiratória, alterações como taquipnéia e bradipnéia, fatores desencadeados pelo estímulo álgico, ou pela depressão ocasionada pela administração de analgésicos opióides, não foram observados quando comparamos os animais tratados com $1 \mathrm{mg} / \mathrm{kg}$ (Grupo I) com os tratados com 4 $\mathrm{mg} / \mathrm{kg}$ (Grupo II), revelando a não existência de diferenças estatísticas nas freqüências respiratórias entre os grupos.

Achado este esperado, já que estudos anteriores postulam que o tramadol produz mínima depressão respiratória, que pode ser explicada através de sua ação mista, não dependendo somente de sua ligação a receptores opióides para promover analgesia. (DUTHIE, 1998; LEE et al., 1993; LEHMAN, 1994). 
A identificação e o tratamento das alterações desta variável são de suma importância, visto que alterações respiratórias associadas à dor e ao estresse são resultantes de maior metabolismo, assim como variações no tônus vascular pulmonar.

A freqüência cardíaca quando estudada caracterizou-se por obter dados que não revelaram diferenças estatísticas $(p>0,05)$ entre os dois grupos.

Neste mesmo sentido, resultados de diversos estudos clínicos, nos seres humanos, constataram a segurança do tramadol em relação ao sistema cardiovascular, por não acarretar alterações como hipotensão e bradicardia importantes. (COETZEE; VAN LOGGERENBERG, 1998; JAMES et al., 1996; NAGUIB et al., 1998; WOLFF et al., 1999).

Alterações cardíacas, tanto a taquicardia quanto a bradicardia podem ser observadas quando as cadelas são submetidas a um estímulo doloroso, ou quando medicamentos analgésicos, principalmente os opióides, são administrados.

Os opióides de um modo geral causam poucos efeitos adversos no sistema cardiovascular. O efeito mais descrito é o de bradicardia e devido ao fato de ser mediada pelo nervo vago, pode ser revertido utilizando um agente anticolinérgico como a atropina, ou o glicopirrolato (PAPICH, 1997.).

O estímulo álgico pode acarretar alterações cardiovasculares que podem ser deletérias se prolongadas, causando aumento do consumo de oxigênio pelo miocárdio, o que, associado à liberação de catecolaminas culmina em hipóxia no músculo cardíaco, ou isquemia, além de arritmias atriais e ventriculares importantes (GAYNOR, 1999).

Outros autores ainda propuseram a existência da hipotensão como resultado do tratamento com analgésicos opióides, mediante a presença de bradicardia, liberação de histamina, depressão miocárdica e/ou efeitos simpatolíticos. (GÓRNIAK, 2006; THURMON; TRANQUILLI, 1996.).

Quando nos detivemos aos valores relativos à pressão arterial (sistólica, diastólica e média), detectamos no primeiro momento (30 minutos) de aferição da pressão arterial sistólica e consequentemente da média, uma diferença estatística $(p<0,05)$ sugerindo um aumento da pressão no grupo tratado com a maior dose $(4 \mathrm{mg} / \mathrm{kg}$ - grupo II). Tal observação escapa à nossa expectativa, já que não encontramos nenhum subsídio teórico, em trabalhos anteriores, para explicar tal 
fato; particularmente quando verificamos que nos demais momentos observados nenhuma diferença estatística entre os dois grupos $(p>0,05)$ pode ser demonstrada.

Diferentemente dos dados obtidos neste presente estudo, o tramadol ocasionalmente, promove uma hipotensão que ocorre secundariamente como decorrência da vasodilatação periférica e pode ser minimizada pela aplicação lenta do medicamento ou pela limitação da dose (BAMIGBADE et al., 1998).

Ao considerar a concentração plasmática do tramadol, foi possível identificar diferenças estatísticas significativas $(p<0,05)$ em 7 momentos de aferição $(10,20,30,45,90,240$ e 480 minutos), revelando que no grupo II, cujos animais foram tratados com $4 \mathrm{mg} / \mathrm{kg}$ de tramadol, as concentrações plasmáticas médias foram mais elevadas. Tal fato era já esperado posto que os animais do grupo II $(4 \mathrm{mg} / \mathrm{kg})$ haviam recebido um tratamento com dose 4 vezes superior aos do grupo I ( $1 \mathrm{mg} / \mathrm{kg})$.

Além dos tratamentos diferenciados entre os grupos, outros fatores poderiam influenciar a falta de correspondência das concentrações plasmáticas nos determinados momentos de avaliação, como o polimorfismo da isoenzima citocromo P 450 2D6 (CYP2D6), responsável pela reação de desmetilação e produção do metabólico O-desmetiltramadol (KUKANICH; PAPICH, 2004).

Adicionalmente Gan et al. (2004), determinaram, em humanos, uma ampla variabilidade interindividual dos valores de clearance do tramadol, sugerindo que embora os valores paramétricos esperados possam ser calculados para determinado paciente, este poderá eliminar a droga de forma diferente do esperado, independentemente do conhecimento de pesquisa e experiência prévia. Isso pode ocorrer devido a uma combinação de fatores, dentre eles o polimorfismo do CYP $2 \mathrm{D} 6$.

O reconhecimento e a avaliação da dor são tarefas bastante difíceis, principalmente na Clínica Veterinária, uma vez que os animais não têm a habilidade de expressar, nem quantificar verbalmente a sensibilidade dolorosa, o que caracteriza a subjetividade da avaliação (GAYNOR, 2001; HARDIE; KILES, 1995).

No sentido de minimizar a subjetividade do método de avaliação da sensibilidade dolorosa, o emprego do mesmo, foi executado pelos mesmos indivíduos, assim como proposto por Hansen e Hardie em 1993, e a administração do fárma- 
co em duplo cego, compõem fatores que validam de sobremaneira a avaliação da analgesia (TAYLOR; HOULTON, 1984).

Os valores relativos aos escores de dor dos grupos tratados com 1 ou 4 $\mathrm{mg} / \mathrm{kg}$ de tramadol (Grupos I e II respectivamente)nas diferentes escalas (EVA e ED) e correspondentes momentos de resgate foram avaliados.

Os dados obtidos através da escala descritiva de não demonstraram diferenças estatísticas significativas entre os dois grupos, porém ao avaliarmos a escala visual analógica encontramos, em um único momento (120 minutos), diferença estatística significativa $(p<0,05)$, obtendo um maior escore de dor no grupo tratado com $1 \mathrm{mg} / \mathrm{kg}$ de tramadol.

Quando comparamos as diferentes escalas de dor observamos, com exceção ao animal 3, uma correspondência entre os escores de resgate. Fato este que reafirma a nossa expectativa, apontando uma equivalência entre as escalas visual analógica e a descritiva, nos permitindo a opção por qualquer uma das duas objetivando a avaliação álgica de animais em pós-operatório imediato.

Os momentos de aplicação dos resgates, ocorridos de acordo com os escores indicativos de sensibilidade dolorosa, demonstraram que a maior dose de tramadol (4 mg/kg) foi capaz de produzir analgesia em $83 \%$ dos animais por até 240 minutos após a administração por via intravenosa, enquanto que a dose de 1 $\mathrm{mg} / \mathrm{kg}$, por até 150 minutos, utilizando a mesma via de administração, configurando-se um período de analgesia mínimo de 2:30 ou de 4:00 horas, respectivamente para o grupo I, ou grupo II.

Adicionalmente, quando atentamos para o momento do período de observação em que se deu cada resgate, constatamos que, em nenhum dos 8 animais resgatados, tal procedimento ocorreu em período inferior a 120 minutos e com uma média de 247,5 minutos, após a administração do analgésico.

Resultados semelhantes foram registrados por Darwish e Hassan (1998) que trabalhando com seres humanos obtiveram, após a administração de 2 $\mathrm{mg} / \mathrm{kg}$ de tramadol, uma analgesia adequada de aproximadamente 3 horas no pós-operatório.

Em discordância ao presente estudo Lascelles, (2003) estudando o controle de dor em animais determinou a dose de 1 a $4 \mathrm{mg} / \mathrm{kg}$ via oral a cada 6 horas para o tratamento da dor secundária ao câncer em cães. Ainda nesse mesmo 
sentido, utilizando a dose de $2 \mathrm{mg}$ kg pela via intravenosa, de maneira profilática, o tramadol demonstrou proporcionar analgesia semelhante à produzida pela morfina, promovendo analgesia por 6 horas (MASTROCINQUE; FANTONI, 2003).

Esse tempo de 2:30 a 4:00 horas poderá ser prolongado quando da utilização de analgésicos, com ação preemptiva, ou de medicamentos que possuam ação sinérgica ao tramadol, associado no pós-operatório imediato.

Prosseguindo na avaliação dos dados obtidos através das escalas, verificamos que $83,3 \%$ (5 dos 6 ) dos animais do grupo I ( $1 \mathrm{mg} / \mathrm{kg}$ de tramadol) requisitaram a dose do resgate, no intervalo de 120 a 450 minutos; enquanto que apenas $50 \%$ ( 3 dos 6 ) dos animais do grupo II ( $4 \mathrm{mg} / \mathrm{kg}$ de tramadol) necessitaram do procedimento do resgate, entre 180 a 360 minutos.

Tal observação encontra amparo em estudos anteriores que afirmam ser a maior porcentagem da analgesia decorrente da administração do tramadol devida a seu metabólico ativo (O-desmetiltramadol) (GARRIDO et al., 2000; GARRIDO et al., 2003; POULSEN et al., 1996; RAFFA et al., 1993) podemos supor que, sendo a dose de tramadol administrada aos indivíduos do grupo II $(4 \mathrm{mg} / \mathrm{kg})$ quatro vezes maior que a do grupo I (1 $\mathrm{mg} / \mathrm{kg})$, o metabólito ativo do tramadol (Odesmetiltramadol) atuaria com uma superior concentração sérica e com uma possível eficiência analgésica maior.

Analisando os mesmos dados e avaliando os animais que sofreram resgate, encontramos 4 animais do grupo tratado com $1 \mathrm{mg} / \mathrm{kg}$ de tramadol, e 1 animal do grupo tratado com $4 \mathrm{mg} / \mathrm{kg}$ de tramadol que receberam mais de um resgate.

Este resultado superior no grupo I pode estar relacionado ao baixo poder analgésico decorrente da reduzida dose de $1 \mathrm{mg} / \mathrm{kg}$ (grupo I) de tramadol, insuficiente para promover uma analgesia adequada ao estimulo álgico, permitindo assim uma sensibilização central que resulta numa resposta exagerada ao estímulo nocivo (hiperalgesia), assim como a disseminação do estímulo a tecidos não lesados (hiperalgesia secundária) e redução na intensidade do estímulo necessário para iniciar a dor, fenômeno conhecido por alodínea (GRISNEAUX et al., 1999).

Quando comparamos as médias da concentração plasmática, com as medianas dos escores de dor não obtivemos correlação entre os valores destas variáveis, possivelmente relacionado com o metabólito ativo do tramadol, denomi- 
nado de O-desmetiltramadol, que como já citado é responsável pela maior parte da analgesia produzida pela administração do tramadol, posto que seu enantiômero (+) apresenta uma potencia de ligação ao receptor de 2 a 200 vezes maior que o enantiômero (+) do tramadol (LEE et al., 1993; POULSEN et al., 1996). Por oportuno vale ressaltar, Wu et al., 2001, detectou o clearance sistêmico do tramadol em cães, cerca de 5 vezes mais rápida que em humanos, com pelo menos 32 metabólitos identificados em cães após a administração oral do tramadol.

Adicionalmente quando atentamos para uma análise isolada dos indivíduos de cada grupo observamos diferentes momentos e concentrações plasmáticas de tramadol em que os pacientes manifestaram sinais de sensibilidade dolorosa, e isso pode ser explicado de acordo com o conceito descrito por Drummond (2000).

"A percepção da dor não envolve apenas uma análise momentânea dos estímulos nociceptivos, mas também implica um processo dinâmico, o qual é influenciado pelos efeitos de experiências passadas. Os estímulos sensoriais atuam sobre estruturas nervosas, que têm sido modificadas por estímulos anteriores, e a reação comportamental é, significativamente, influenciada pela "memória" daqueles eventos vivenciados". 


\section{CONCLUSÕES}

A análise dos resultados obtidos permitiu concluir que:

- O tramadol, nas doses de 1 e $4 \mathrm{mg} / \mathrm{kg}$, administrado pela via intravenosa imediatamente após o término do procedimento cirúrgico, não causa alterações importantes na freqüência respiratória, cardíaca e pressão arterial (sistólica, diastólica e média), em 8 horas de observação no pós operatório imediato de cadelas submetidas a ovário-salpingo-histerectomia.

- O tramadol, administrado pela via intravenosa, na dose de $1 \mathrm{mg} / \mathrm{kg}$ produziu analgesia em $83 \%$ das cadelas submetidas a ovário-salpingohisterectomia, por até 150 minutos, enquanto que na dose de $4 \mathrm{mg} / \mathrm{kg}$ produziu analgesia nesta mesma porcentagem por até 240 minutos.

- O tramadol, na dose de $1 \mathrm{mg} / \mathrm{kg}$, promoveu analgesia adequada no período de 8 horas no pós-operatório imediato em 17\% (1 animal) das cadelas submetidas a ovário-salpingo-histerectomia, enquanto que na dose de 4 $\mathrm{mg} / \mathrm{kg}$, neste mesmo período, em $50 \%$ (3 animais) das cadelas submetidas ao mesmo ato cirúrgico.

- As escalas visual analógica e descritiva apresentaram equivalência, permitindo a opção por qualquer uma na avaliação álgica de animais em pósoperatório imediato.

- Não foi encontrada correlação entre os níveis plasmáticos de tramadol e os escores de dor em cadelas submetidas a ovário-salpingo-histerectomia, que receberam este fármaco por via intravenosa.

- O período médio de resgate foi de 247,5 minutos e nenhum dos 8 animais resgatados manifestou escore de dor indicativo deste procedimento em período inferior a 120 minutos. 


\section{REFERÊNCIAS}

ACVA Position Paper. American College of Veterinary Anesthesiologists Position paper on the treatment of pain in animals. Journal of American Veterinary Medical Association, v. 213, n. 5, p. 628-630, 1998.

AMARAL, J. L. G.; JOAQUIM, M. R. G.; RODRIGUES, G. R.; SAKATA, R. K. Analgesia. In: AMARAL, J. L. G. Sedação, analgesia e bloqueio neuromuscular em UTI - Série Clínicas Brasileiras de Medicina Intensiva (CBMI). Rio de Janeiro: Atheneu, 1996. v. 2, p. 47-74.

BAMIGBADE, T. A.; LANGFORD, R. M. The clinical use of tramadol hydrochloride. Pain Reviews, v. 5, p. 155-182, 1998.

BHATNAGAR, S.; SAXENA, A.; KANNAN, T. R.; PUNJ, J.; PANIGRAHI, M.; MISHRA, S. Tramadol for post operative shivering: a double-blind comparison with petidine. Anaesthesia and Intensive Care, v. 29, p. 149-154, 2001.

BONICA, J.J. General considerations of acute pain. In: BONICA, J. J.; LOSER, J. D.; CHAPMAN, C. R.; FORDYCE, W. E. The management of acute pain, 2. ed. Philadelphia: Lea \& Febiger, 1990. p. 159-179.

BOSENBERG, A. T.; RATCLIFFE, S. The respiratory effects of tramadol in children under halothane anaesthesia. Anaesthesia, v. 53, p. 960-964, 1998.

BUDD, K.; LANGFORD, R. Tramadol revisted. British journal of Anaesthesia, v. 82, n. 4, p. 493-495, 1999.

CARROL, G. L. Analgesics and pain. Veterinary Clinics of North America (Small Animal Practice), v. 29, n. 3, p. 701-717, 1999.

CARVALHO, W. B.; LIMA, C. L. Q. Sedativos e Analgésicos. In: CARVALHO, W. B.; SOUZA, N.; SOUZA, R. L. Emergência e terapia intensiva pediátrica. 2. ed. São Paulo: Editora Atheneu, 2004. p. 682-693.

COETZEE, J. F.; VAN LOGGERENBERG, H. Tramadol or morphine administered during operation: a study of immediate postoperative abdominal hysterectomy. British Journal of Anaesthesia, v. 81, p. 737-741, 1998. 
CORTOPASSI, S. R. G.; FANTONI, D. T. Anestesia em cães e gatos. São Paulo: Roca, 2003. 389 p.

DARWISH, A. M.; HASSAN, Z. E. A. Z. Intraperitoneal bupivacaine vs. Tramadol for pain relief following day case laparoscopy surgery. Gynaecological Endoscopy, v. 8, p. 169-173, 1999.

DAYER, P.; DESMEULES, J.; COLLART, L. Pharmacology of tramadol. Drugs, v. 53, n. 2, p. 18-24, 1997. Supplementum. 2.

DE WITTE, J.; DELOOF, T.; DE VEYLDER, J.; HOUSMANS, P. R. Tramadol in the treatment of postanaesthesic shivering. Acta Anaesthesiologica Scandinavica, v. 41, p. 506-510, 1997.

DE WITTE, J.; RIETMAN, G. W.; VANDENBROUCKE, G.; DELOOF, T. Postoperative effects of tramadol administered at wounded closure. European Journal of Anaesthesiology, v. 15, p. 190-195, 1998.

DRIESSEN, B.; REIMANN, W. Interaction of the central analgesic, tramadol, with the uptake and release of 5-hidroxytryptamine in the rat brain in vitro. British Journal of Phamacology, v. 105, n. 147-151, 1992.

DRIESSEN, B.; REIMANN, W.; GIERTZ, H. Effects of the central analgesic tramadol on the uptake and release of noradrenalin and dopamine in vitro. British Journal of Phamacology, v. 108, p. 806-811, 1993.

DRUMMOND, J. P. Dor aguda: fisiopatologia, clínica e terapêutica. São Paulo: Editora Atheneu, 2000. 262 p.

DUTHIE, D. J. R. Remifentanil and tramadol. British Journal of Anaestesia, v. 81, p. 51-57, 1998.

ENGELHARDT, T.; STEEL, E.; JOHNSTON, G.; VEITCH, D. Y. Tramadol for pain relief in children undergoing tonsillectomy: a comparison with morphine. Paediatric Anaesthesia, v. 13, p. 249-252, 2003.

FANTONI, D. T.; MASTROCINQUE, S. Fisiopatologia e controle da dor. In: FANTONI, D. T.; CORTOPASSI, S. R. G. Anestesia em cães e gatos. São Paulo: Roca, 2002. p. 323-336.

FIRTH, A. M.; HALDANE, S. L. Development of scale to evaluate postoperative pain in dogs. Journal of American Veterinary Medical Association, v. 214, n. 5, p. 651-659, 1999. 
FRANCESCHINI, D.; LIPARTITI, M.; GIUSTI, P. Effects of acute and chronic tramadol on $[3 \mathrm{H}]$ - norepinephrine uptake in rat cortical synaptosomes. Progress in Neuropsychopharmacology and Biological Psychiatry, v. 23, n. 3, p. 485496, 1999.

GAN, S. H.; ISMAIL, R. Validation of a high performance liquid chromatography method for tramadol and O-desmethyltramadol in human plasma using solid phase extraction. Journal of Chromatography B, v. 759, p. 325-335, 2001.

GAN, S. H.; ISMAIL, R.; WAN ADNAN, W. A.; ZULMI, W.; JELLIFFE, R. W. Population pharmacokinetic modeling of tramadol with application of the NPEM algorithms. Journal of Clinical Pharmacy and Therapeutics, v. 29, p. 455-463, 2004.

GARRIDO, M. J.; SAYAR, O.; SEGURA, C.; RAPADO, J.; DIOS-VIEITEZ, M. C.; RENEDO, M. J.; TROCONIZ, L. F. Pharmacokinetic/pharmacodyamic modeling of the antinociceptive effects of (+)-tramadol in the rat: role of cytochrome P450 2D activity. Journal of Phamacology and Expermental Therapeutics, v. 305, p. 710-718, 2003.

GARRIDO, M. J.; VALLE, N.; CAMPANERO, M. A.; CALVO, R.; TROCONIZ, L. F. Modeling of the in vivo antinociceptive interation between na opioid agonist (+)-Odesmethyltramadol, and a monoamine reuptake inhibitor, (-)-Odesmethyltramadol, in rats. Journal of Phamacology and Expermental Therapeutics, v. 295, p. 352-359, 2000.

GAYNOR, J. S. Pain Management for the Oncology Patient. In: WITHROW, S. J.; MACEWEN, E. G. Small animal clinical oncology, W. B. Saunders Company, 2001. p. 219-232.

GÓRNIAK, S. L. Hipnoanalgésicos e Neuroleptoanalgesia. In: SPINOSA, H. S.; GÓRNIAK, S. L.; BERNARDI, M. M. Farmacologia Aplicada à Medicina Veterinária. Rio de Janeiro: Guanabara Koogan, 2006. p. 178-183.

GRISNEAUX, E.; PIBAROT, P.; DUPUIS, J.; BLAIS, D. Comparison of ketoprofen and carprofen administered prior to orthopedic surgery for control of postoperative pain in dogs. Journal of American Veterinary Medical Association, v. 215, $n$. 8, p. 1105-1110, 1999.

GROND, S.; MEUSER, T.; ZECH, D., U.; LEHMANN, K. A. Analgesic efficacy and safety of tramadol enantiomers in comparison, double-blind study with gynecological patients using intravenous patient-controlled analgesia. Pain, v. 62, p. 313320, 1995.

HALFPENNY, D. M.; CALLADO, L. F.; HOPWOOD, S. E.; BAMIGBADE, T. A.; LANGFORD. M.; STAMFORD, J. A. Effects of tramadol steroisomers on norepinephrine efflux and uptake in the rat locus coeruleus measured by real time voltammetry. British Journal of Anesthesia, v. 83, n. 6; p. 909-915, 1999. 
HANSEN, B. Trough a glass darkly: using behavior to assess pain. Seminars in Veterinary Medicine and Surgery (Small Animals), v. 12, n. 2, p. 61-74, 1997.

HANSEN, B.; HARDIE, E. Prescription and use of analgesics in dogs and cats in a veterinary teaching hospital: 258 cases (1983-1989). Journal of American Veterinary Medical Association, v. 202, n. 9, p. 1485-1494, 1993.

HASKINS, S. C. Use of analgesics postoperatively in a small animal intensive care setting. Journal of American Veterinary Medical Association, v. 10, p. 1266-1268, 1987.

HARDIE, E. M.; KYLES, E. Pharmacological management of pain and infection in the surgical oncology patient. Veterinary Clinics of North America - Small Animal Practice, v. 25, n. 1, p. 77-95, 1995.

HELLEBREKERS, L. J. In: . Dor em Animais. Barueri: Manole, 2002. p. 9-10.

HELLYER, P. W. Management of acute and surgical pain. Seminars in Veterinary Medicine and Surgery (Small Animals), v. 12, n. 2, p. 106-114, 1997.

HOPKINS, D.; SHIPTON, E. A.; PORTGIETER, D.; VAN DER MERWE, C. A.; BOON, J.; WET, C. de; MURPHY, J. Comparison of tramadol and morphine via subcutaneous PCA following major orthopedic surgery. Canadian Journal of Anaesthesia, v. 45, n. 5, p. 435-442, 1998.

HOUMES, R. M.; VOETS, M. A.; VERKAAIK, A.; ERDMANN, W.; LACHMANN, B. Efficacy and safety of tramadol vs morphine for moderate and severe postoperative pain with special regard to respiratory depression. Anesthesia and Analgesia, v. 74, p. 510-514, 1992.

JAMES, M. F.; HEIJKE, A. S.; GORDON, P. C. Intravenous tramadol versus epidural morphine for posthoracotomy pain relief a placebo - controlled double blind trial. Anesthesia and Analgesia, v. 83, n. 1, p. 87-91, 1996.

JAIN, N. C. Comparative hematology of common domestic animals. Essentials of Veterinary Hematology, 4 ed., Philadelphia: Lea \& Febiger, 1993, 453 p.

KANEKO, J. J.; HARVEY, J. W.; BRUSS, M. L. Clinical biochemistry of domestic animals, 5 ed., New York: Academic Press; 1997, 581 p.

KÜÇÜK, A.; KADIOGLU, Y.; ÇELEBI, F. Investigation of the pharmacokinetics and determination of tramadol in rabbit plasma by a high-performance liquid chromatography-diode array detector method using liquid-liquid extraction. Journal of Chromatography B, v. 816, p. 203-208, 2005.

KUKANICH, B.; PAPICH, M. G. Pharmacokinetics of tramadol and the metabolite O-desmethyltramadol in dogs. Journal of Veterinary Pharmacology Therapeutics, v. 27, p. 239-246, 2004. 
LASCELLES, S. J.; BUTTERWOR, T. H.; WATERMAN, A. E. Postoperative analgesic and sedative effects of carprofen and phetidine in dogs. Veterinary Record, v. 134, p. 187-190, 1994.

LEE, C. R.; TAVISH, D.; SORKIN, E. M. Tramadol. A preliminary review of its pharmocodynamic and its pharmacokinetic properties, and therapeutic potential in acute and chronic pain states. Drugs, v. 46, n. 2, p. 313-340, 1993.

LEHMANN, K. A. Tramadol for the management of acute pain. Drugs, v. 47, p. 19-32, 1994. Supplementum 1.

LEHMANN, K. A.; KRATZENBERG, U.; SCHROEDER-BARK, B.; HORRICHSHAERMEYER, G. Postoperative patient-controlled analgesia with tramadol; analgesic efficacy and minimum effective concentrations. Clinical Journal of Pain, v. 6, p. 212-220, 1990.

LESTER, P.; GAYNOR, J. S. Management of cancer pain. The Veterinary Clinics of North America - Small Animal Practice, v. 30, n. 4, p. 951-966, 2000.

LLOYD-THOMAS, A. R. Pain management in pediatric patients. British Journal of Anaesthesia, v. 64, p. 85-104, 1990.

MASTROCINQUE, S.; FANTONI, D. T. A comparision of preoperative tramadol and morphine for the control nof early postoperative pain in canine and ovariohysterectomy. Veterinary Anaesthesia Analgesia, v. 30, p. 220-228, 2003.

MATHEWS, S.; MULLA, A. A.; VARGHESE, P. K.; RADIM, K.; MUMTAZ, S. Postanaesthesic shivering - a new look at tramadol. Anaesthesia, v. 57, p. 387403, 2002.

MCMILLAN, F. D. Maximizing quality of life in ill animals. Journal of American Animal Hospital Association, v. 39, p. 227-235, 2003b.

MCMILLAN, F. D. Quality of life in animals. Journal of American Veterinary Medical Association, v. 216, n. 12, p. 1904-1910, 2000.

MCMILLAN, F. D. A world of hurts - is pain special? Journal of American Veterinary Medical Association, v. 223, n. 2, p. 183-186, $2003 a$.

MELLANBY, R. J.; HERRTAGE, M. E.; DOBSON, J. M. Owners assessments of their dog's quality of life during palliative chemotherapy for lymphoma. Journal of Small Animal Practice, v. 44, p. 100-103, 2003.

MORTON, D. B.; GRIFFITHS, P. H. M. Guidelines on the recognition of pain, distress and discomfort in experimental animals and a hypothesis for assessment. The Veterinary Record, v. 116, p. 432-436, 1985.

NAGUIB, M.; SERAJ, M.; ATTIA, M.; SAMARKANDI, A. H.; SEET, M.; JAROUDI, R. Perioperative antinociceptive effects of tramadol. A prospective, randomized, 
double blind comparison with morphine. Canadian Journal of Anaesthesia, v. 45, n. 12, p. 1168-1175, 1998.

NISHIMURA, S. L.; RECHT, L. D.; PASTERNAK, G. W. Biochemical characterization of high affinity $\mathrm{H}$-opioid binding: further evidence for um sites. Molecular Pharmacology, v. 25, p. 29, 1984.

NG, K. F. J.; TSUI, S. L.; YANG, J. C. S.; HO, E. T. F. Increased nausea and dizziness when using tramadol for post-operative patient-controlled analgesia (PCA) compared with morphine after intraoperative loading with morphine. European Journal of Anaesthesiology, v. 15, p. 565-570, 1998.

NOBILIS, M.; KOPECKY, J.; KVETINA, J.; CHLADEK, J.; SVODOBA, Z.;

VORISEK, V. High-performance liquid chromatography determination of tramadol and its $\mathrm{O}$-desmethylated metabolic in blood plasma. Journal of Chromatography A, v. 949, p. 11-22, 2002.

PAPICH, M. G. Principles of analgesic drug therapy. Seminars in Veterinary Medicine and Surgery (Small Animals), v. 12, n. 2, p. 80-93, 1997.

PARKER, R. Tramadol. Compendium-Pharm Profile, p. 800-803, 2004.

PASCOE, P. J. Opioid analgesics. Veterinary Clinics of North America - Small Animal Practice, v. 30, p. 757-772, 2000.

PORTENOY, R. K.; LESAGE, P. Management of cancer pain. Lancet, n. 353, p. 1695-1700, 1999.

POULSEN, L.; ARENDT-NIELSEN, L.; BROSEN, K.; SINDRUP, S. H. The hypoalgesic effect of tramadol in relation to CYP2D6. Clinical Pharmacology and Therapeutics, v. 60, p. 636-644, 1996.

RAFFA, R. B.; FRIDERICHS, E.; REIMANN, W.; SHANK, R. P.; CODD, E. E.; VAUGHT, J. L. Opioid and non-opioid components independently contribute to tha mechanism of action of tramadol, and 'atypical' opióide analgesic. Journal of Pharmacology and Experimental Therapeutics, v. 92, p. 275-285, 1992.

RAFFA, R. B.; FRIDERICHS, E.; REIMANN, W.; SHANK, R. P.; CODD, E. E.; VAUGHT, J. L.; JACOBY, H. I.; SELVE, N. Complementary and synergistic antinociceptive interaction between the enantiomers of tramadol. Journal of Pharmacology and Experimental Therapeutics, v. 267, p. 331-340, 1993.

ROBERTSON, S. A. What is pain? Journal of American Veterinary Medical Association, v. 221, n. 2, p. 202-205, 2002.

ROLLIN, B. E. Pain and Ideology in Human and Veterinary Medicine. Seminars in Veterinary Medicine and Surgery (Small Animal), v. 12, n. 2, p. 56-60, 1997.

SAKATA, R. K.; ISSY, A. M. Guias de medicina ambulatorial e hospitalar da UNIFESP/Escola Paulista de Medicina: dor. Barueri, SP: Manole, 2004. 260 p. 
SAKATA, R. W. Dor no câncer. In: SAKATA, R. K.; ISSY, A. M. Guias de medicina ambulatorial e hospitalar da UNIFESP/Escola Paulista de Medicina: dor. Barueri, SP: Manole, 2004. p. 117-125.

SAKATA, R. K.; ISSY, A. M.; VLAINICH, R. Opióides. In: SAKATA, R. K.; ISSY, A. M. Guias de medicina ambulatorial e hospitalar da UNIFESP/Escola Paulista de Medicina: dor. Barueri, SP: Manole, 2004. p.153-162.

SCOTT, L. J.; PERRY, C. M. Tramadol: a review of its use in perioperative pain. Drugs. V. 60, p. 139-176, 2000.

SEVCIK, J.; NIEBER, K.; DRIESSEN, B.; ILLES, P. Effects of the central analgesic tramadol and its main metabolite, O-desmethyltramadol, on rat locus coeruleus neurons. British Journal of Pharmacology, v. 110, p. 169-176, 1993.

STAMER, U. M.; MAIER, C.; GROND, S.; VEH-SCHMIDT, B.; KLASCHIK, E.; LEHMANN, K. A. Tramadol in the management of post-operativa pain: a doubleblind, placebo-and active drug-controlled study. European Journal of Anaesthesiology, v. 14, p. 646-654, 1997.

TARRADEL, R.; POL, O.; FARRÉ, M.; BARRERA, E.; PUIG, M. M. Respiratory and analgesics effects of meperidine and tramadol in patients undergoing orthopedic surgery. Methods and Findings in Experimental and Clinical Pharmacology, v. 18, p. 211-218, 1996.

TAYLOR, P. M.; HOULTON, J. E. F. Postoperative analgesia in the dog: a comparison of morphine, buprenorphine and pentazocine. Journal of Small Animal Practice, v. 25, p. 437-451, 1984.

TEIXEIRA, M. J. Fisiologia da dor. In: TEIXEIRA, M.J. Dor: conceitos gerais. 1. ed. São Paulo: Limay, 1994. p. 8-32.

TEIXEIRA, M. J. Dor no doente com câncer. In: Dor contexto interdisciplinar. Curitiba: Maio, 2003, p. 327-341.

TEIXEIRA, M. J.; VALLE, L. B. S. Tratamento farmacológico da dor. In: TEIXEIRA, M. J.; FIGUEIRÓ, J. A. B. F. Dor: epidemiologia, fisiopatologia, avaliação, síndromes dolorosas e tratamento. São Paulo: Grupo Editorial Moreira Jr., 2001. p. $93-130$.

THURMON, J.C.; TRANQUILLI, W.J.; BENSON, G.J. Perioperative pain distress. In: THURMON, J.C.; TRANQUILLI, W.J.; BENSON, G.J. Lumb and Jone's veterinary anaesthesia. 3. ed. Baltimore: William and Wilkins, 1996. p.40-62.

TRANQUILLI, W. J.; GRIMM, K. A.; LAMONT, L. A. Tratamento da dor para o clínico de pequenos animais. 2. ed. São Paulo: Roca, 2005. 130 p.

VICKERS, M. D.; O'FLAHERTY, D.; SZEKELY, S. M.; READ, M.; YOSKIZUMI, J. Tramdol: pain relief by an opióide without depression of respiration. Anaesthesia, v. 47, p. 291-296, 1992. 
VICKERS, M. D.; PARAVICINI, D. Comparison of tramadol with morphine for postoperative pain following abdominal surgery. European Journal of Anaesthesiology, v. 5, p. 265-271, 1995.

VLAINICH, R. Avaliação do Paciente com Dor. In: SAKATA, R. K.; ISSY, A. M. Guias de medicina ambulatorial e hospitalar da UNIFESP/Escola Paulista de Medicina: dor. Barueri, SP: Manole, 2004. p. 17-26.

WISEMAN, M. L.; NOLAN, A. M.; REID, J.; SCOTT, E. M. Preliminary study on owner-reported behavior changes associated with chronic pain in dogs. Veterinary Record, v. 149, p. 423-424, 2001.

WOLFF, M. H.; LEATHER, H. A.; WOUTERS, P. F. Effects of tramadol on minimum alveolar concentration (MAC) of isoflurane in rats. British Journal of Anaesthesia, v. 83, n. 5, p. 780-783, 1999.

WRIGHT, B. D. Clinical pain management techniques for cats. Clinical techniques in Small Animal Practice, v. 17, n. 4, p. 151-157, 2002.

WU, W. N.; MCKOWN, L. A.; GAUTHIER, A. D.; JONES, W. J.; RAFFA, R. B. Metabolism of the analgesic drug, tramadol hydrochloride, in rat and dog. Xenobiotica, v. 31, p. 423-441, 2001. 